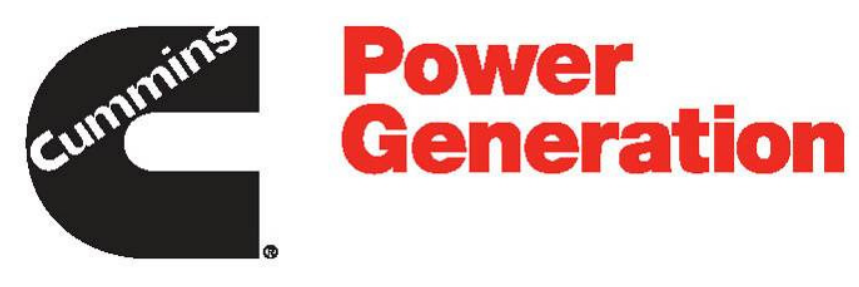

\author{
Final Report
}

\title{
Diesel Fueled SOFC for Class 7/Class 8 On- Highway Truck Auxiliary Power
}

Document Number: FR-PUB-CPG-GD54151-R01

Agreement No.: DE-FC36-04G014318

Revision: 0

Date: March 31, 2010

Report Submitted to:

David Peterson

Golden Field Office

1617 Cole Blvd.

Golden, CO 80401-3305

Prepared by:

Cummins Power Generation

$140073^{\text {rd }}$ Avenue NE

Minneapolis, Minnesota, 55432 


\section{Summary Page}

Project Start Date: $\quad 09 / 01 / 2004$

Project End Date: 12/31/2009

Principal Author:

Name

Charles J.P. Vesely III

\section{Company}

Cummins Power Generation

Principal Investigator(s):

\section{Name}

\section{Company}

Daniel A. Norrick

Cummins Power Generation

Chuck W. Booten

Protonex Technology, LLC

\section{Contributing Author(s):}

Name

Chuck W. Booten

Benjamin S. Fuchs

\section{Company}

Protonex Technology, LLC

Cummins Power Generation

Date of Issue: March 31, 2010

DOE Award Number: DE-FC36-04G014318

Submitting Organization:

Cummins Power Generation

$140073^{\text {rd }}$ Ave NE

Minneapolis, MN 55432

\section{Principal Subcontractor(s):}

Protonex Technology, LLC

510 Compton Street, Suite 106

Broomfield, CO 80020 


\section{Disclaimer}

"This report was prepared with the support of the U.S. Department of Energy, under Award No. DE-FC36-04GO14318. However, any opinions, findings, conclusions, or recommendations expressed herein are those of the author(s) and do not necessarily reflect the views of the DOE”.

This report was prepared as an account of work sponsored by an agency of the United States Government. Neither the United States Government nor any agency thereof, Cummins and its subcontractors, nor any of their employees, makes any warranty, express or implied, or assumes any legal liability or responsibility to third parties for the accuracy, completeness, or usefulness of any information, apparatus, product or process disclosed, or represents that its use would not infringe privately owned rights. Reference herein to any specific commercial product, process, or service by trade name, trademark, manufacturer, or otherwise does not necessarily constitute or imply its endorsement, recommendation, or favoring by the United States Government or any agency thereof. The views and opinions of authors expressed herein do not necessarily state or reflect those of the United States Government or any agency thereof. 
Revision History

\begin{tabular}{|l|l|l|l|}
\hline Revision & Date & By & Revision Details \\
\hline \hline 0 & March 31, 2010 & Charles Vesely & Released Report \\
\hline
\end{tabular}

\section{Table of Contents}

1 Executive Summary

2 Reference Documents

3 Definitions and Acronyms

$4 \quad$ Background

5 Stack/Reformer/Module Development - Overview 12

5.1 Stack/Reformer/Module Analysis and Design 13

5.2 Stack/Reformer Subsystem Test and Development 20

5.3 Stack/Reformer/Module Subsystem Test- PTX Tubular Technology 35

6 Controls \& Power Electronics Development 47

6.1 Controls Development - CPG 47

6.2 Power Electronics Development 53

7 SOFC APU System - Overview 56

7.1 SOFC APU System Analysis and Design 56

7.1.1 System Development - Packaging 58

7.2 System Development - Low cost integrated BOP 62

8 SOFC APU Demonstration Results 74

$\begin{array}{lll}8.1 & \text { SOFC APU Test Article } & 76\end{array}$

8.2 SOFC APU Performance Results 77

9 Outlook $\quad 81$

10 Summary 82

11 Acknowledgements 82 


\section{Figures}

5-1 Ø10x136 mm tubular cell 14

5-2 P\&ID for single module 14

5-3 Stack and hot zone for $75 \mathrm{~W}$ portable generator 15

5-4 Anode flow distribution computational modeling.. 16

5-5 Diesel atomizer prototype 17

5-6 Measured performance of earlier-generation... 18

5-7 Cumulative droplet size distribution 19

5-8 Sauter mean diameter (D32) vs. air feed pressure 19

5-9 Assembled view of fuel injection device... 20

5-10 Integrated atomizer and catalyst CPOX reactor 20

5-11 Cell power vs. time for single tube operating... 21

5-12 Testing apparatus for vaporizer 22

5-13 Photograph of flame and CPOX catalyst 22

5-14 Vaporizer stability map for $\mathrm{O} / \mathrm{C}=1.11 \quad 23$

5-15 Vaporizer pressure drop data with varying fuel... 24

5-16 Estimated operating window for catalyst B2... 26

5-17 Prototype CPOX reactor 27

5-18 Hydrogen and carbon monoxide selectivities 28

5-19 Cell voltage as a function of fuel utilization 29

5-20 Comparison of cell performance 30

5-21 Polarization plot for 12-cell bundle 31

5-22 Power vs. time for subscale stack cycled ... 31

5-23 Details of stack temperature during one thermal.. 32

5-24 Interconnect test facility 33

5-25 Module test facility process and instrumentation... 34

5-26 Module test facility 35

5-27 Voltage and power curves for bundle \#3 36

5-28 Voltage and power curves for bundles 36

5-29 Reduction VI curves for deliverable stacks 37

5-30 Load curves for BR66-012 during reduction... 38

5-31 Startup temperatures for BR66-007 upright \& inv.. 38

5-32 Stack voltages during startup for ...orientations $\quad 39$

5-33 Load curves for BR66-013 during reduction 39

5-34 Load curve comparison between kerosene/ULSD 40

5-35 Power degradation over all thermal cycles 41

5-36 Startup temperatures 42

5-37 Shutdown temperatures 42

5-38 Steady state temperatures, $3.15 \mathrm{~g} / \mathrm{min}$ ULSD... 43

5-39 Total power production for final testing 44

5-40 Average DC power produced by SOFC...

5-41 Peak DC power produced by SOFC... 45

5-42 Average AC power produced by SOFC... 46 
Figures (continued)

6-1 Modular Control Module 47

6-2 Topological view of the complete control system 48

6-3 Test case for cathode air controlled Stack... 50

6-4 O/C ratio error in percentage for all fuel cell stacks 51

6-5 Fuel Cell Control and Simulator 52

6-6 SIMULINK model of digital filter 52

6-7 Schematic of the Simple Inductor Based Boost 54

6-8 Schematic of SOFC APU Truck Auxiliary Power 54

6-9 AC power output period 55

7-1 ComfortGuard case and conceptual APU case 56

7-2 Selected hot zone arrangements considered 57

7-3 Inner frame of SOFC APU 58

7-4 Outer frame of the SOFC APU 59

7-5 metal bracket for supporting blowers 60

7-6 Outer frame of SOFC APU 61

7-7 Integrated Cathode/Anode distribution manifold 62

7-8 Integrated manifold prototype 62

7-9 Stepper controller 63

7-10 Improvement of delivered fuel flow accuracy 64

7-11 Accuracy of controlled $\mathrm{O} / \mathrm{C}$ ratio in operation range 64

7-12 Air system startup sequence 65

7-13 Steady state and transient ... control response 66

7-14 Fuel cell frame, four modules, waste heat recovery 67

7-15 Top and side view of the inner assembly 68

7-16 Assembled modules and BOP components 68

7-17 Solid model of assembly and associated hardware 69

7-18 Final assembly with top door open 69

7-19 Solid model of APU housing 70

7-20 FE model of APU housing 71

7-21 Vibration test setup of fuel cell stack module 72

7-22 Vibration test setup of fuel cell system 73

8-1 SOFC APU Demonstration Article at CPG 75

8-2 Total power production for final testing 77

8-3 Average DC power produced by SOFC sub-system 78

8-4 Peak DC power produced by SOFC sub-system 79

8-5 Average AC power produced by SOFC sub-system 79

8-6 AC power output period 80

\section{Tables}

1-1 Performance Results 7

5-1 Performance of catalysts B1 and B2 ... 25

8-1 Performance Results 74

10-1 Performance Results 82

11-1 Acknowledgements 82 


\section{Executive Summary}

The following report documents the progress of the Cummins Power Generation (CPG) Diesel Fueled SOFC for Class 7/Class 8 On-Highway Truck Auxiliary Power (SOFC APU) development and final testing under the U.S. Department of Energy (DOE) Energy Efficiency and Renewable Energy (EERE) contract DE-FC36-04G014318. This report overviews and summarizes CPG and partner development leading to successful demonstration of the SOFC APU objectives and significant progress towards SOFC commercialization.

Significant SOFC APU Milestones:

- Demonstrated:

- Operation meeting SOFC APU requirements on commercial Ultra Low Sulfur Diesel (ULSD) fuel.

- SOFC systems operating on dry CPOX reformate.

- Successful start-up and shut-down of SOFC APU system without inert gas purge.

- Developed:

- Low cost balance of plant concepts and compatible systems designs.

- Identified low cost, high volume components for balance of plant systems.

- Demonstrated efficient SOFC output power conditioning.

- Demonstrated SOFC control strategies and tuning methods.

The following table illustrates the results achieved for the SOFC APU Demonstration:

Table 1.1 - Performance Results

\begin{tabular}{|l|l|l|}
\hline RESULTS AGAINST PROJECT OBJECTIVES \\
\hline OBJECTIVE & TARGET & DEMONSTRATED \\
\hline Operation on Liquid Fuel & ULSD & ULSD \\
\hline Average Power (Net DC) & & 1100 Watts \\
\hline Average Power (Net AC) & & 820 Watts \\
\hline Combined Heat and Power (CHP) & & $>4 \mathrm{kWatts}$ \\
\hline Peak Power (Net DC) & & 1250 Watts \\
\hline Specific Power (Net DC) & $17 \mathrm{~W} / \mathrm{kg}$ & $9 \mathrm{~W} / \mathrm{kg}$ \\
\hline Power Density & $8 \mathrm{~W} / \mathrm{L}$ & $3 \mathrm{~W} / \mathrm{L}$ \\
\hline Start-up Time (Cold) & 1 hour & 1 hour \\
\hline Efficiency @ Rated Power & $25 \%$ LHV & $11 \%$ LHV \\
\hline In Vehicle Demonstration & $\begin{array}{l}\text { Operation on a Class } 8 \\
\text { Truck }\end{array}$ & $\begin{array}{l}\text { Operation on } \\
\text { Hardware in Lab }\end{array}$ \\
\hline
\end{tabular}

The SOFC APU demonstration was carried out at the Cummins Power Generation facility in Minneapolis, Minnesota on February 26, 2010. The demonstration was successfully completed on February 27, 2010 including the necessary steady-state, transient, and peak power operation tests. 


\section{Reference Documents}

- Quarterly reports:

- 14318R01.pdf

14318R02.pdf

14318R03.pdf

14318R04.pdf

14318R05.pdf

14318R06.pdf

14318R07.pdf

14318R08.pdf

14318R09.pdf 


\section{Definitions and Acronyms}

\begin{tabular}{|c|c|}
\hline APU & Auxiliary Power Unit \\
\hline CAN & Controller Area Network \\
\hline cBOP & Cold Balance of Plant \\
\hline $\mathrm{cc} / \mathrm{min}$ & cubic centimeters per minute \\
\hline CPG & Cummins Power Generation \\
\hline CPOX & Catalytic Partial Oxidation \\
\hline cpsi & cells per square inch \\
\hline DC & Direct Current \\
\hline DOE & U.S. Department of Energy \\
\hline FCV & Flow Control Valve \\
\hline GC & Gas Chromatograph \\
\hline hBOP & Hot Balance of Plant \\
\hline HEX & Heat Exchanger \\
\hline HQD & Hybrid Quiet Diesel (CPG Inverter/Charger) \\
\hline IT & Current Transducer \\
\hline $\mathrm{kg} / \mathrm{s}$ & kilo-grams per second \\
\hline $\mathrm{kPa}$ & kilo-Pascals \\
\hline LHV & Lower Heating Value \\
\hline LSCF & Lanthanum Strontium Cobaltite Ferrite \\
\hline LSGM & Lanthanum Strontium Gallate Magnesite \\
\hline kWatt & kilowatts \\
\hline mlpm & Milliliters per minute \\
\hline NOC & Normal (or Nominal) Operating Conditions \\
\hline $\mathrm{O} / \mathrm{C}$ & Oxygen to Carbon (ratio) \\
\hline P\&ID & Piping \& Instrumentation Diagram \\
\hline PCU & Power Conditioning Unit \\
\hline PDT & Pressure Differential Transducer \\
\hline PMP & Pump \\
\hline ProE & 3D Computer Aided Design software from Parametric Technologies Corporation \\
\hline PTX & Protonex Technologies, LLC \\
\hline PWM & Pulse Width Modulation \\
\hline SLD & Single Line Diagram \\
\hline slpm & Standard liters per minute $\left(1\right.$ atmosphere, $\left.70^{\circ} \mathrm{F}\left(21.1^{\circ} \mathrm{C}\right)\right)$ \\
\hline SMAF & Secondary Mass Air Flow sensor from automotive applications \\
\hline SOFC & Solid Oxide Fuel Cell \\
\hline SOFC APU & Diesel Fueled SOFC for Class 7/Class 8 On-Highway Truck Auxiliary Power \\
\hline TGC & Tail Gas Combustor \\
\hline ULSD & Ultra Low Sulfur Diesel \\
\hline W & Watts \\
\hline
\end{tabular}




\section{Background}

With the release of the US Department of Energy's Request for Proposals (RFP) in 2003, Cummins Power Generation (CPG) recognized the potential for Solid Oxide Fuel Cell (SOFC) technology in serving a number of CPG markets. The Hydrogen Futures Act (104-271) RFP was particularly well aligned with CPG interests in its focus on the On-Highway truck APU which is a good fit to a number of consumer markets that value the very low noise, exhaust emissions, and vibration potential of the SOFC. CPG conducted a survey of available SOFC technology partners for stack and hot zone technologies and engaged in discussions with a number of developers, settling on SOFCo Technology LLC as a promising combination of technology development capability and commercial fit with CPG's aims. In 2003 SOFCo ceramic interconnect structure appeared to offer a number of significant advantages compared to the state of metallic interconnects which characteristically suffered from a number of durability related problems. CPG subsequently formed a SOFC APU team with SOFCo and were successful in receiving an EERE Cooperative Agreement for an SOFC APU demonstration on September 01, 2004. A Congressional funding driven project hiatus in 2006 temporarily put development on hold. In this interim period SOFCo ceased operation (assimilated by Rolls Royce) and a new partner was identified in Mesoscopic Devices LLC (later incorporated into Protonex Technologies LLC). Protonex Technology LLC (PTX) develops and manufactures compact, lightweight and high- performance fuel cell systems for portable power applications in the 100 to $2000 \mathrm{~W}$ range. The Company's fuel cell systems are designed to meet the needs of military, consumer and original equipment manufacturer (OEM) customers for off-grid applications underserved by existing technologies by providing customizable, stand-alone portable power solutions and systems that may be hybridized with existing power technologies. This new partnership moved the SOFC technology from a planar to a tubular topology. Protonex Technologies LLC (PTX) undertook to scale-up their current modularized tubular platform to be suitable for the SOFC APU demonstration. The tubular design allowed for a system that is more tolerant to thermal cycling; the modular SOFC platform minimized technical risk associated with scaling up in power and increased economies of scale in production. Each SOFC module consists of a highly integrated dry CPOX fuel reformer, SOFC stack and tail gas heat exchanger all enclosed in a compact thermal package. The sub-kW power of each SOFC sub-system was ideal for PTX product development over a range of markets, while the modular system design allowed simultaneous development of larger systems in the 1-2 kW power range.

Upon receipt of the award, detailed planning and development work started and the program began ramping up in 2004. Early work included development of product technical objectives that would guide the design and development of the stacks, Balance of Plant (BOP), Controls, Power Electronics, and system integration. Development of product technical objectives produced a number of insights into practical product requirements for SOFC's that greatly enhanced understanding of the range of technical challenges inherent in the effort to commercialize the technology.

Cooperative development with PTX was a productive and effective combination with CPG developing lower cost BOP components, Application specific hardware, and high efficiency power electronics with PTX modularized stack, fuel reformer, and system integration expertise to produce and successfully demonstrate deliverable SOFC APU system. The finale of the project occurred on February 26, 2010 and completed the primary demonstration objectives of the SOFC APU program for CPG and PTX. 
Significant SOFC APU Milestones:

- Demonstrated:

- Operation on ULSD pump fuel.

- Demonstration of continuous operation capability of a commercially available air conditioning unit for a truck hotel load (providing actual space cooling).

- Hybridization of APU for instant-on electrical power capability and increased peak loading capacity up to 3800 W AC available from combination of fuel cell and battery boost.

- Combined heat and power (CHP) system providing heat for cab or engine.

- Recharging batteries from the SOFC sub-system.

- $1,250 \mathrm{~W}$ net peak demonstrated DC power.

- Average net power produced over test period of 1,100 W DC or $820 \mathrm{~W} \mathrm{AC.}$

- Successful start-up and shut-down of SOFC APU system without inert gas purge.

- Packaging of SOFC APU similar to the CPG Diesel powered ComfortGuard APU product compatible with space available on vehicle.

- Developed:

- Low cost balance of plant concepts and compatible systems designs.

- Identified low cost, high volume components for balance of plant systems.

- Demonstrated high efficiency SOFC output power conditioning.

- Demonstrated SOFC control strategies and tuning methods. 


\section{Stack/Reformer/Module Development - Overview}

The CPG SOFC APU stack development began with the SOFCo ceramic interconnect planar cell stack construction and transitioned to a metallic interconnect tubular cell. With the selection of Protonex Technology, LLC as the new partner responsible for supplying an integrated fuel reformer, stack and hot zone. Protonex tubular cell technology and highly thermally and mechanically integrated hot zone package promised to reduce costs using more economic materials while still providing a robust, compact SOFC sub-system capable of achieving the SOFC APU goals, including operation on ultra low sulfur diesel (ULSD). The anode supported tubular cell technology drastically reduced technical issues associated with cell and interconnect cost, sealing and durability. Protonex innovative hot zone integration allowed the use of lower cost materials and simple fabrication techniques. These elements result in a SOFC subsystem with superior performance and reduced cost relative to previous technology. 


\subsection{Stack/Reformer/Module Analysis and Design- PTX Tubular Technology}

The analysis and design of the SOFC/reformer sub-system consisted of two major components: the interface specification between Protonex and Cummins, the stack and module design and subsequent upgrades to the design.

Interface specification. The first activity under the design task was to establish the basic module design and an interface specification controlling the interfaces between the SOFC modules supplied by Protonex and the structure, controls and balance of plant provided by Cummins. The interface specification identified 15 interfaces between the hot zone and the remainder of the system:
1. Fuel lines
2. CPOX air lines
3. Cathode air lines
4. Coolant air lines
5. Power leads
6. Thermocouples
7. TGC igniter leads
8. CPOX igniter leads
9. Mounting bulkhead
10. Exhaust lines
11. Hot zone outside envelope
12. Hot zone case cooling
13. Reformate sampling lines
14. Vaporizer leads
15. Purge lines

These interfaces include mechanical, thermal, electrical interfaces. A formal interface specification document was prepared and maintained subject to joint revision control at Protonex and Cummins.

Stack and module design. CPG's proposed APU is based on the use of four modules, with a gross DC output power of approximately $450 \mathrm{~W}$ each. The modular design leverages work already in progress at Protonex on $500 \mathrm{~W}$ class portable generators, and enables the creation of a family of generators spanning the 500-2000 W range, all based on a common tube and stack design. CPG's baseline module consists of a tubular stack with 66 cells. Each module is $\varnothing 205 \times 215 \mathrm{~mm}$ (a little larger than a number $10 \mathrm{can}$, or about 4L). The baseline cells for this unit are from TOTO, in Japan. The TOTO cells use Ni-YSZ anodes, LSGM electrolytes, and LSCF cathodes, with barrier layers designed to prevent interaction between the electrolyte and anode. Figure 5-1 shows an example cell. 


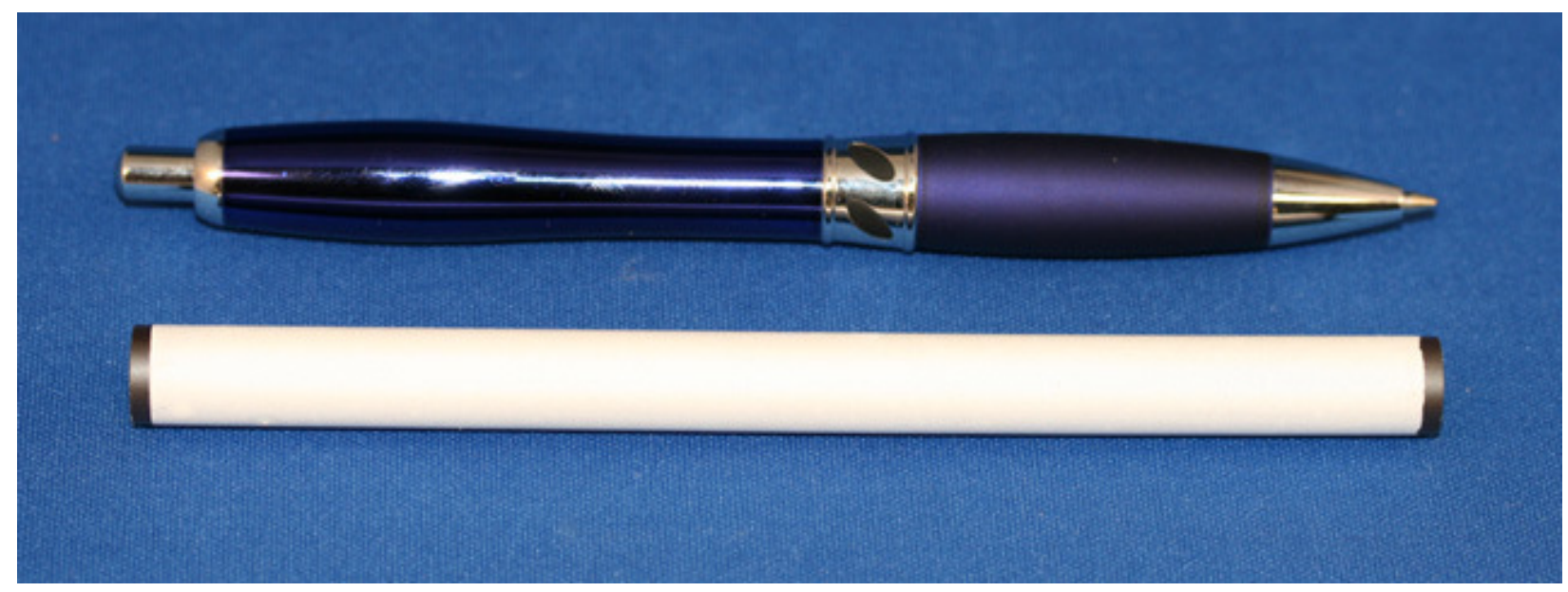

Figure 5-1. $\varnothing 10 \times 136 \mathrm{~mm}$ tubular cell.

Figure 5-2 shows a process and instrumentation diagram for a single module. Cathode flow enters the module, passes through the cold side of the recuperator and into the stack, then out of the stack, where it mixes with anode exhaust and flows through the tail-gas combustor and the hot side of the recuperator. Anode air enters the module, is mixed with fuel in the vaporizer or atomizer, then passes through the CPOX reformer and into the stack.

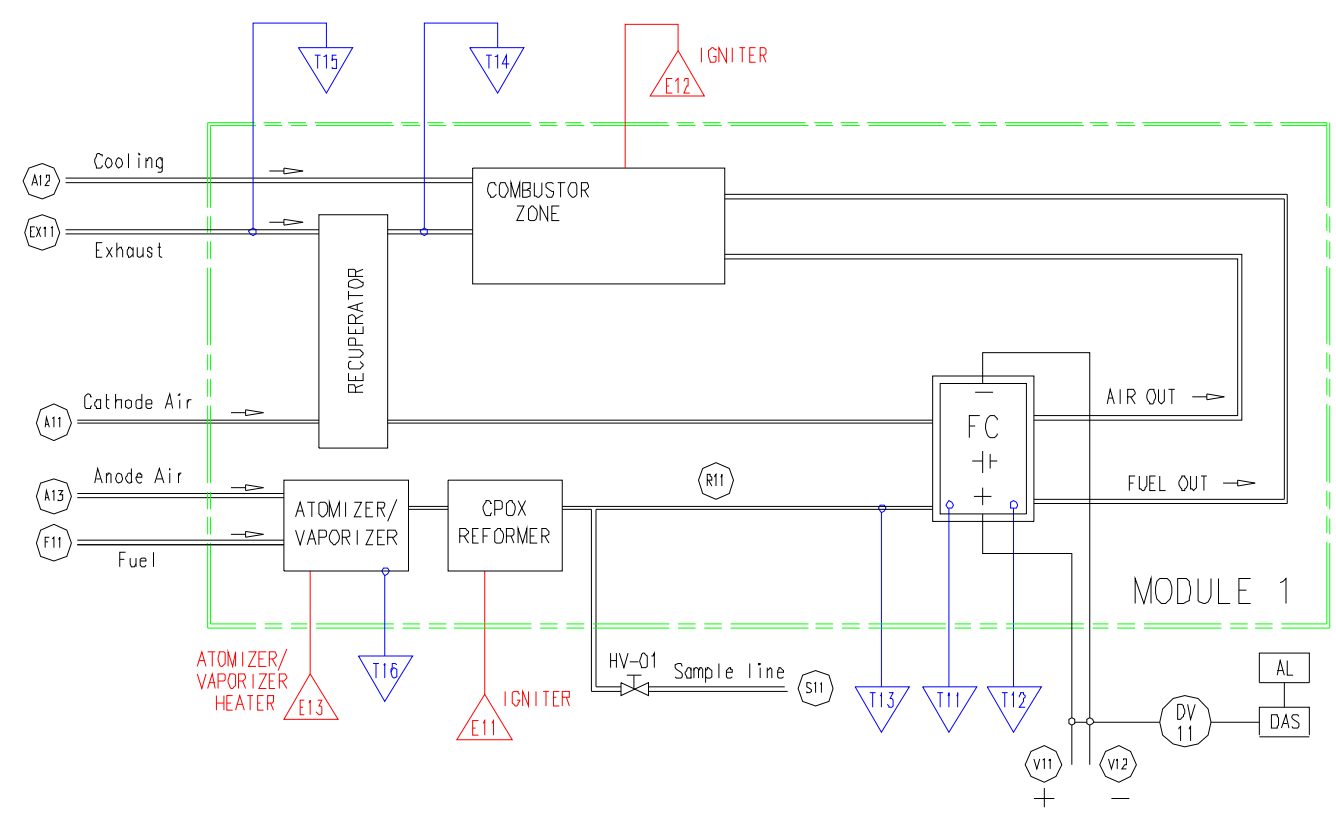

Figure 5-2. P\&ID for single module.

The module design is based on the proprietary hot zone design currently used in Protonex's portable generators. Key features of this design include ${ }^{1}$ :

\footnotetext{
${ }^{1}$ Multiple aspects of this hot zone design are covered by Protonex patents and patent applications.
} 
- ceramic tubes sheets

- proprietary, low-cost interconnects

- hot seals

- integral heat exchangers

- tight thermal, structural and electrical integration among components

Figure 5-3 shows an assembled stack and complete hot zone from PTX $75 \mathrm{~W}$ portable generator prototype.
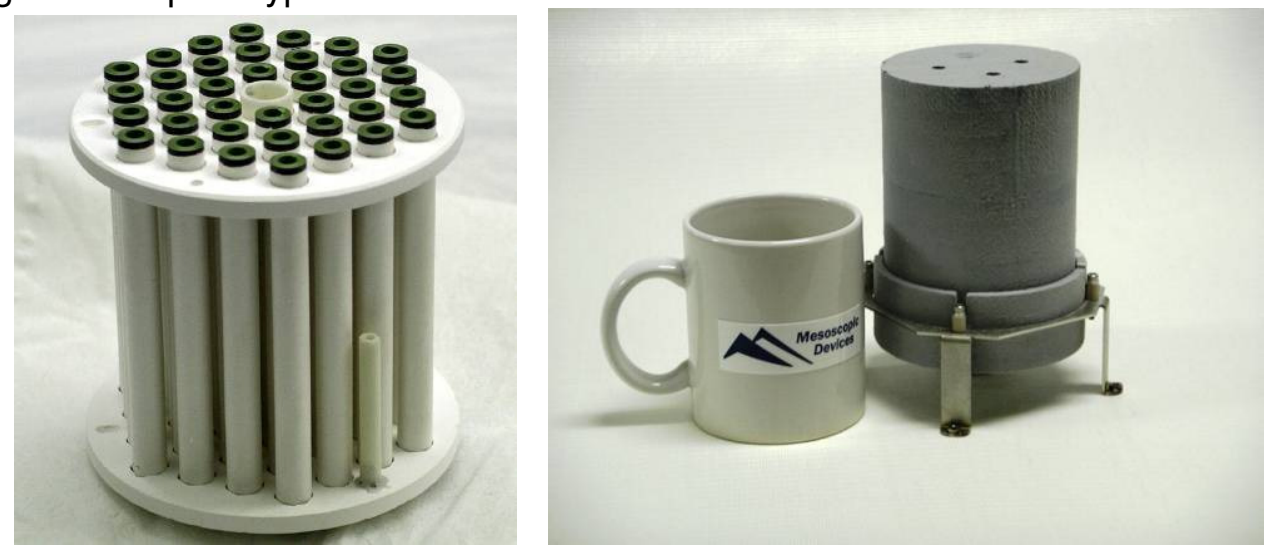

Figure 5-3. Stack and hot zone for $75 \mathrm{~W}$ portable generator.

PTX's baseline design for the APU module differs from the existing design primarily in details of the cathode flow path. This change will provide improved cathode flow uniformity and enables the use of higher-effectiveness counterflow recuperators. Most other aspects of the proven design have been retained.

CPG explored multiple alternatives for arranging the modules in the case. There were two primary considerations for the module layout. The first was arranging the modules so as to require the least amount of modification to the CPG ComfortGuard envelope as possible. The second consideration was how to efficiently assemble/disassemble and connect the modules to the balance of plant.

The completed module design effort included extensive analytical and computational modeling of system components and sub-assemblies. Examples include the recuperator, cathode air feed supply, reformate flow distribution and thermal insulation. Figure 5-45-4 shows computational and experimental results on the flow distribution through the tubes. 


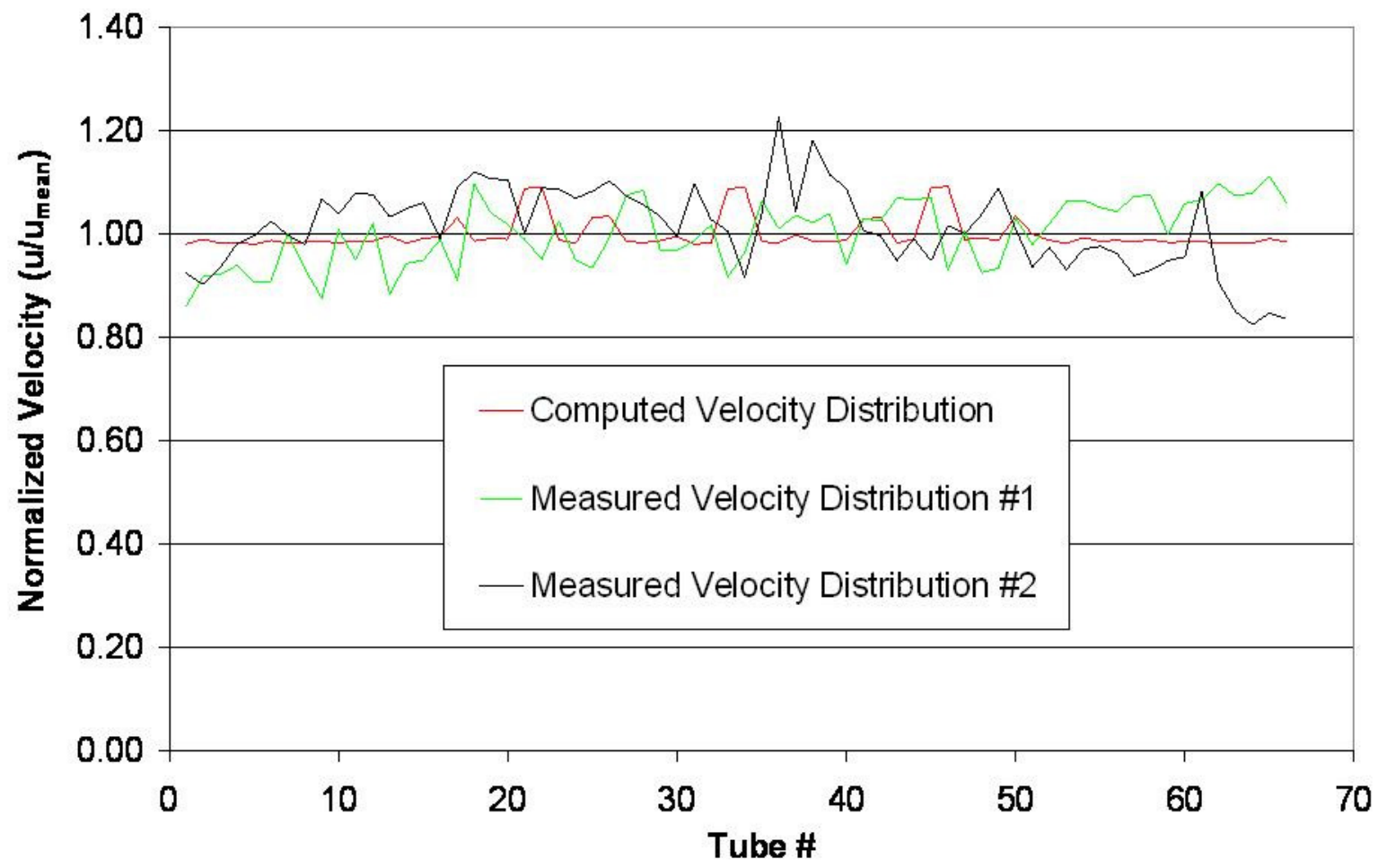

Figure 5-4. Anode flow distribution computational modeling and experiments used in module design.

Special attention was paid to design components that can be easily adapted for quantity manufacturing. An example is a redesign of the thermal insulation and how it attaches to the module to eliminate geometric complexity per part and to use cheaper, more robust materials. Another example was to design machined parts such that they could be produced using alternate fabrication methods such as spinning or stamping in larger quantities.

Material selection was also an important consideration. The high temperatures in these modules mean that thermal expansion, corrosion and oxidation become major factors that must be considered. Cost effective alloys were chosen wherever possible and appropriate design changes were made to reflect different properties such as lower maximum temperatures or smaller thermal expansion, etc.

Two fuel feed systems were developed in this program, a vaporizer-based approach and an atomizer-based approach. Atomizers have potential advantages over the vaporizers, particularly in lifetime and longer maintenance intervals, but additional pressure drop and associated parasitic losses are problematic. PTX fabricated a test facility to test each method including a vaporizer (or atomizer), a CPOX reactor and a single SOFC tube to collect long-term performance data on the fuel feed system combination. 


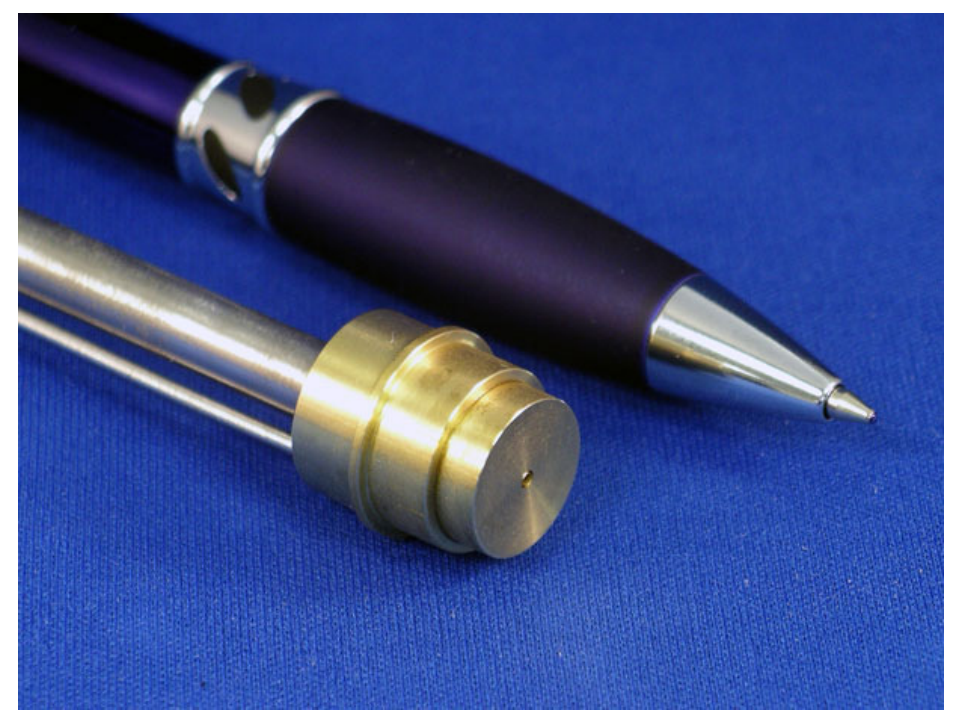

Figure 5-5. Diesel atomizer prototype

The first option was a low-pressure drop air-blast atomizer based on the MesoSpray ${ }^{\mathrm{TM}}$ atomizer developed by Mesoscopic Devices, LLC (now Protonex). This atomizer (fig. 5-5) is specifically designed for combustion and partial oxidation applications where low pressure drop and fine droplet dispersion is critical. The MesoSpray ${ }^{\mathrm{TM}}$ atomizer is a pre-filming, pure-air-blast atomizer capable of operating at very low air feed pressures $(<5 \mathrm{kPa})$. This atomizer uses a low-pressure air-blast design using fluid dynamic forces to draw a free-surface flow of fuel into very thin sheets, with no requirement for tiny, clog-prone flow passages. The atomizers are well suited for fuel and air mixing in diesel reformers since they avoid local variations in fuel to air ratio, which can cause autothermal ignition. Using laser diffraction droplet size analyzing equipment, previous MesoSpray ${ }^{\mathrm{TM}}$ atomizers have demonstrated the ability to produce average droplet sizes less than $35 \mu \mathrm{m}$ (Figure 5-65-6). Further, the MesoSpray TM atomizer can be fabricated in large volumes using die-casting or lost-wax casting, both high-volume industrial processes capable of producing precision features at low cost. 


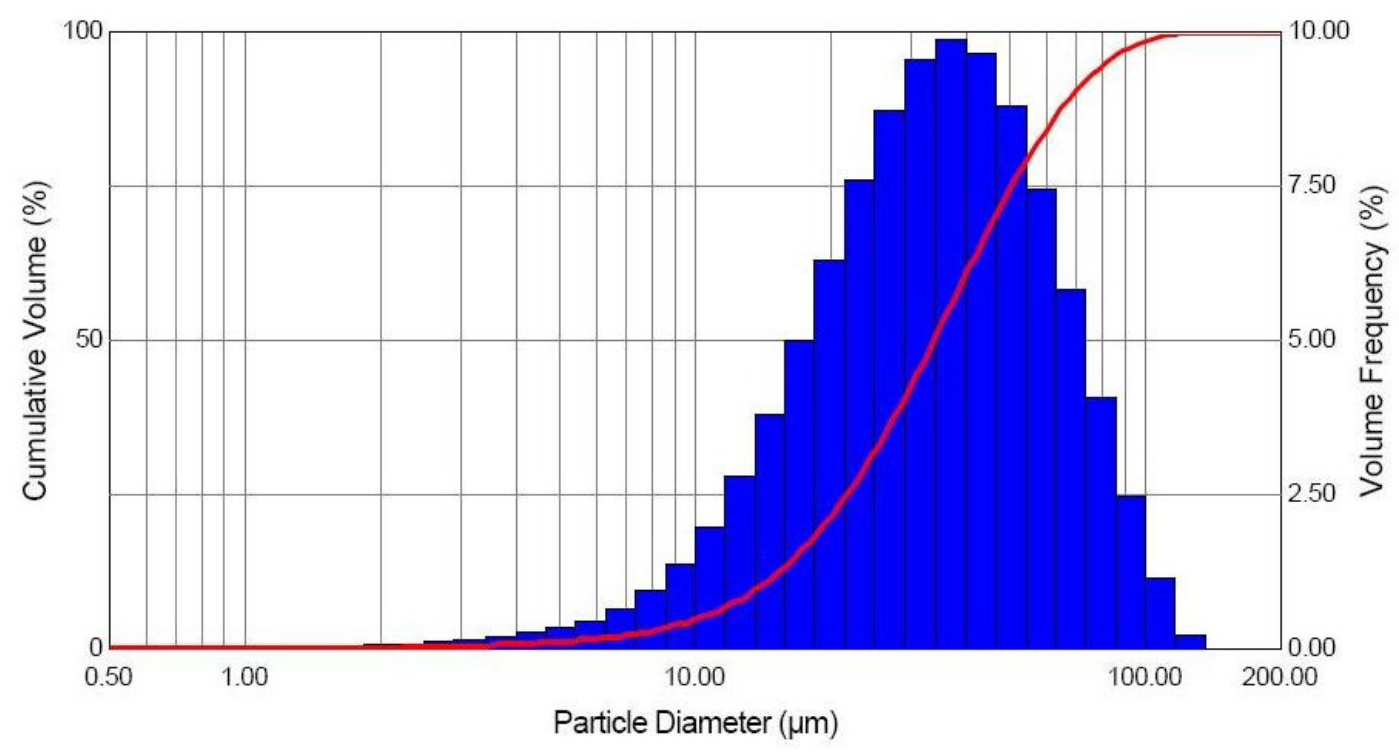

Figure 5-6 Measured performance of earlier-generation atomizer. Feed pressure $<40 \mathrm{kPa}$.

For this APU program, a new version of the atomizer was designed and prototypes were produced for testing purposes. The primary changes of the newest atomizer are changes to the atomizer geometry to reduce the spray cone angle. Prior experience showed that large spray cones may cause droplets at the outer perimeter of the dispersion to strike the outer walls of the CPOX reactor vessel and condense, causing liquid pooling and poor reactor performance. Initial testing was performed with the new prototypes confirming a reduction of the spray angle by roughly $25 \%$, from approximately $28^{\circ}$ to $21^{\circ}$ full cone angle.

Measurements showed that Protonex's patent-pending MesoSpray ${ }^{\mathrm{TM}}$ atomizers can provide very small droplet sizes and uniform fuel-air mixing with very low feed pressures of $6-15 \mathrm{kPa}$ (1-2 psi). As shown in Figure 5-7 and Figure 5-8, this atomizer produced sprays with mean diameters under $40 \mu \mathrm{m}$ with a feed pressure of only $6 \mathrm{kPa}$. At a design pressure of $12 \mathrm{kPa}$, sprays with mean diameters under $25 \mu \mathrm{m}$ are achievable. Low feed pressure is critical to minimizing the parasitic power in the fuel feed subsystem. Theoretical minimum pumping power for these atomizers is $<20 \mathrm{~W}$ for a full four-module APU. Even at a modest $20 \%$ efficiency, this means that these atomizers would consume less than $5 \%$ of the gross power of the APU. 


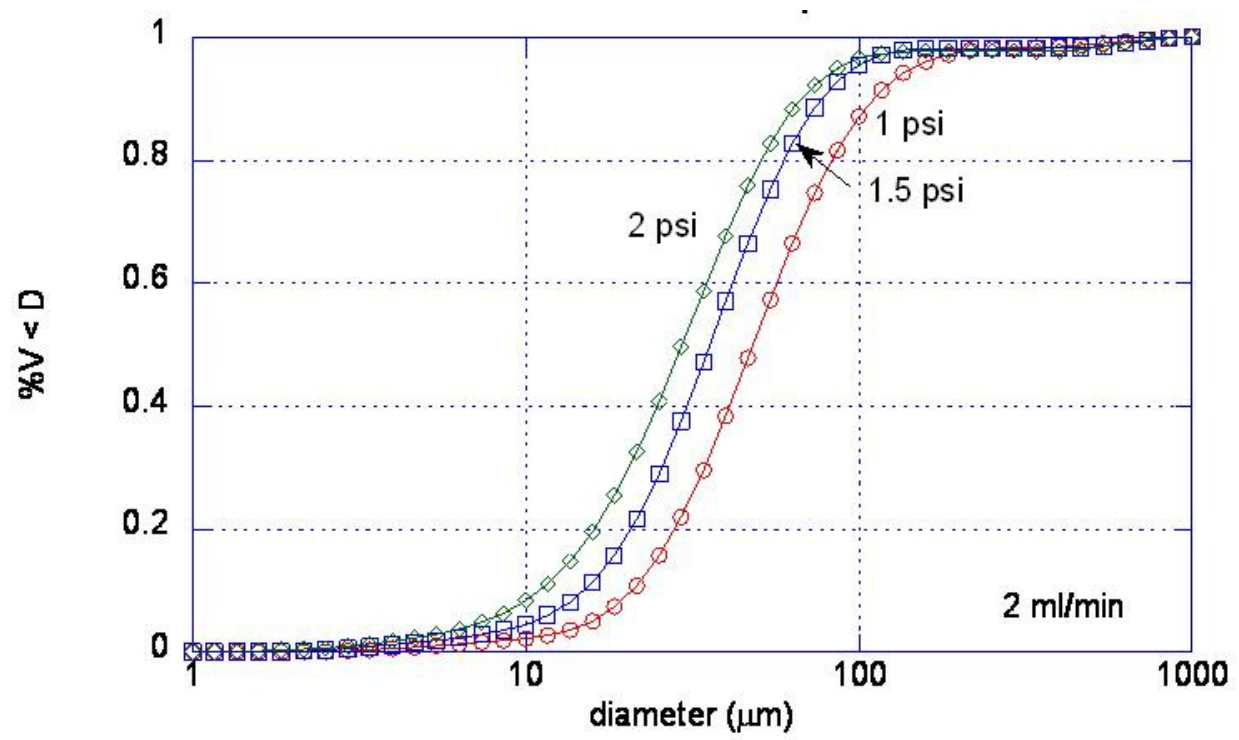

Figure 5-7. Cumulative droplet size distribution as a function of air feed pressure.

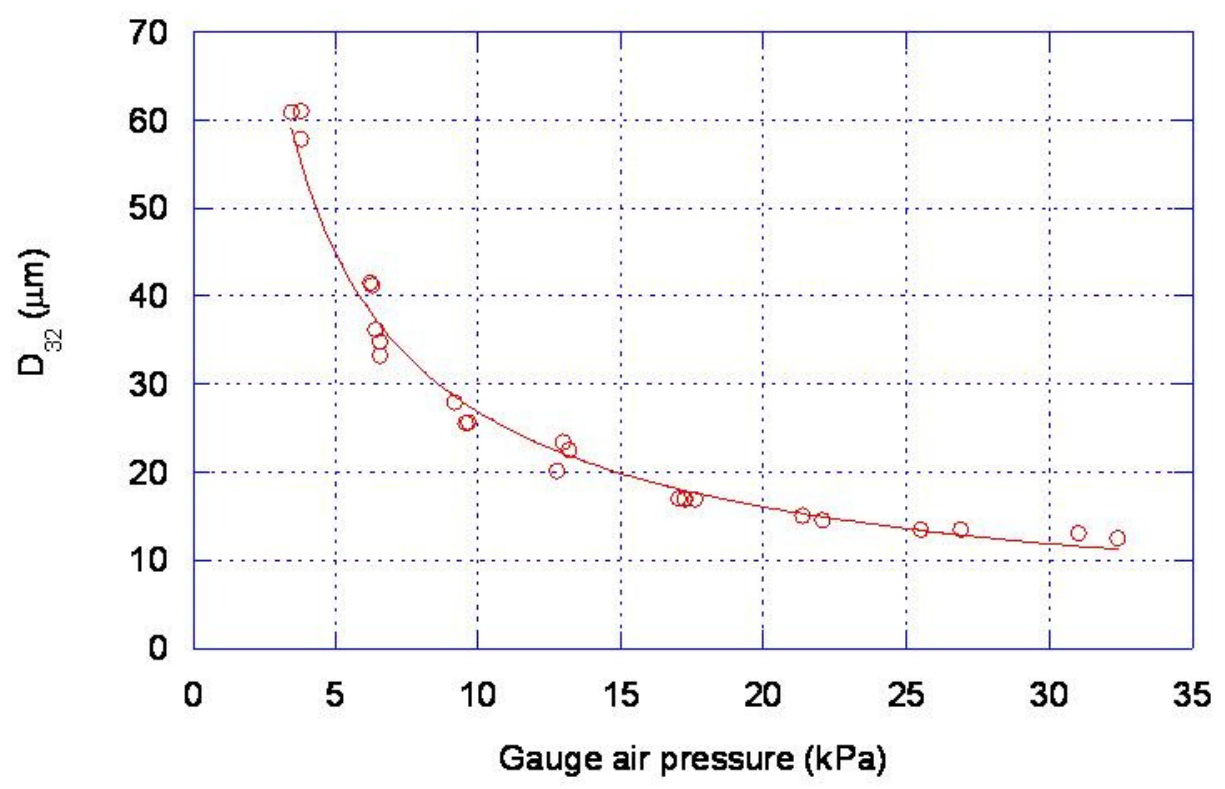

Figure 5-8. Sauter mean diameter $\left(D_{32}\right)$ vs. air feed pressure.

The second approach for fuel feeding was based on the use of a vaporizer. Protonex developed a new vaporizer design based on the use of a proprietary vaporization approach. Diesel fuel is notoriously difficult to vaporize, as the final boiling point is close to the breakdown temperature of the fuel. This leads to the formation of heavy tars that tend to clog vaporizers using small flow passages. Figure shows the first assembled fuel injection apparatus for the new vaporizer. This was designed to test the concept of the new vaporizer. When assembled, it had an approximate diameter and length of $36 \mathrm{~mm}$. 


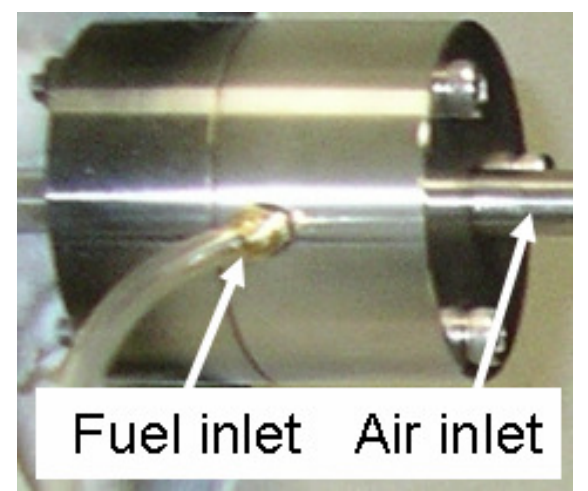

Figure 5-9. Assembled view of fuel injection device for vaporizer.

\subsection{Stack/Reformer Subsystem Test and Development- PTX Tubular Technology}

Sub-system test and development work on the SOFC/Reformer subsystem consisted of fuel feed system testing and down-selection, reformer and catalyst operation, cell characterization, sub-scale stack testing and facility fabrication.

Fuel feed system testing. PTX coupled the atomizer design with CPOX catalyst in an integrated reformer, and the basic reactor design is sketched in Figure. The reformer was ignited using an external torch, insulated, and run at steady state for 24 hours at a ULSD feed rate of 4.47 $\mathrm{ml} / \mathrm{min}$ and 15.4 SLPM air without preheat. Hydrogen and carbon monoxide selectivity were each steady at $92 \%$ throughout the 24 -hour run. This baseline selectivity and stability is a major improvement over PTX's previous attempts at atomizer driven CPOX. The air side pressure drop across the atomizer increased over the 24-hour run. Deposits were observed on the downstream face of the atomizer, and these deposits are believed to be the source of the increased pressure drops.

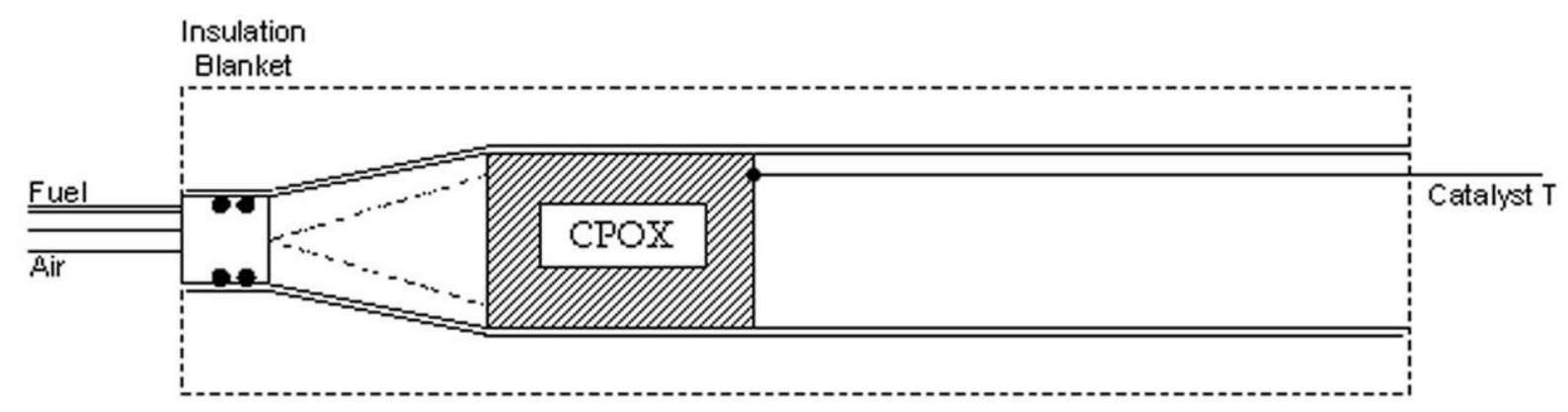

Figure 5-10. Integrated atomizer and catalyst CPOX reactor.

Subsequent testing demonstrated stable operation of this design for more than 500 hours. During this time, the tube power output varied by less than $20 \%$ from initial values. These tests clearly establish the potential of the atomizer to provide long-term stable performance of a dry CPOX reformer with ULSD fuel. One limitation of this atomizer design is that high performance can only be obtained over a relatively narrow range of fuel flows. While this range is more than adequate to accommodate power variations at steady-state, it is not large enough to allow good 
atomization under the low fuel flow rates typical of shutdown or hot standby. Continued atomizer work, developed techniques to allow atomizer operation over a wider range of fuel and air flows.

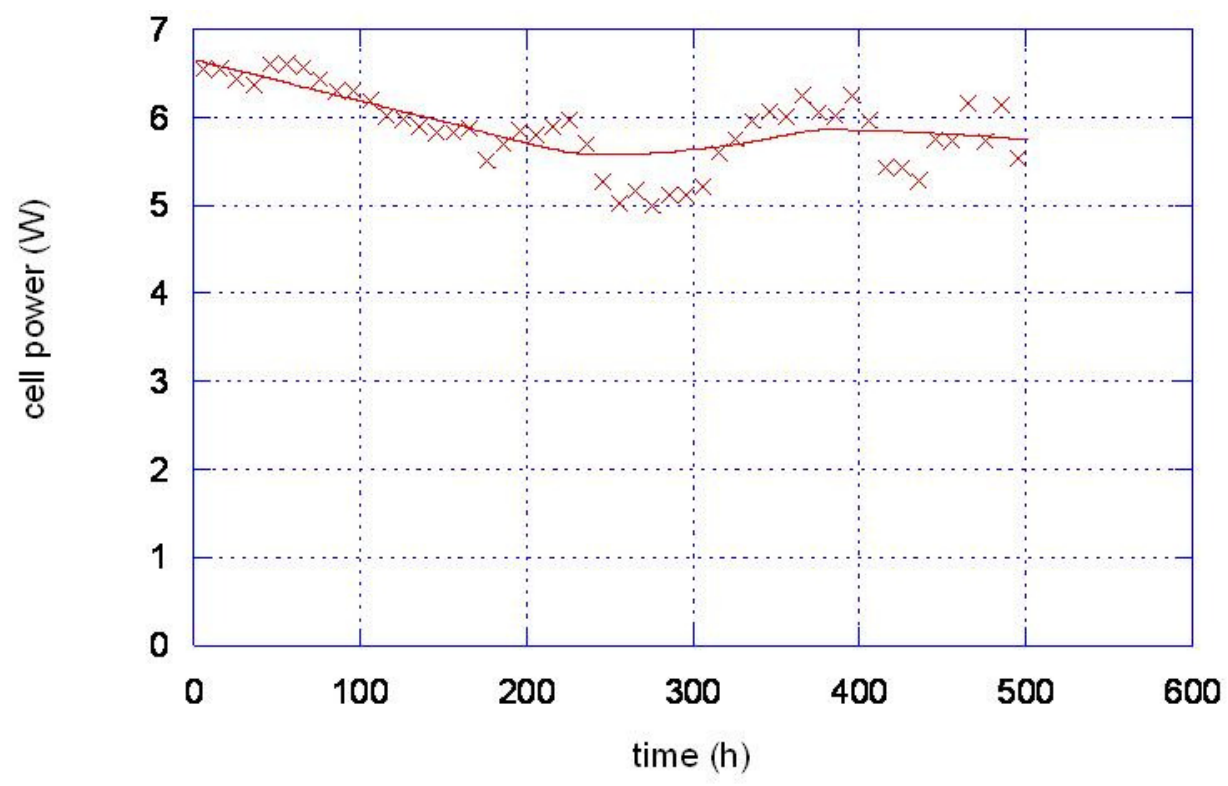

Figure 5-11. Cell power vs. time for single tube operating on atomized ULSD.

While the initial testing was an improvement over previous Mesospray ${ }^{\mathrm{TM}}$ atomizers in terms of spray cone angle, it was not optimized for the specific flow (such as turn down ratio) and pressure drop requirements of this APU project. Therefore, this approach was not selected for integration with the modules.

Preliminary tests of the vaporizer showed very encouraging results. Stability tests were performed using a $19 \mathrm{~mm}$ diameter quartz tube with a 17.3-mm diameter rhodium CPOX catalyst, as shown in Figure2. The reformate exiting this simple reformer was combusted in a diffusion flame at the end of the tube. The exit flame and reformer color intensity were used to qualitatively indicate the stability of the vaporizer. The blue flame indicates near-complete conversion of higher hydrocarbons to carbon monoxide and hydrogen. To document observations at each flow condition, digital photographs and movies were recorded. Figure5-13 presents a sample photograph collected at the design fuel flow rate $(\sim 4.4 \mathrm{ml} / \mathrm{min})$ with an $\mathrm{O} / \mathrm{C}$ ratio of 1.11 and furnace temperature of $600^{\circ} \mathrm{C}$. 


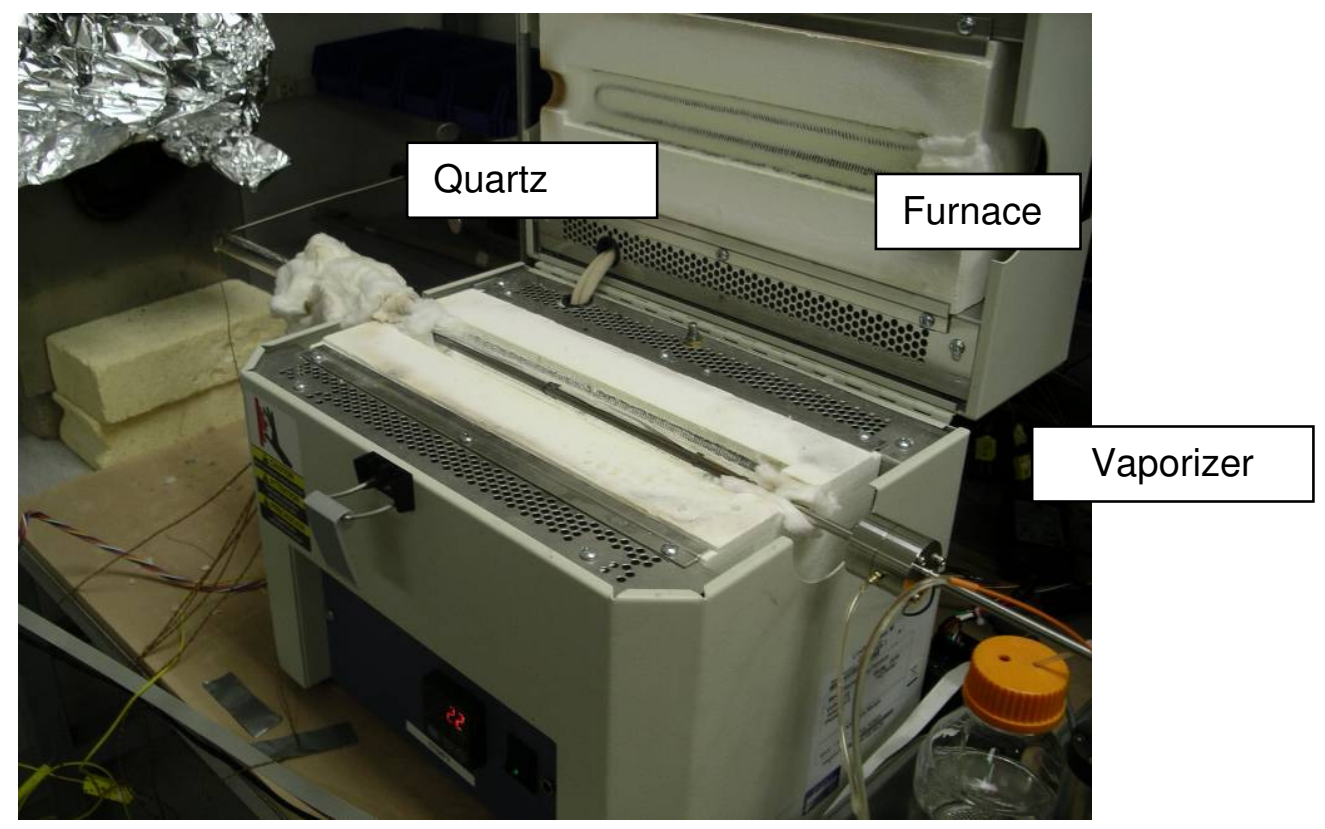

Figure 5-12. Testing apparatus for vaporizer.

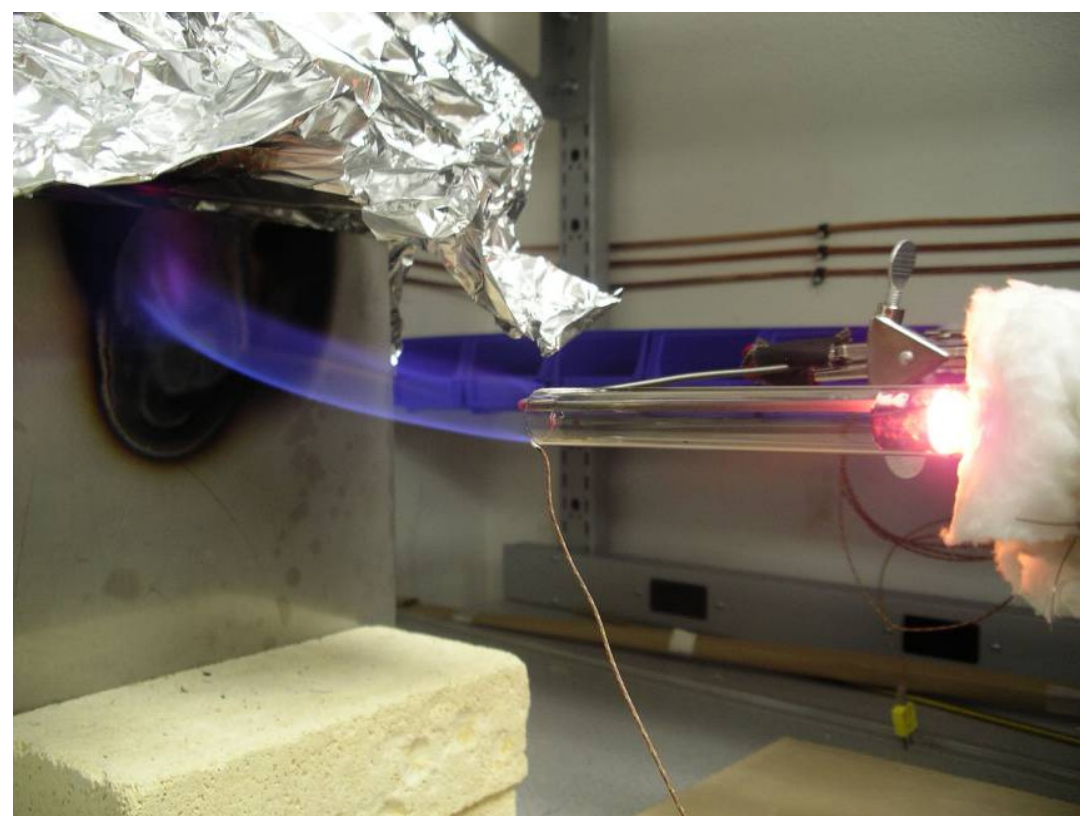

Figure 5-13. Photograph of flame and CPOX catalyst at design flow fuel flow rates, $\mathrm{O} / \mathrm{C}$ ratio of 1.11 , and furnace temperature of $\mathrm{T}=600{ }^{\circ} \mathrm{C}$.

To determine the approximate operating region of the vaporizer, the furnace temperature was systematically varied, as were the fuel flow rates and O/C ratio. Figure 5-145-14 presents a sample stability map for the vaporizer with an O/C ratio of 1.11 . The locations where PTX performed qualitative investigations are indicated with an " $X$ ". The ULSD flow rate was varied to approximate conditions for the $75 \mathrm{~W}$ portable generator ( $285 \mathrm{~W}$ firing rate, $0.52 \mathrm{ml} / \mathrm{min}$ ), $250 \mathrm{~W}$ system ( $800 \mathrm{~W}$ firing rate, $1.5 \mathrm{ml} / \mathrm{min}$ ) and proposed APU (2400 W firing rate, $4.4 \mathrm{ml} / \mathrm{min}$ ) systems. The gray section of Figure 5-145-14 represents the predicted operating range of the vaporizer based on measurements. 


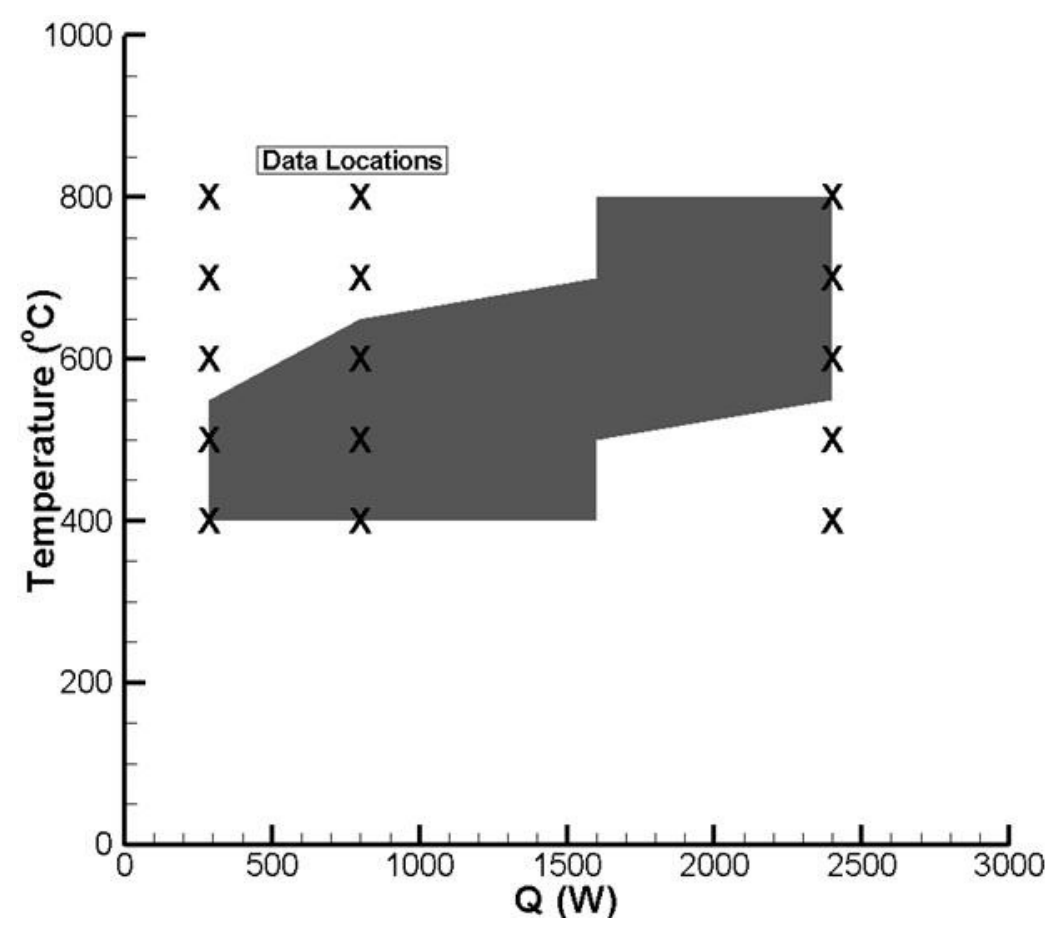

Figure 5-14. Vaporizer stability map for $\mathrm{O} / \mathrm{C}=1.11$ at various firing rates and furnace temperatures.

The air and fuel flow rates were varied over wide range of conditions to characterize the pressure drop of the vaporizer. As Figure 5-15 indicates, the pressure drop across the vaporizer is relatively insensitive to fuel flow rate. On this basis, PTX were able to characterize the pressure drop using an empirical power law fit of the form shown below. The constants for this relationship for the vaporizer are shown in Figure 5-15. These data indicate that at design conditions, the pressure drop across the vaporizer is approximately $1.2 \mathrm{kPa}$.

$$
\Delta P=\kappa \dot{m}^{b}
$$




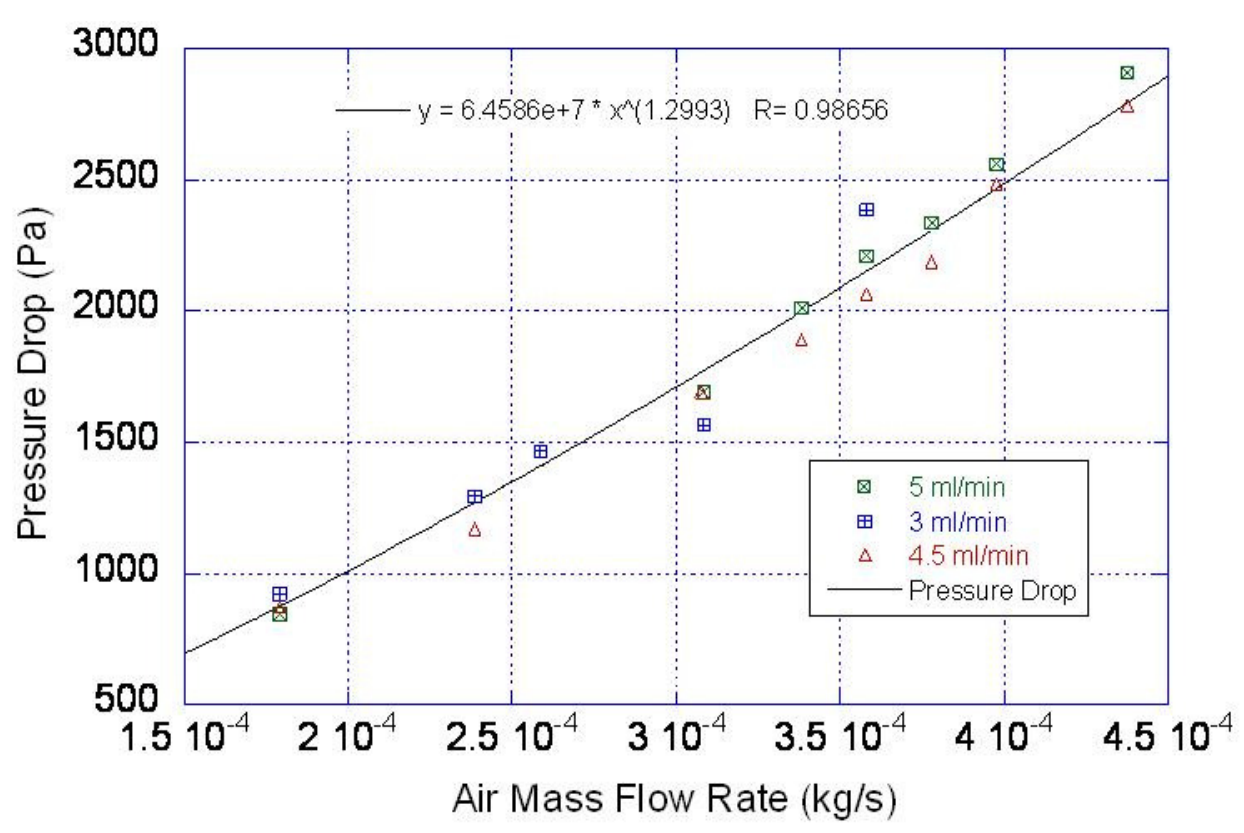

Figure 5-15. Vaporizer pressure drop data with varying fuel flow rates.

This basic vaporizer design was implemented in initial modules. Testing indicated the performance would be enhanced through design changes that allowed for more uniform preheating over a longer length. This allowed for easier control of electrical heating, more stable performance over a wide range of temperatures and a larger margin against the need for electrical heating during steady state operation on zero sulfur kerosene (Kleanheat) or ULSD.

The optimal vaporizer length was initially estimated using a radiation analysis based on previous experimental temperature data of the exhaust and the insulation surface temperature. These data were combined with an estimated view factor of the exhaust cap and port and the insulation. This calculation provided an estimated Vaporizer length of $0.35 \mathrm{~m}$. Initial experiments in a hot zone confirmed this was the approximate length required and allowed for optimizing the heat transfer to the vaporizer from the hot zone waste heat.

Reformer design and catalyst selection. Reformer work focused on catalyst characterization and selection and reactor design. The objective was to select a catalyst for ULSD catalytic partial oxidation (CPOX) having good hydrogen and carbon monoxide selectivity as well as durability under expected system operating conditions including startup and shutdown. The reactor design was then optimized for the best catalyst in order to maximize performance over a range of operating conditions expected for system operation.

Four catalysts were tested, two each from two vendors, designated A1, A2, B1 and B2. All catalysts were supported on $600 \mathrm{cpsi}$ cordierite monolith and were applied by the manufacturer. These catalysts were selected based on the recommendation by the manufactures for catalytic partial oxidation of ULSD. All partial oxidation tests were run using commercially available ULSD having 9.8 ppm sulfur.

All four catalysts were tested at two sets of conditions to examine and compare their short-term activity and stability: steady-state (i.e., all operating parameters are fixed for 8 hours) and O/C 
cycling. The $\mathrm{O} / \mathrm{C}$ ratio is a measure of the oxygen to carbon atomic ratio in the feed and strongly affects catalyst temperature. High $\mathrm{O} / \mathrm{C}$ ratios lead to high catalyst temperatures and stability at high $\mathrm{O} / \mathrm{C}$ ratios is necessary for durability during the startup and shutdown phases of operation. Steady-state and cycling durability studies were conducted in a reactor holding a $\varnothing 37 \mathrm{~mm} \times 25$ $\mathrm{mm}$ catalyst plug. Upstream of the catalyst was a short foam plug which was used to distribute the fuel and air flow evenly over the inlet face of the cordierite supported catalyst. Liquid ULSD was fed at a rate of $5 \mathrm{cc} / \mathrm{min}$, vaporized, and mixed with air at $\mathrm{O} / \mathrm{C}$ ratios ranging from 1.1 to 1.3.

Both catalysts from vendor $A$ degraded at high $\mathrm{O} / \mathrm{C}$ ratios showing decreasing $\mathrm{H}_{2}$ and $\mathrm{CO}$ concentrations and increasing $\mathrm{CO}_{2}$ and hydrocarbon products with time. The catalysts from vendor B, however, were much more stable. Catalyst B1 exhibited the best performance overall, but this catalyst is not expected to be produced in commercial quantities. Catalyst B2 is in commercial production. With only a slightly lower hydrogen and carbon monoxide selectivity than B1, PTX chose catalyst B2 for ULSD CPOX in this program.

The B2 catalyst can produce a product stream with about $20 \% \mathrm{H} 2,23 \% \mathrm{CO}$, and less than $0.5 \%$ $\mathrm{CH} 4$ at an $\mathrm{O} / \mathrm{C}$ ratio of 1.1 . Over 8 hours of steady-state operation, no carbon formation was observed within the reactor. Over an 8 hour period, 530 -minute cycles at an $\mathrm{O} / \mathrm{C}$ ratio of 1.3 did not measurably decrease the steady state performance at an $\mathrm{O} / \mathrm{C}$ ratio of 1.1 .

Three tests were conducted using this reactor configuration, two using B1 catalyst and one using B2 catalyst. A turndown ratio of 6:1 was achieved over both catalysts. At the lowest diesel feed rate tested $(1 \mathrm{cc} / \mathrm{min})$, the reactor was operated at $\mathrm{O} / \mathrm{C}$ ratios as high as 1.5 without incurring significant gas-phase diesel combustion before the catalyst. Although the highest diesel feed rate used in the tests was $6 \mathrm{cc} / \mathrm{min}$, it is likely possible to further increase the fuel feed rate before $\mathrm{H}_{2}$ and $\mathrm{CO}$ concentrations begin to fall. Table 5-1 shows the reformate composition for the $\mathrm{B} 1$ and $\mathrm{B} 2$ catalysts at the different turn down ratios.

Table 5-1. Performance of catalysts B1 and B2 at Different ULSD Feed Rates

\begin{tabular}{|c|c|c|c|c|c|c|c|c|c|c|c|}
\hline & \multirow{2}{*}{$\begin{array}{l}\text { Diesel } \\
\mathrm{ml} / \mathrm{min}\end{array}$} & \multirow[b]{2}{*}{$\mathrm{O} / \mathrm{C}$} & \multicolumn{7}{|c|}{ Wet Reformate Composition (\%) } & \multirow{2}{*}{$\begin{array}{l}\mathrm{H}_{2} \\
\text { Yield }\end{array}$} & \multirow{2}{*}{$\begin{array}{l}\text { CO } \\
\text { Yield }\end{array}$} \\
\hline & & & $\mathrm{N}_{2}$ & $\mathrm{H}_{2}$ & $\mathrm{CO}$ & $\mathrm{CO}_{2}$ & $\mathrm{CH}_{4}$ & $\mathrm{Ar}$ & $\mathrm{H}_{2} \mathrm{O}$ & & \\
\hline B1 & 6.0 & 1.1 & 51.2 & 20.9 & 23.3 & 0.75 & 0.47 & 0.61 & 2.8 & 0.88 & 0.93 \\
\hline B1 & 5. & 1.1 & 50.7 & 21.7 & 23.7 & 0.59 & 0.40 & 0.61 & 2.3 & 0.92 & 0.96 \\
\hline B1 & 1.0 & 1.5 & 56.5 & 15.8 & 17.1 & 3.6 & 0.42 & 0.68 & 6.0 & 0.82 & 0.84 \\
\hline B2 & 6.0 & 1.1 & 50.6 & 21.9 & 23.9 & 0.50 & 0.24 & 0.61 & 2.2 & 0.93 & 0.97 \\
\hline B2 & 5.0 & 1.1 & 50.8 & 21.5 & 23.8 & 0.49 & 0.40 & 0.61 & 2.5 & 0.91 & 0.96 \\
\hline B2 & 1.0 & 1.5 & 57.0 & 15.9 & 16.9 & 4.2 & 0.05 & 0.68 & 5.4 & 0.82 & 0.83 \\
\hline
\end{tabular}

PTX tested the operating limits of the B2 catalyst in order to define the operating window for the CPOX reactor. The reactor operation is controlled by three parameters: firing rate, $\mathrm{O} / \mathrm{C}$ ratio, and preheat temperature. Assuming a well mixed and completely vaporized fuel and air stream are fed to the reactor, these parameters must be maintained within certain limits to avoid catalyst deactivation and carbon formation within the reactor or downstream from the reactor.

Firing rate has a small effect on performance between about 1 and $6 \mathrm{cc} / \mathrm{min}$ at an $\mathrm{O} / \mathrm{C}$ ratio of 1.1. $\mathrm{O} / \mathrm{C}$ ratio is perhaps one of the most critical operating parameters affecting not only the performance of the CPOX reformer, but also its durability. Higher $\mathrm{O} / \mathrm{C}$ ratios lead to lower $\mathrm{H}_{2}$ and $\mathrm{CO}$ yields and higher temperatures, while at lower $\mathrm{O} / \mathrm{C}$ ratios carbon formation is a main concern. For diesel CPOX reforming, an O/C ratio of 1.1 is recommended for steady-state operation. For catalyst $\mathrm{B} 2,1250{ }^{\circ} \mathrm{C}$ was selected as the upper temperature limit to avoid rapid catalyst degradation induced by thermal sintering. The recommended maximum use 
temperature for cordierite support is $\sim 1300{ }^{\circ} \mathrm{C}$, above which melting can occur. With this temperature limit, $\mathrm{O} / \mathrm{C}$ was limited to about 1.2 at a diesel feed rate of $5 \mathrm{cc} / \mathrm{min}$.

For the reformer used in the present study, which had a designed diesel feed capacity of 5 $\mathrm{cc} / \mathrm{min}$, its $\mathrm{O} / \mathrm{C}$ range is shown in Figure 5-16. Although this graph was generated based on a very limited number of experimental data, it does establish a preliminary boundary for the operation of the reformer. A factor which was not considered, due to lack of experimental data, is the low temperature limit which means that the temperature of catalyst is too low to generate the desired $\mathrm{H}_{2}$ and $\mathrm{CO}$ yields. Too low catalyst temperature typically occurs at low fuel feed rates and low $\mathrm{O} / \mathrm{C}$ ratios. The effect of preheat temperature was also not investigated or presented in Figure 5-16, but increased preheat temperatures are expected to decrease the area of the operating zone at high $\mathrm{O} / \mathrm{C}$ ratios.

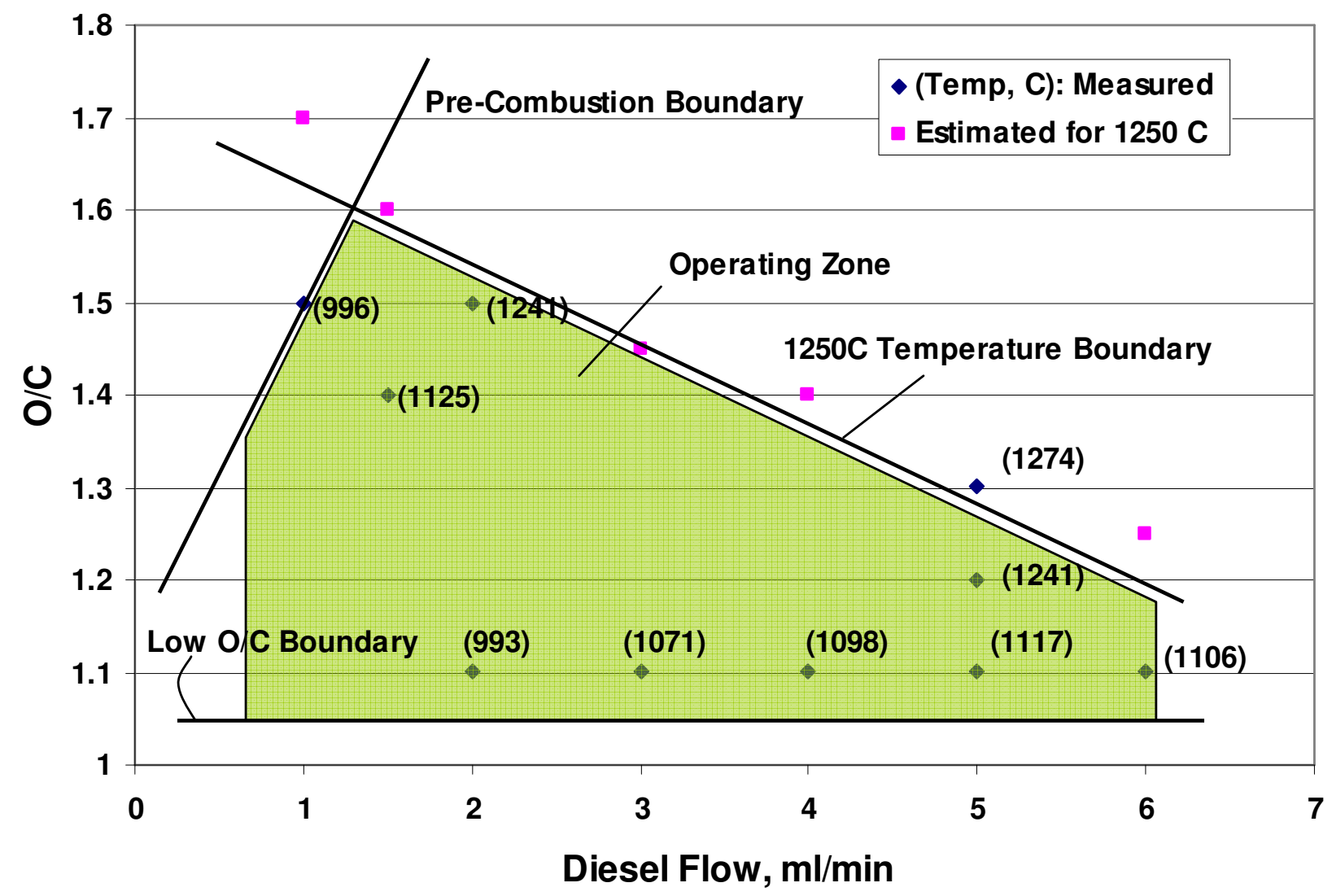

Figure 5-16. Estimated operating window for catalyst B2 at feed preheat temperature of about $325{ }^{\circ} \mathrm{C}$.

PTX demonstrated over 200 hours of continuous operation on ULSD with a vaporizer driven CPOX reactor and over 500 hours of cumulative run time on a single CPOX reactor and catalyst sample, processing over 130 liters (34 gallons) of ULSD. The CPOX reactor hardware used for this testing is shown in Figure 5-17. Two of these reactor systems and a vaporizer were delivered to Cummins for evaluation. The reformer system required external ignition using a torch or other heat source, but once ignited is thermally self sustaining except for the heat required to run the vaporizer. 


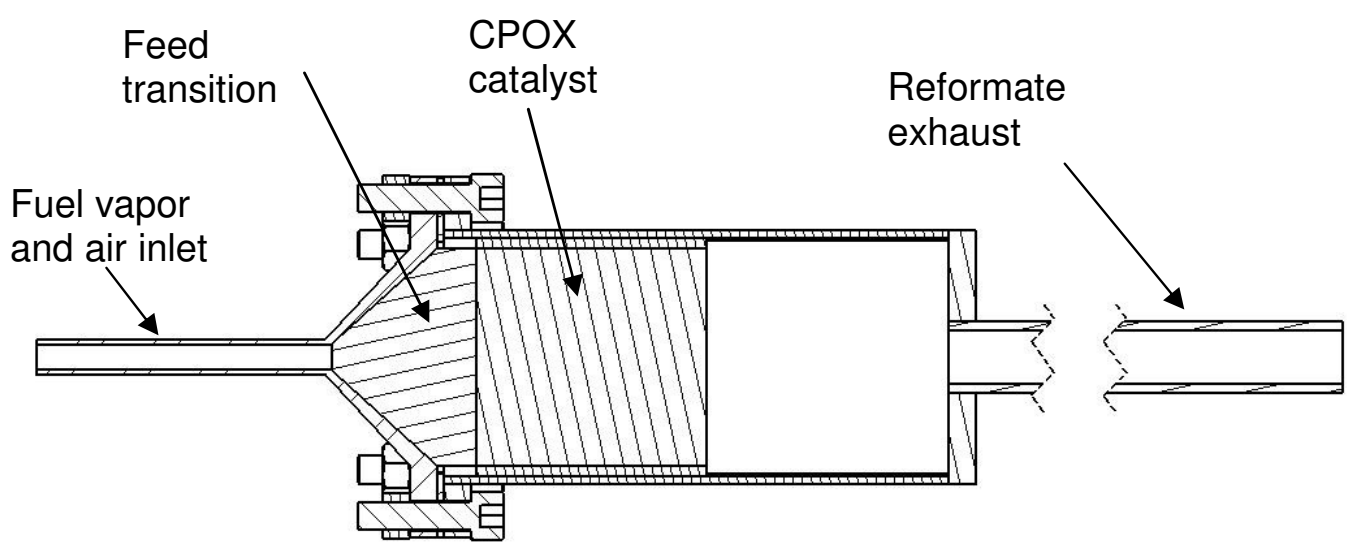

Figure 5-17. Prototype CPOX reactor.

Some amount of deposit formation was observed during these tests, and the pressure drop across the vaporizer and reactor increased with time. Periodic cleaning of these deposits allowed continued operation; maintenance intervals were up to 200 hours. Carbonaceous deposits were observed primarily near the outlet end of the vaporizer. No deposits were observed in the catalytic section.

Catalyst performance was very steady for this lifetime test. Figure 5-18 shows hydrogen and carbon monoxide selectivities over the cumulative 500 hours of testing. Note that the catalyst sample was not changed or treated over these 500 hours. After an initial decline in the first 40 hours, the selectivities remain constant at about $90 \%$. 


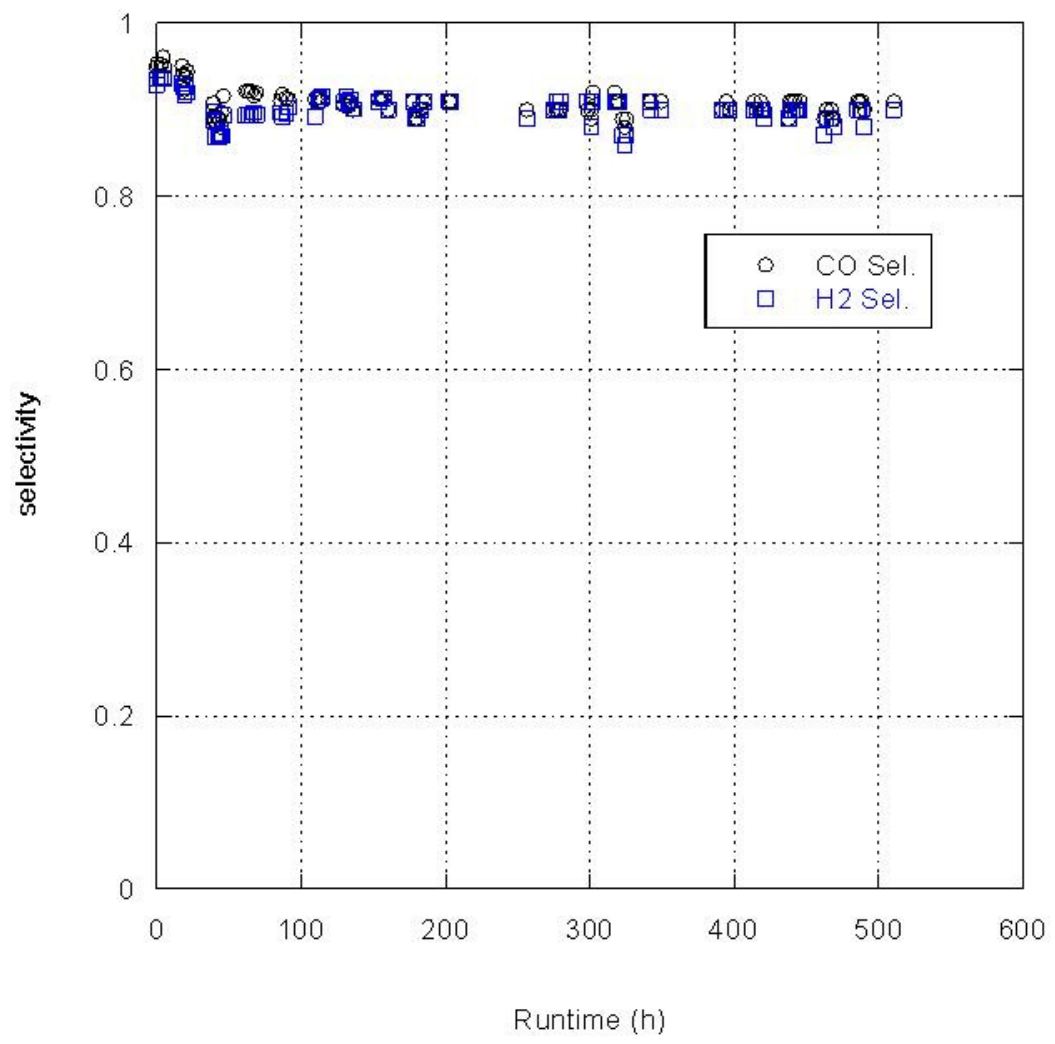

Figure 5-18. Hydrogen and carbon monoxide selectivities versus time.

Cell testing. PTX's first $\varnothing 10 \mathrm{~mm}$ cells were received late in the first quarter of the project. This performance was measured at $0.4 \mathrm{slpm} \mathrm{H}_{2}$ in $0.4 \mathrm{slpm} \mathrm{N}_{2}$ (anode), $3 \mathrm{slpm}$ air (cathode). PTX also mapped the cell voltage at constant current when varying the fuel flow rate. The results of this test are shown in Figure 5-19. The voltage is presented as a function of the fuel utilization, where the fuel utilization is defined as flow rate of hydrogen divided by ideal hydrogen consumption at $6 \mathrm{~A}$. Up to approximately $82 \%$ fuel utilization, the cell voltage change (and hence power) is varying linearly, with only a $12 \%$ loss in power from that measured at $10 \%$ fuel utilization. This information will be used to determine the uniformity of flow required amongst the cells to ensure that no cells are fuel starved. 


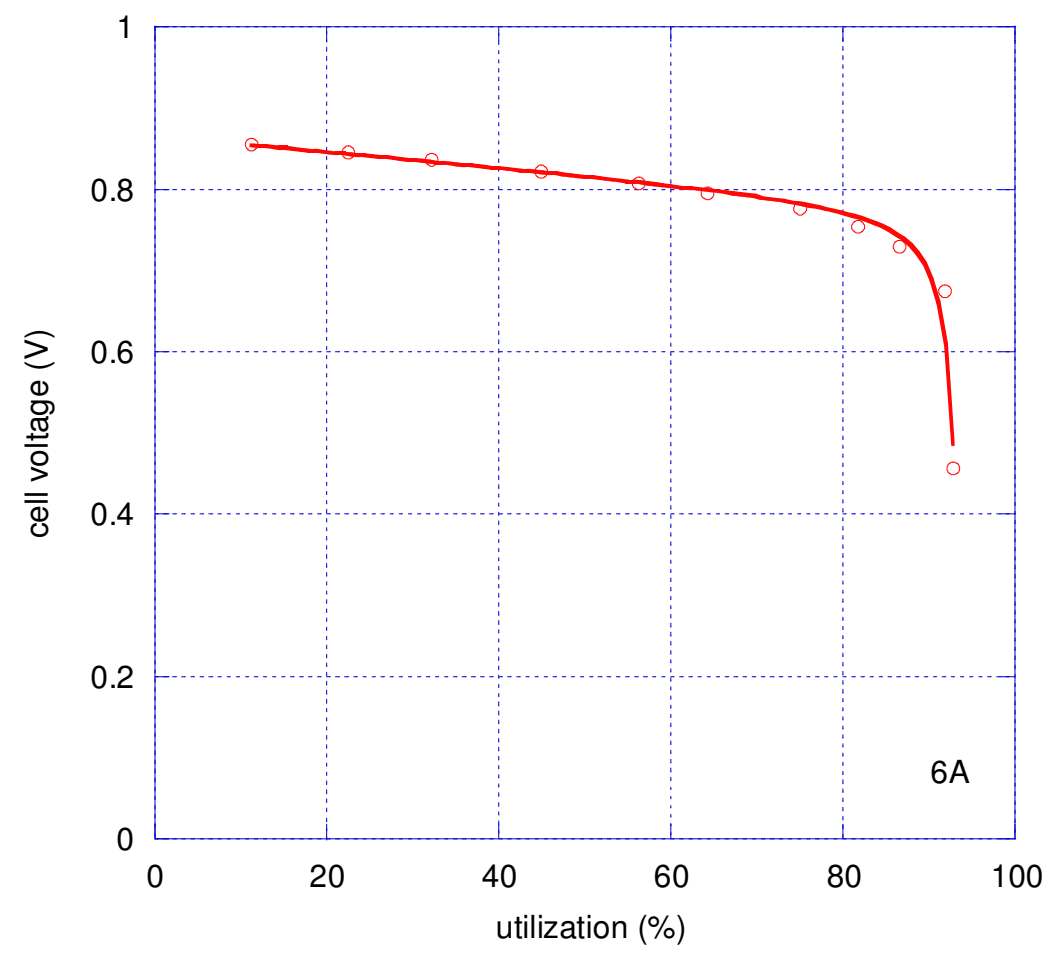

Figure 5-19. Cell voltage as a function of fuel utilization at constant $6 \mathrm{~A}$ current.

Initial testing with the full-sized cells used two cell configurations-a standard configuration and a configuration with improved current collection. Although data for only three cells are shown in Figure 5-20, note that performance curves for the two standard cells collapse to single curves.

The cell with improved current collection significantly outperforms the standard cell. Although PTX have not repeated these measurements with a large enough statistical sample to confirm these results; these data suggest that the improved current collector can improve the cell performance. On the other hand, the current collector improvements add complexity and cost to the stack manufacturing.

PTX investigated how cell performance changes with power cycling. The power was cycled sinusoidally from approximately $100 \%$ to $25 \%$ of full power with the following cycling configurations: 100 cycles with a 1 minute period; 100 cycles with a 30 second period; 100 cycles with a 15 second period and; 10 cycles with a 10 minute period. Comparison of this data to cells operated at steady state indicates no effect of power cycling on cell degradation rates. 


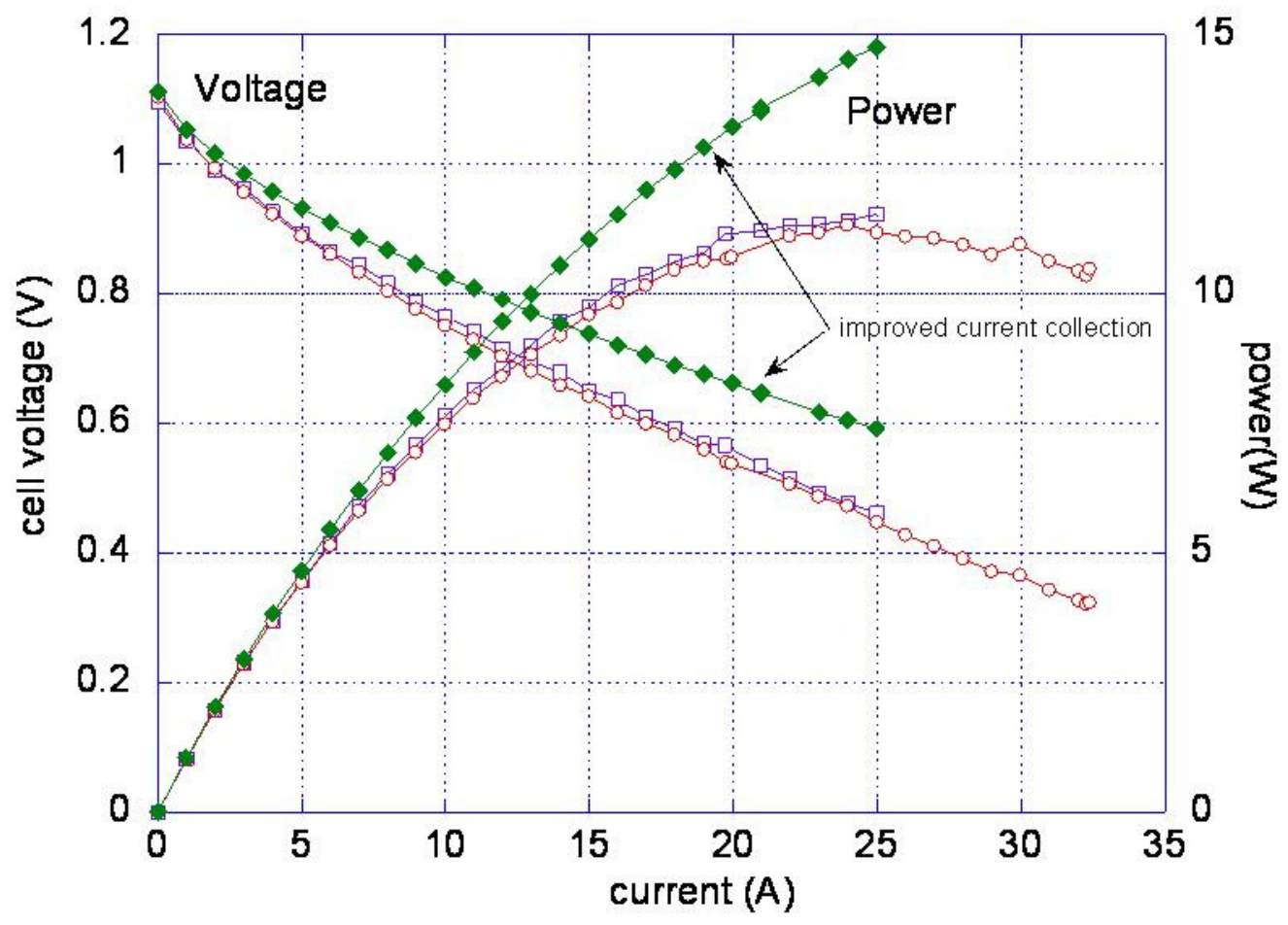

Figure 5-20. Comparison of cell performance with standard and improved current collection $\left(\dot{V}_{H_{2}}=0.4\right.$ SLPM, $\dot{V}_{N_{2}}=0.4$ SLPM, $\dot{V}_{A I R}=0.4$ SLPM).

12-cell subscale bundle testing. A 12 cell stack was tested as a proof of concept for several design features. The cathode air feed system was redesigned from past generators, improvements were made to the interconnects and their attachments and this test was the first multiple cell stack to use the $\varnothing 10.2 \mathrm{~mm}$ diameter tubes. All of these improvements resulted in good performance that scaled up to meet the power requirements of the full scale modules. A representative polarization plot is shown in Figure 5-21. Power at $0.7 \mathrm{~V} /$ cell and $\sim 50 \%$ fuel utilization was just under $10 \mathrm{~W} /$ cell. After accounting for potential losses associated with scaling up to the full scale module, this tube performance was deemed adequate. 


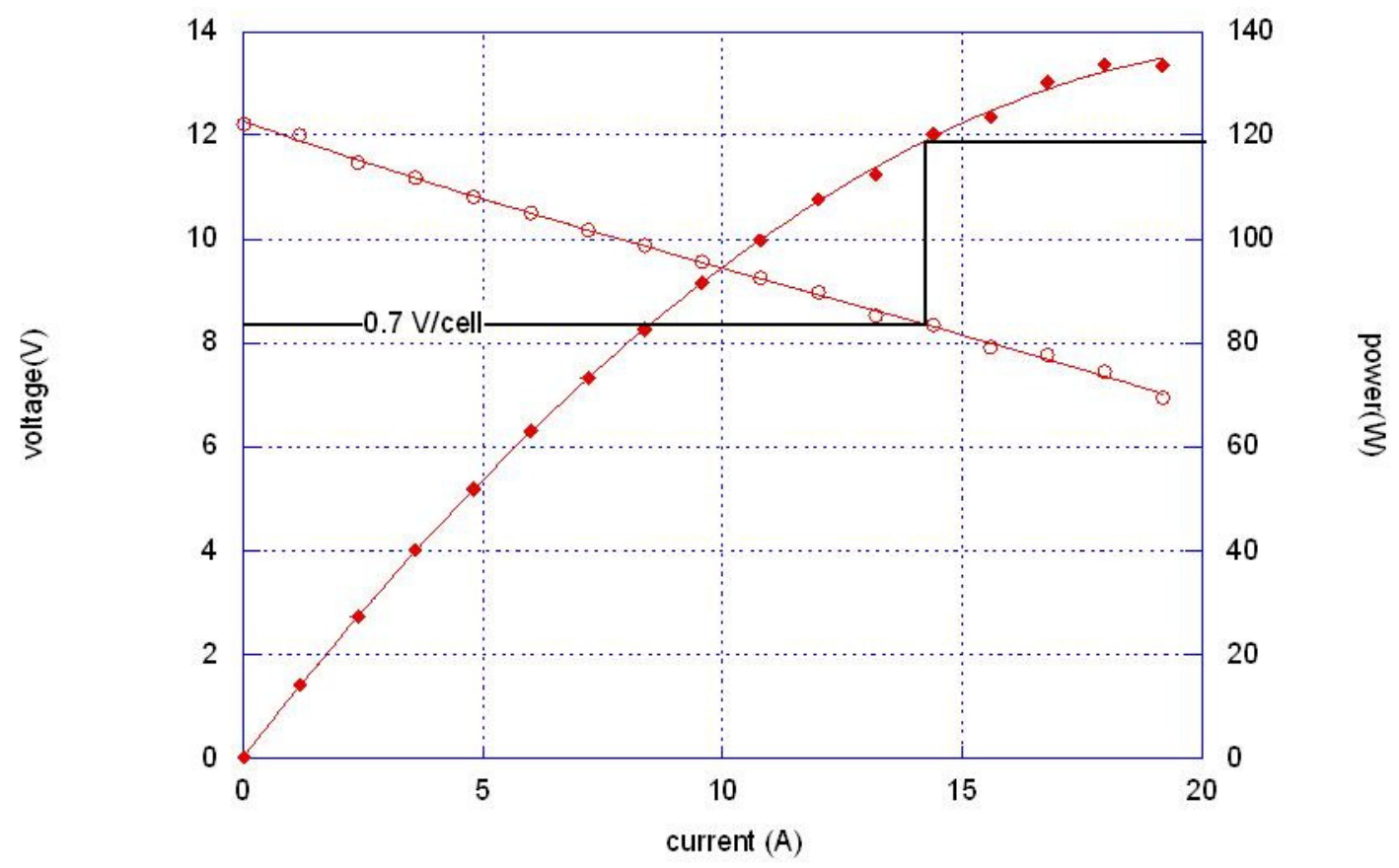

Figure 5-21. Polarization plot for 12-cell bundle.

Subscale stacks were also tested on liquid fuels to determine the proper setpoints for the fuel processor and cathode air flow to enable reliable startup and shutdown of stacks on liquid fuels. These tests included operation on both ULSD and low-sulfur kerosene fuels. Figure 5-22 and Figure 5-23 show typical results from these tests. As Figure 5-22 shows, the power was very stable over these cycles, with less than $1 \%$ power loss over 10 thermal cycles. This is excellent thermal cycling performance, even given these relatively rapid heating and cooling rates.

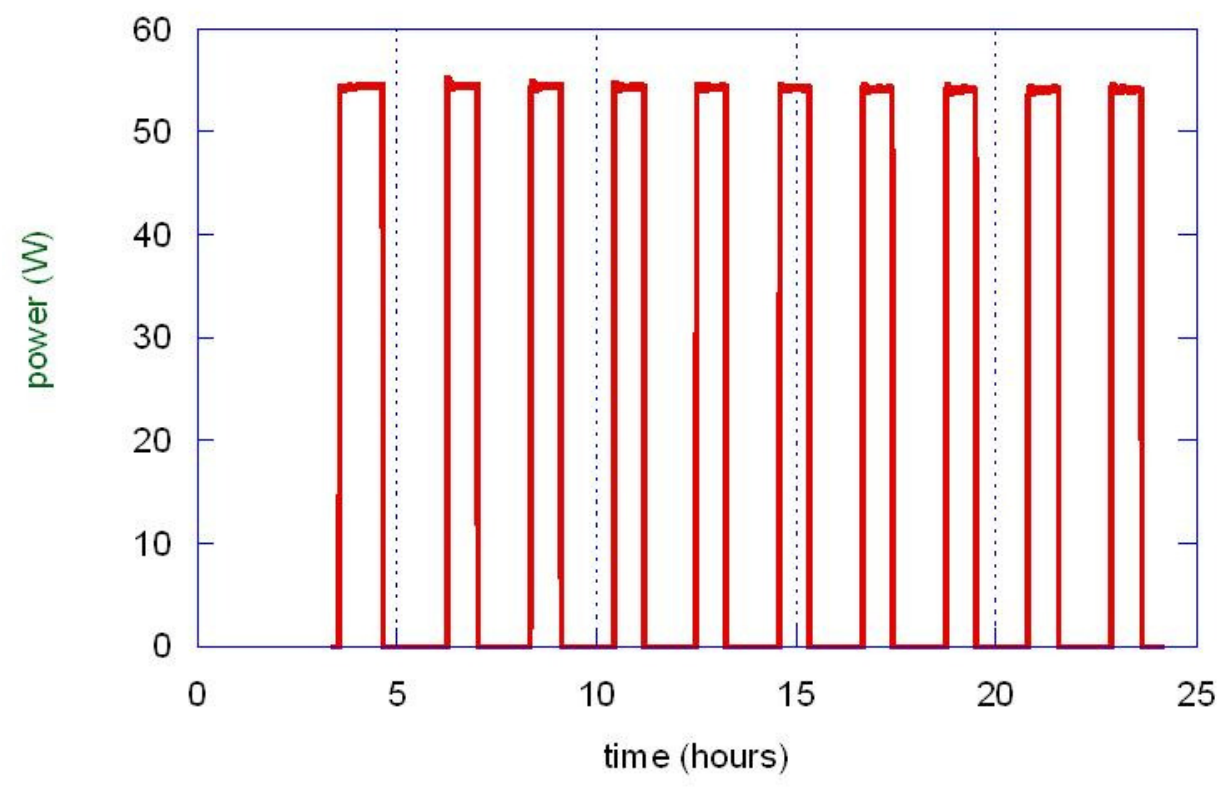

Figure 5-22. Power vs. time for subscale stack cycled on liquid fuel. Stack power decreased by less than $1 \%$ over these ten thermal cycles. 


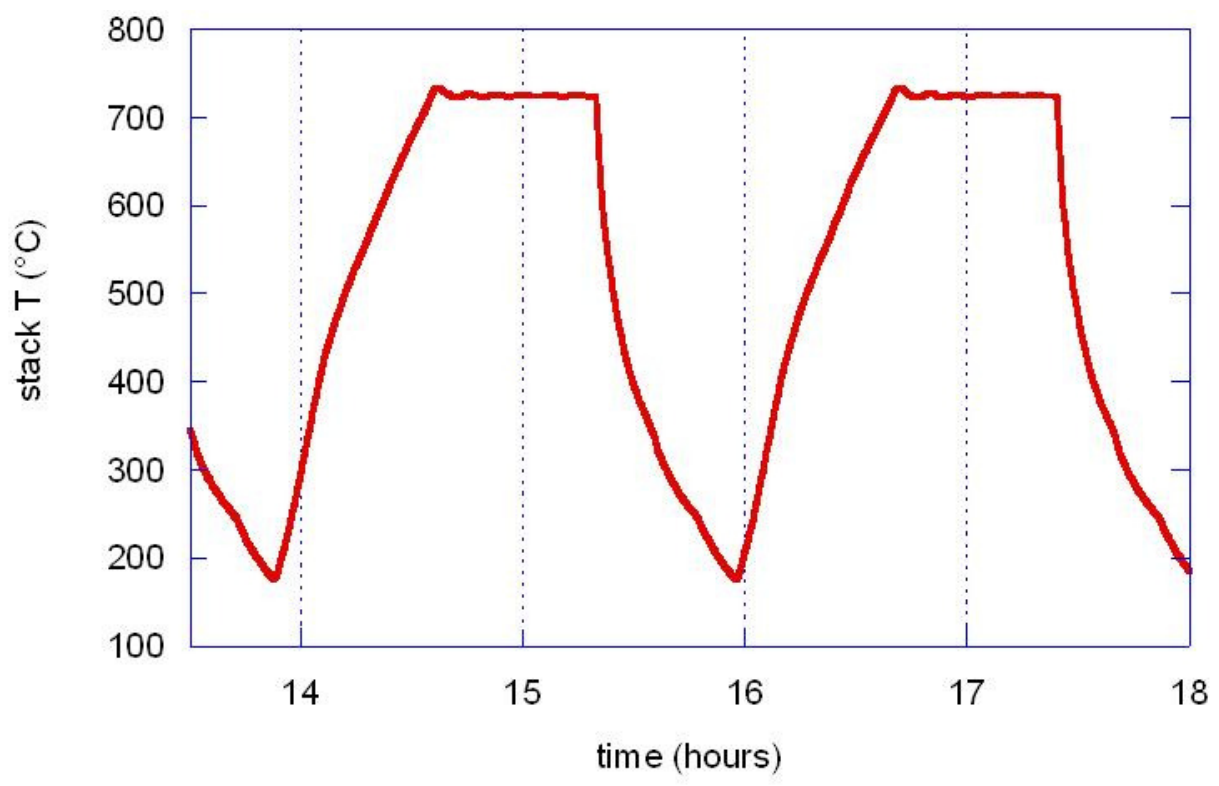

Figure 5-23. Details of stack temperature during one thermal cycle. Heating and cooling times are approximately 40 minutes each.

Although these tests were conducted with a sub-scale stack, they used a full-scale fuel reformer, so they provide a complete test of the fuel processor and a high-fidelity simulation of the conditions inside a full-scale module.

Interconnect testing. As all the tubes in a single module are wired in series, very high reliability interconnects are required. Initial production yield on interconnects was very high, but the spread in performance over time remains larger than desired. PTX constructed a dedicated interconnect test stand for testing advanced interconnect materials and contact aids. In this facility, ten short sections of tubes are connected by interconnects in series. The tubes are internally shorted, and a controlled current is fed through the tube string, passing through each interconnect in series. Voltage taps allow four-wire measurement of the voltage drop across the anode-interconnect junction, interconnect, the interconnect-cathode junction and the entire repeat unit. PTX used this facility to investigate improved fabrication techniques for the interconnects and alternate contact aids. Repeat unit resistance under $6 \mathrm{~m} \Omega$ was achieved in tests of up to 350 hours, sufficient to meet initial system performance goals. 


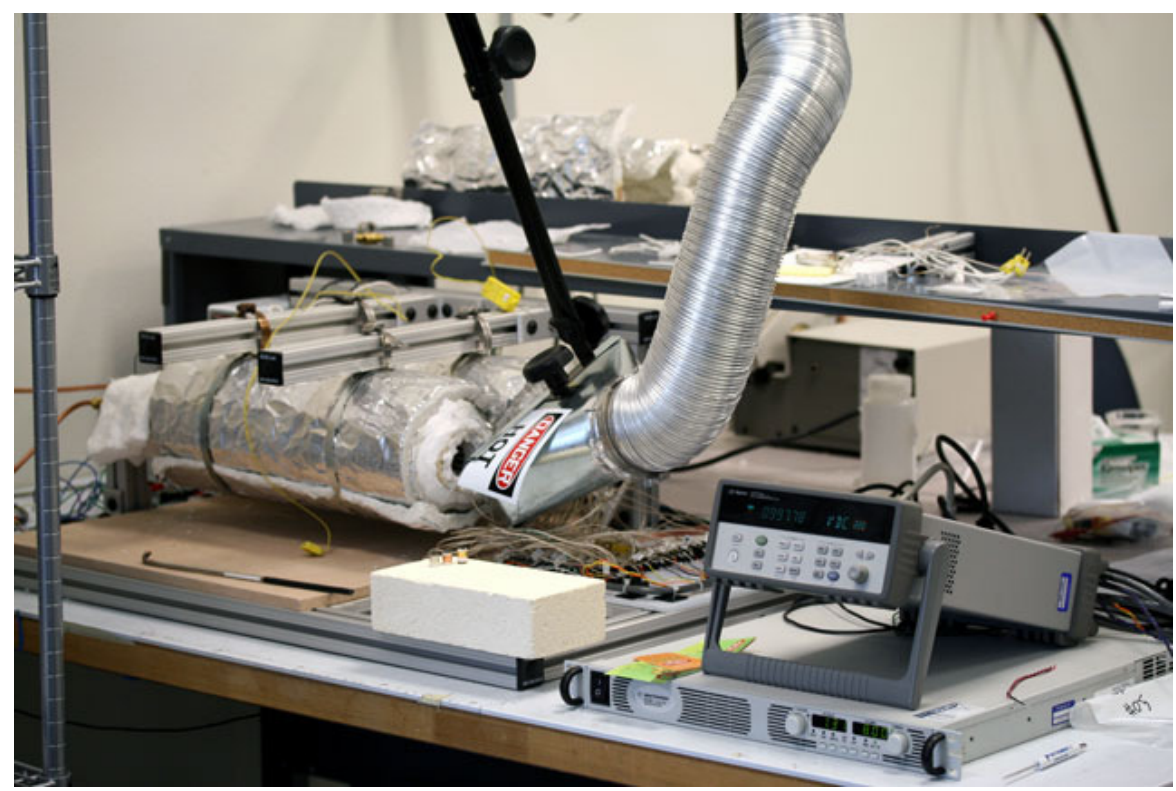

Figure 5-24. Interconnect test facility.

Test facility fabrication. During this program, PTX built a dedicated test facility for testing modules. This facility will be used for initial tube reduction, testing of stacks, and testing of full modules. Figure 5-25 shows the process and instrumentation diagram for the facility, and Figure 5-26 shows a photograph of the facility. The facility includes the capability to feed air, propane, nitrogen, hydrogen and forming gas $\left(4 \% \mathrm{H}_{2}\right.$ in $\left.\mathrm{N}_{2}\right)$. An active load can sink up to $1.2 \mathrm{~kW}$ for module testing, and all equipment, including a four-zone furnace is controlled by custom LabVIEW software running on compact FieldPoint hardware from National Instruments. Multiple layers of safety equipment protect the operator, the facility and the module. 


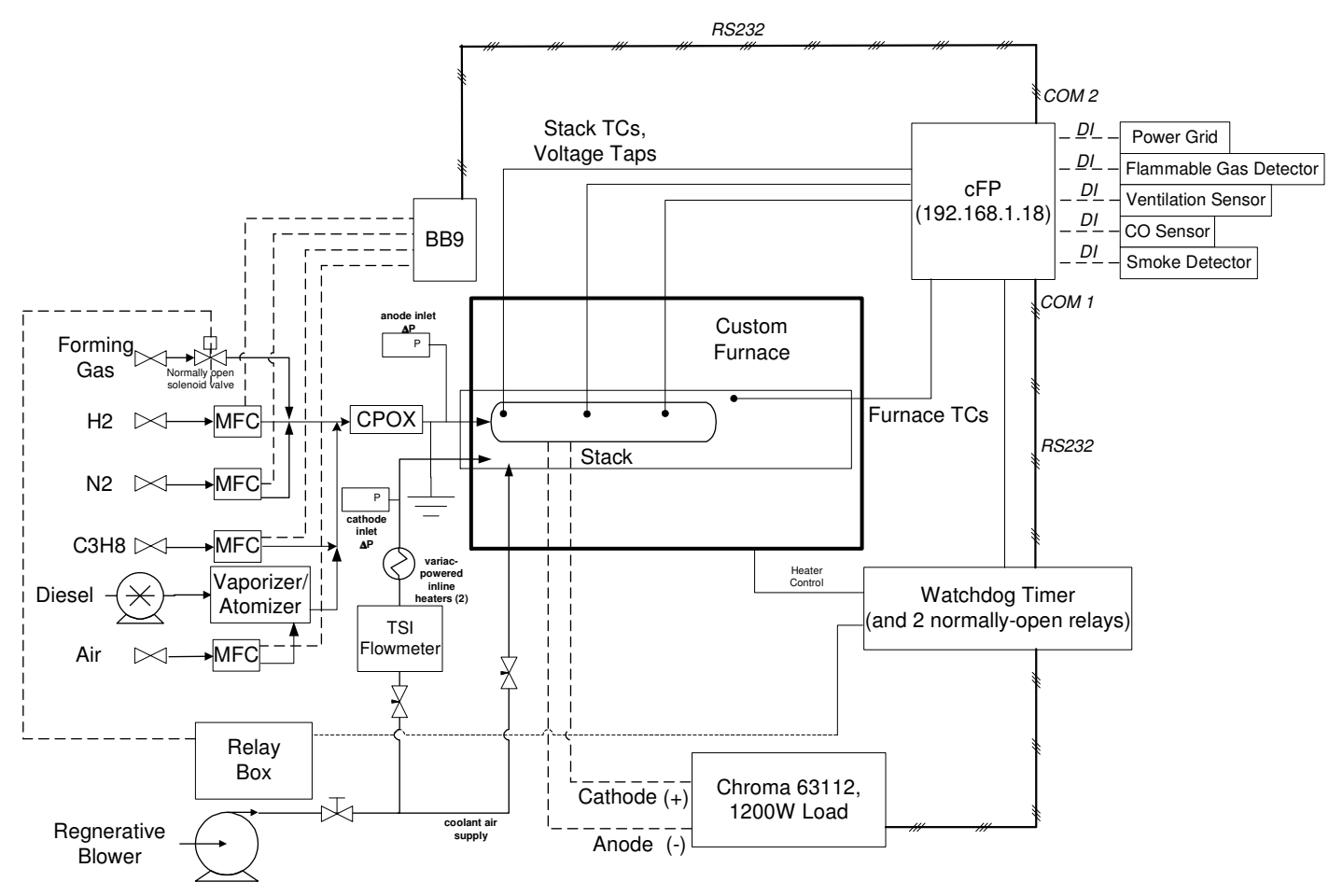

Figure 5-25. Module test facility process and instrumentation diagram. 


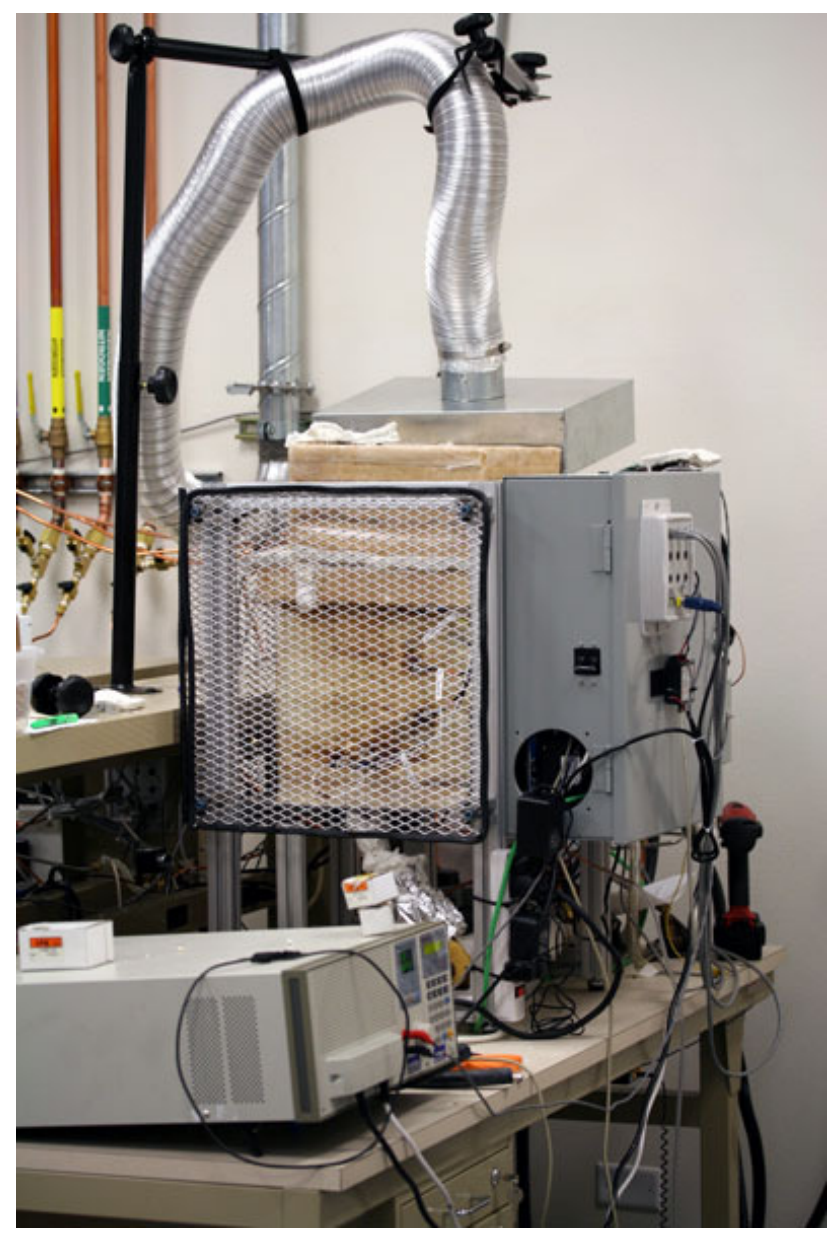

Figure 5-26. Module test facility.

\subsection{Stack/Reformer/Module Subsystem Test- PTX Tubular Technology}

This task consisted primarily of testing and characterization of full scale stacks and hot zone modules and final integrated system testing at Cummins. The tests were representative of the conditions that were encountered in the final testing including orientation and fuel.

Stack and Module testing. Sixty-six cell bundles were fabricated and reduced in a dedicated test facility that provides heating from the bottom and sides. The bundles were reduced under dilute hydrogen flow, and then tested with hydrogen/nitrogen mixtures over a range of flows and temperatures.

Performance of initial bundles was quite good, producing approximately $450 \mathrm{~W}$ at $11.7 \mathrm{~A}$ and $46 \mathrm{~V}(0.7 \mathrm{~V} /$ cell $)$. After initial characterization in the furnace, this bundle was installed in the module hardware, including recuperative heat exchangers and insulation, and operated outside the furnace. Information from these tests will be used to finalize the insulation design for the final deliverable. Figure 5-27 shows typical results for this bundle at $~ 8$ SLPM of hydrogen. Fuel utilization at $11 \mathrm{~A}$ was approximately $70 \%$. 


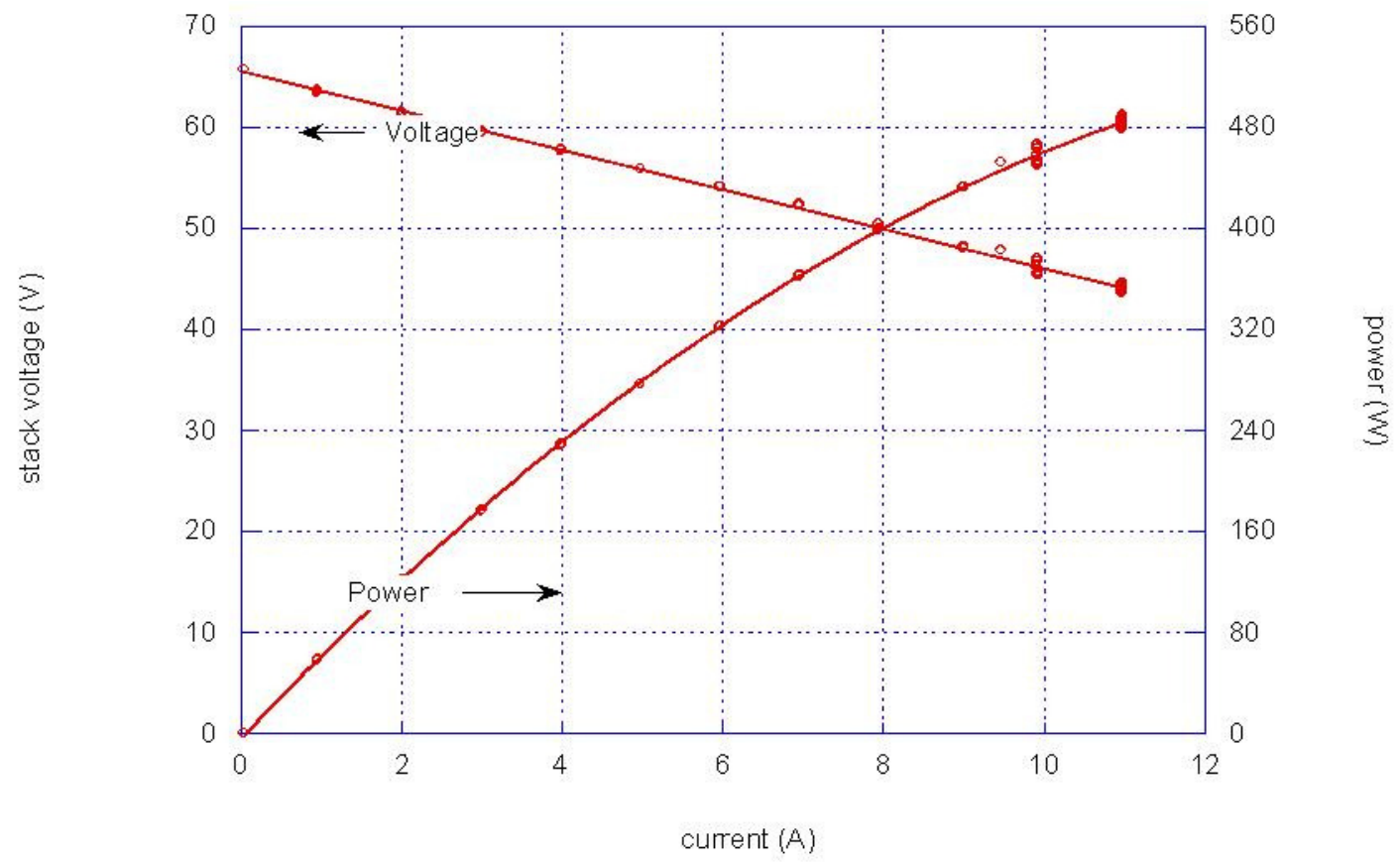

Figure 5-27. Voltage and power curves for bundle \#3

Subsequent early bundles showed very repeatable initial performance. Figure shows the composite data set for three early bundles, with a best-fit line through the composite data set. Performance for all three of these bundles was within $5 \%$ of each other. Later bundles also had very repeatable performance, within $8 \%$ at $0.7 \mathrm{~V} /$ cell; however, they produced approximately $10 \%$ higher power as a result of changes to improve the uniformity of fuel flows, air flows and temperature, see Figure 5-29.

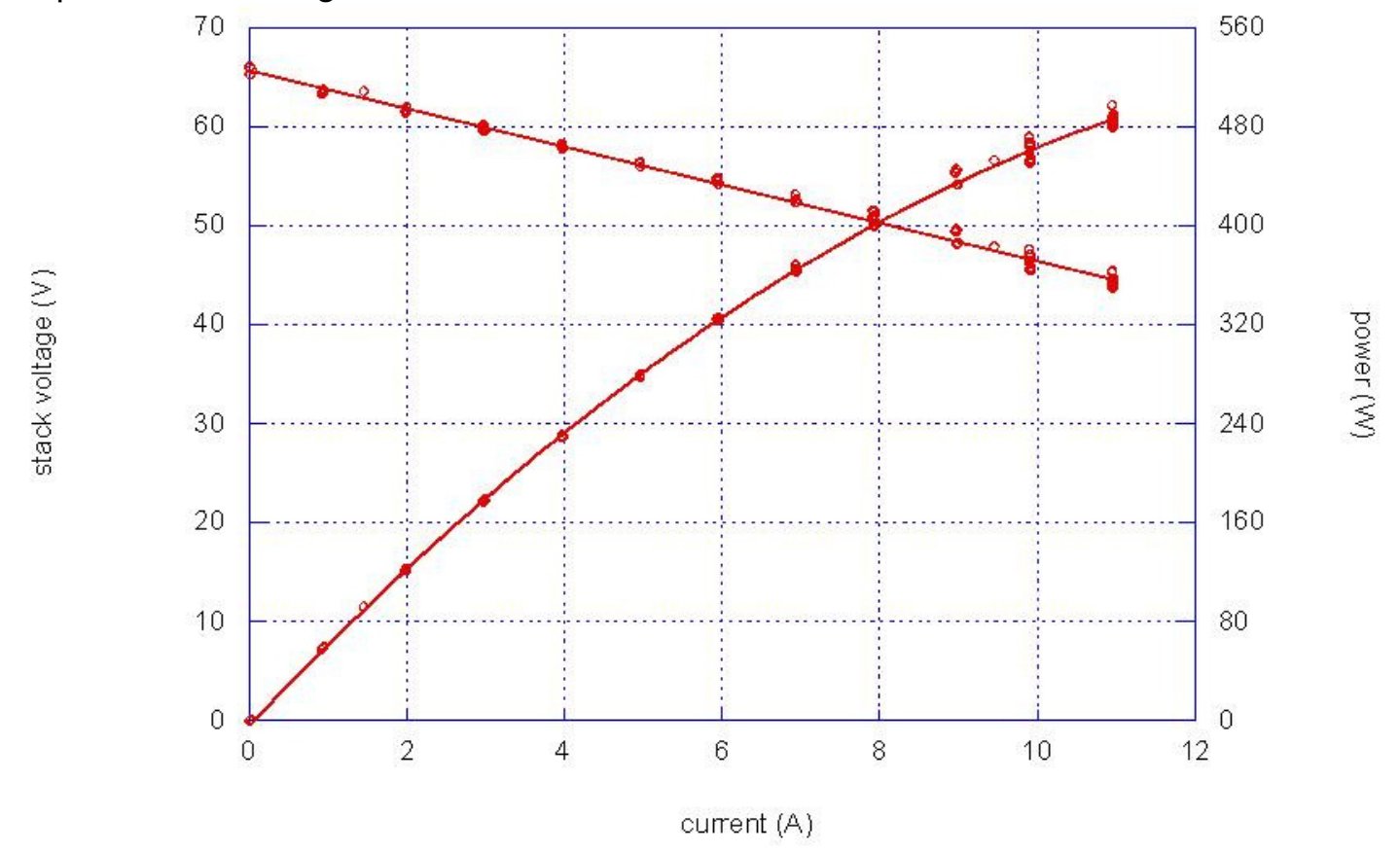

Figure 5-28. Voltage and power curves for bundles -003, -004, and 005, showing highly repeatable performance. 


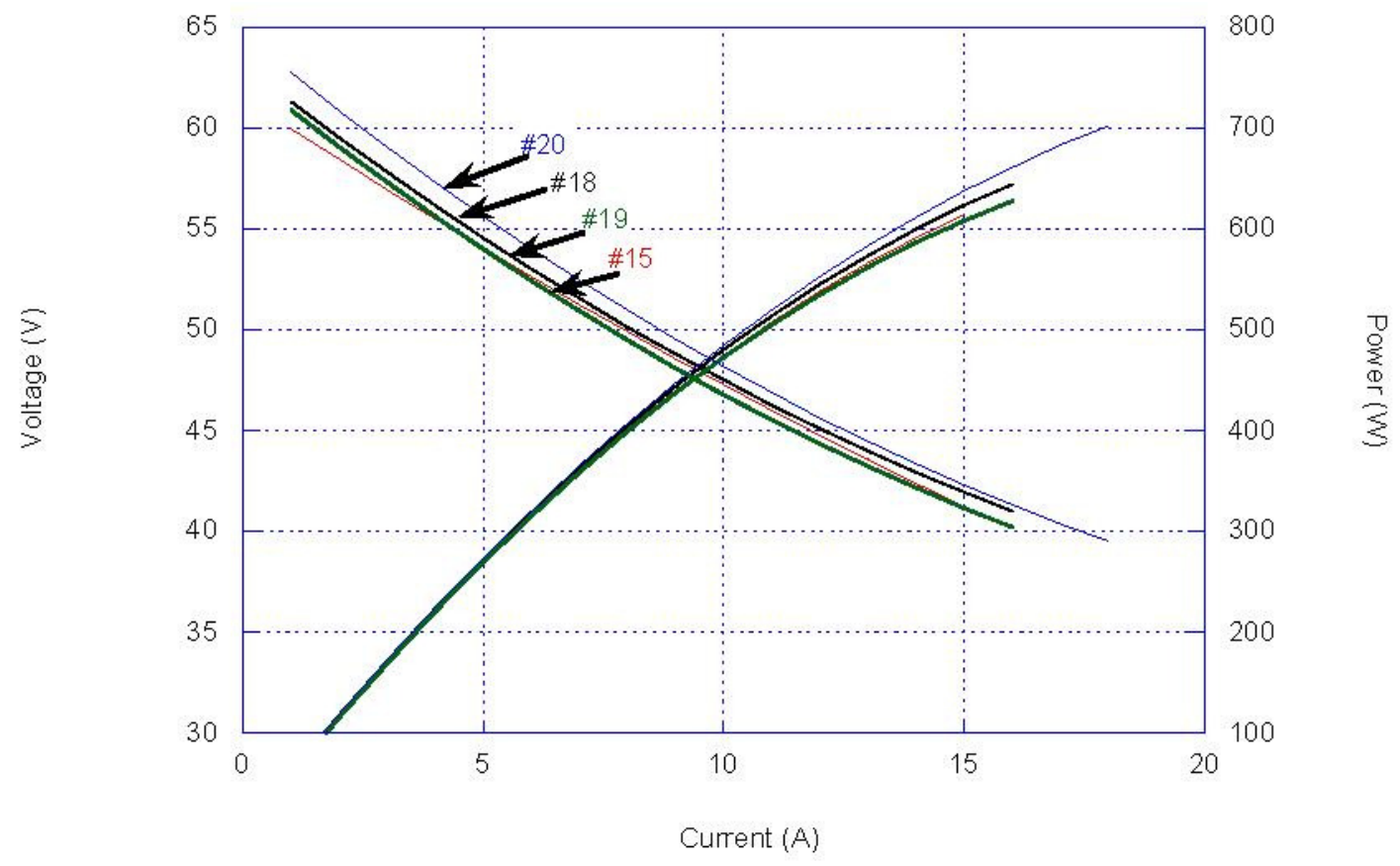

Figure 5-29. Reduction VI curves for deliverable stacks.

The next step in testing was to move from a furnace to an integrated hot zone module. Figure 530 compares the performance of stack 012 during reduction in a furnace and in subsequent testing in the hot zone; both tests were on a 50/50 hydrogen/nitrogen fuel mixture. The difference in power at $0.7 \mathrm{~V} / \mathrm{cell}$ is approximately $5 \%$, and is due to small non-uniformities in the temperatures in the hot zone compared to the furnace. 


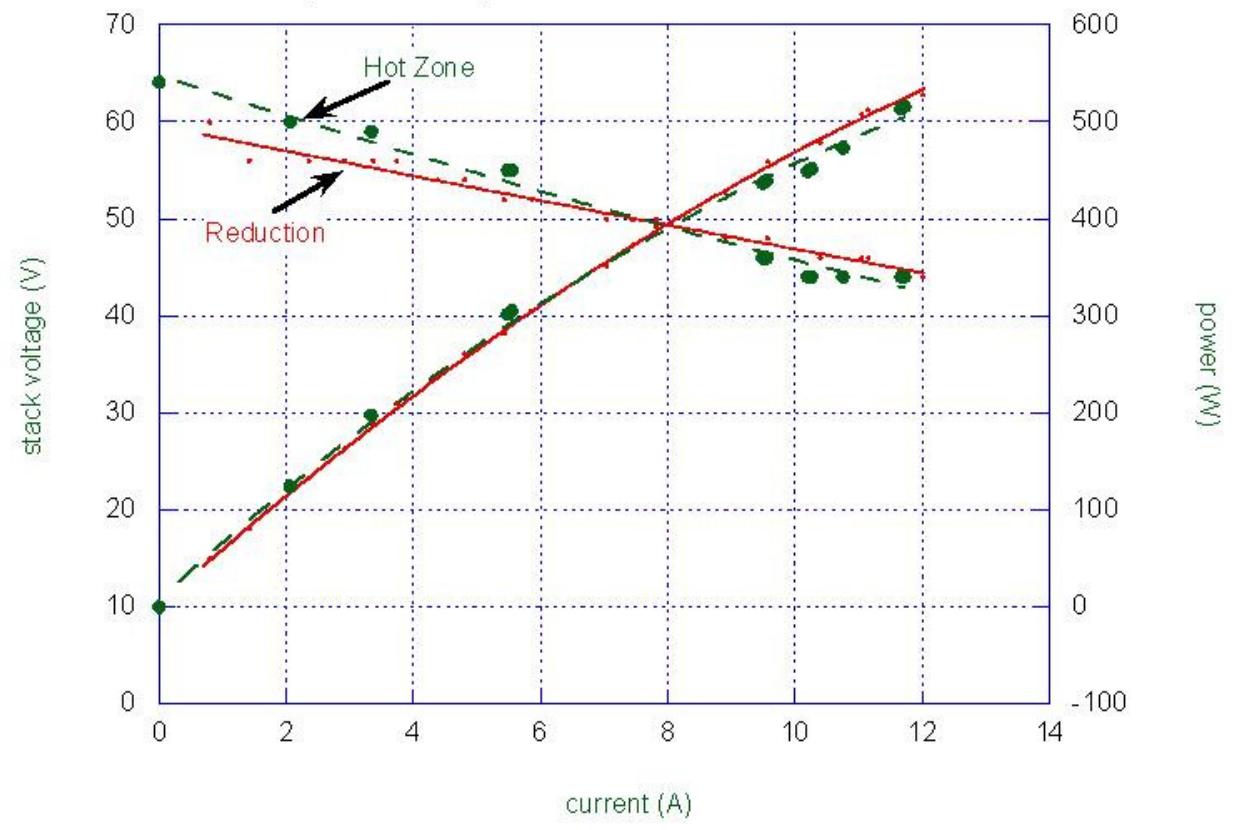

Figure 5-30. Load curves for BR66-012 during reduction and in a hot zone on hydrogen/nitrogen.

Orientation of the hot zone module was another factor that needed to be tested. Two of the modules in the final testing at CPG were inverted. Therefore, BR66-007 was tested inverted and upright to gauge any differences in thermal distributions or startup times. Figure 5-31 shows that there is no difference in temperatures during startup for the two positions. Figure 5-32 shows the voltages during startup which again are almost identical. These data clearly demonstrate that our fuel feed system is orientation independent.

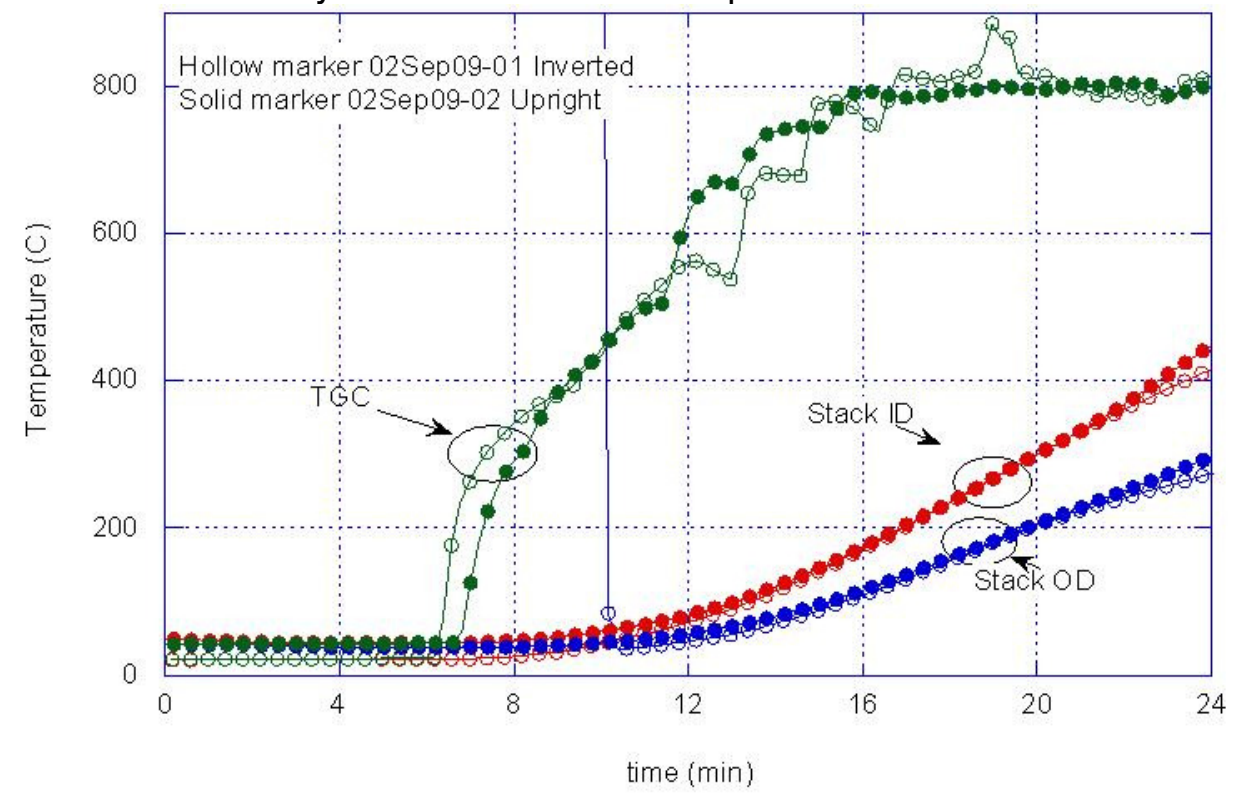

Figure 5-31. Startup temperatures for BR66-007 upright and inverted. 


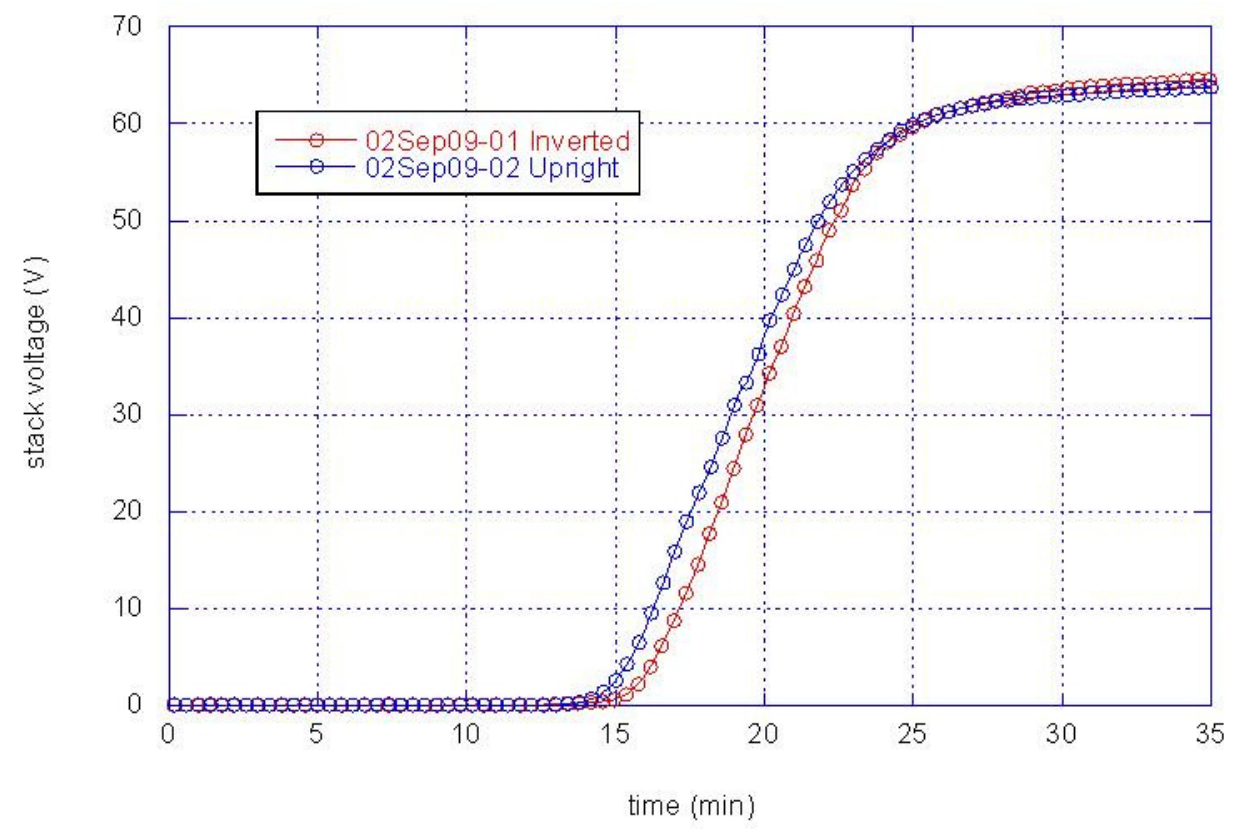

Figure 5-32. Stack voltages during startup for upright and inverted orientations.

The next step in the development and testing was to operate a module on liquid fuel. Figure 533 compares stack 13 power in the furnace and in a hot zone operating on low sulfur kerosene. The data show a decrease in power at $0.7 \mathrm{~V} /$ cell of approximately $6-8 \%$ when moving from operation on a $50 \%$ hydrogen mixture in a furnace to operation on low sulfur kerosene in a hot zone.

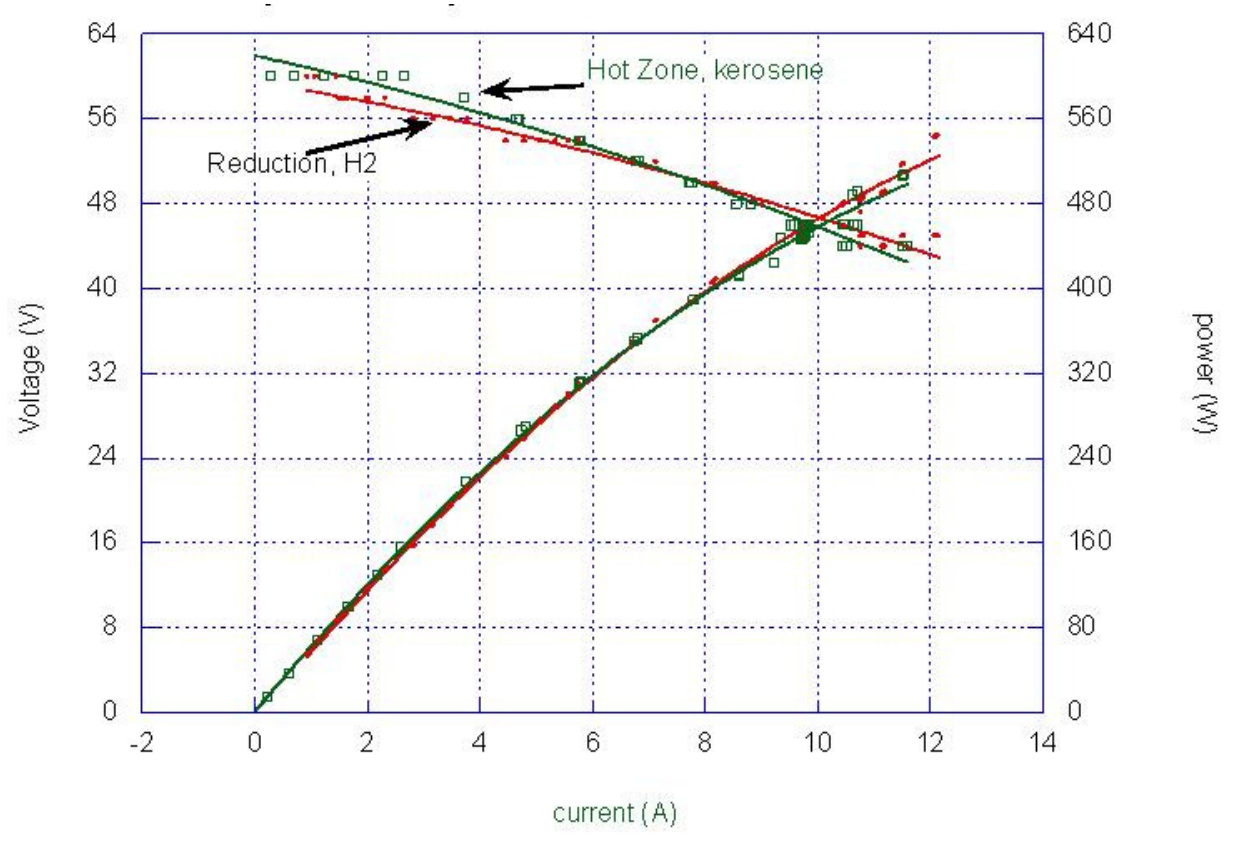

Figure 5-33. Load curves for BR66-013 during reduction and on liquid fuel in a hot zone.

The last five modules were the culmination of the improvements in procedure, process control and design throughout the entire program. The first of these was used for in-house testing, the 
last four were delivered to Cummins for final testing. The performance of the deliverable stacks is given in Figure 5-29; the performance of the stack/module for in-house testing is described below.

After initial characterization of the module for in-house testing on liquid fuel using low-sulfur kerosene, the module was transitioned to ULSD operation. The change was initiated between cycles, while the hot zone was not operating; there were no "hot-swaps" of liquid fuel. Figure 534 shows the load curve comparison on the two fuels. The power at $45 \mathrm{~V}$ was $3 \%$ lower for ULSD than for low-sulfur kerosene, at $40 \%$ fuel utilization.

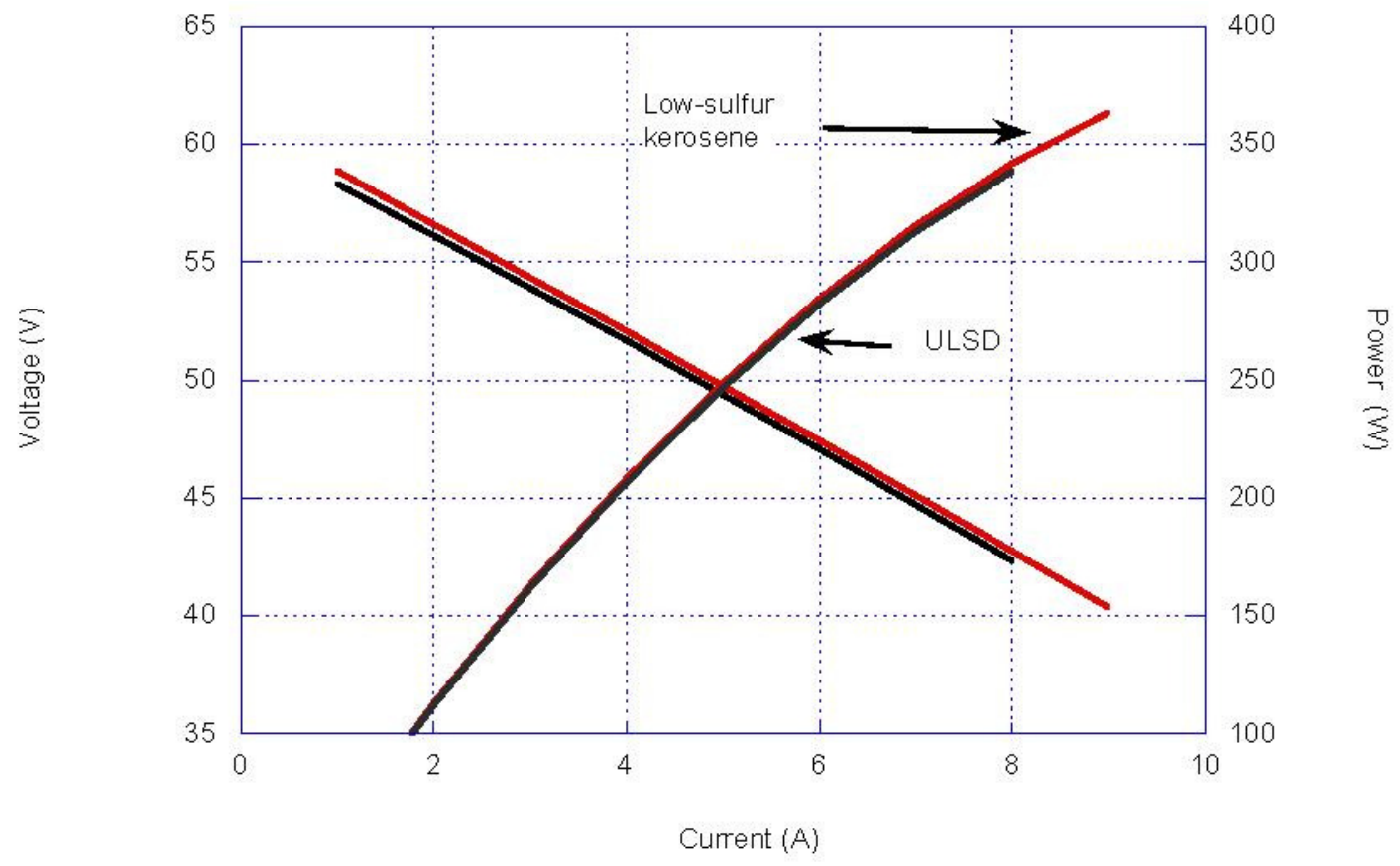

Figure 5-34. Load curve comparison between low-sulfur kerosene, and ULSD in the hot zone.

The power produced at steady state over the 16 thermal cycles is shown in Figure 5-35. The largest change in performance was due to fuel starvation while at operating conditions on cycle 11. Irreparable damage occurred during this starvation, however, relatively steady thermal cycling performance was observed even after this event. Cycle 13 exhibited low power which is known to occur when the tubes are too hot. Subsequent cycles showed a rebound in performance when temperature was controlled to standard conditions of $650-800{ }^{\circ} \mathrm{C}$. 


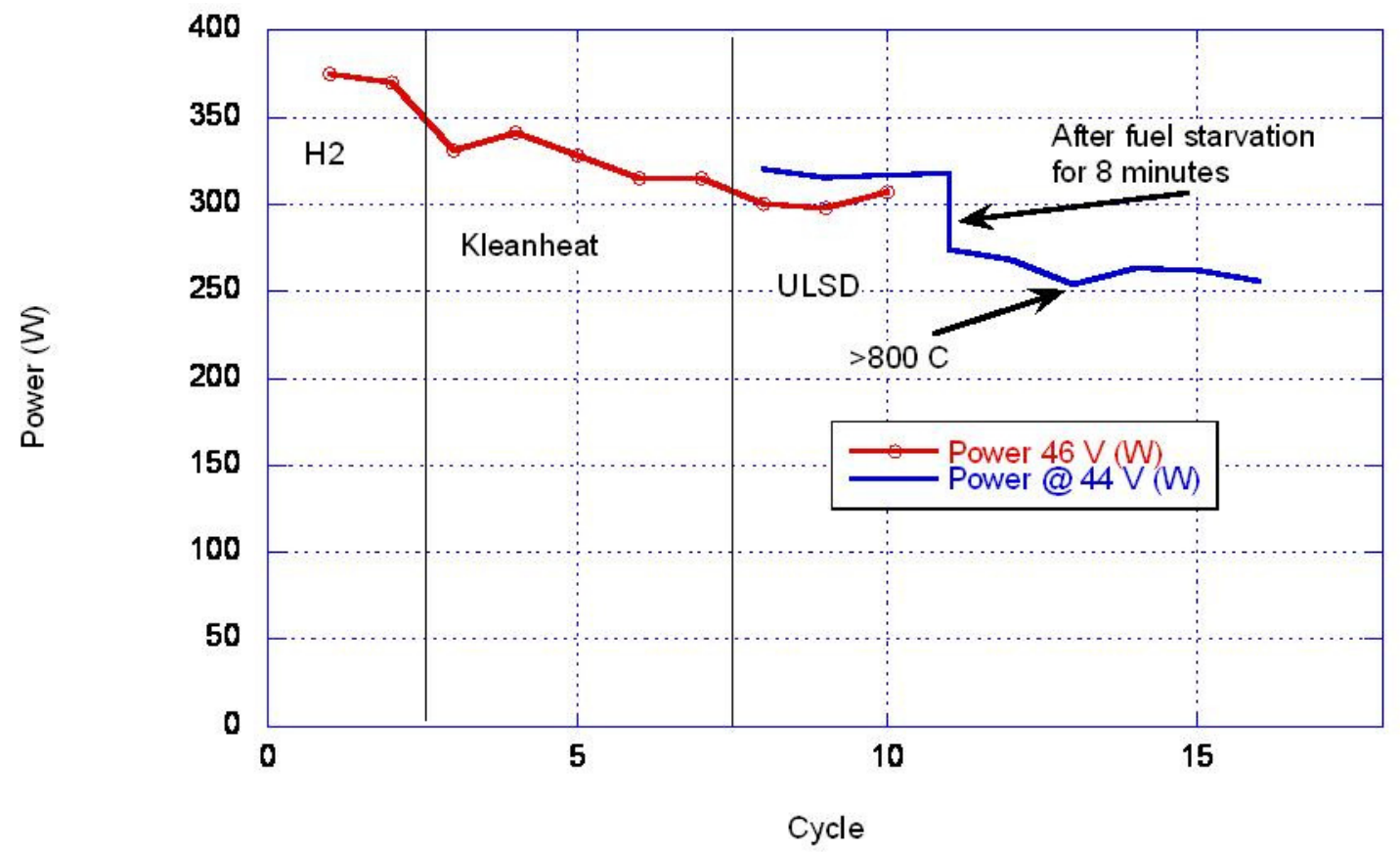

Figure 5-35. Power degradation over all thermal cycles.

Figure 5-36 shows typical thermal profiles during steady state operation. All temperatures achieved an acceptable steady state level, indicating hot zone stability during the test. The stack ID and OD thermocouples represent the radial temperature variation within the stack. They are less than $25{ }^{\circ} \mathrm{C}$ apart. The CPOX igniter thermocouple is located on the exterior surface of the CPOX reactor housing and is used as an indicator of changes in performance of the reformer during operation. The tail gas combustor (TGC) indicates whether the exhaust gases are combusting properly, which is important for proper recuperation and pre-heating of the cathode air. The exhaust thermocouple is used for subsequent analysis and for added information on recuperator performance. The vaporizer heater temperature is used to control the electrical heating during startup and shutdown and for monitoring of the fuel and CPOX air flow for proper mixing. 


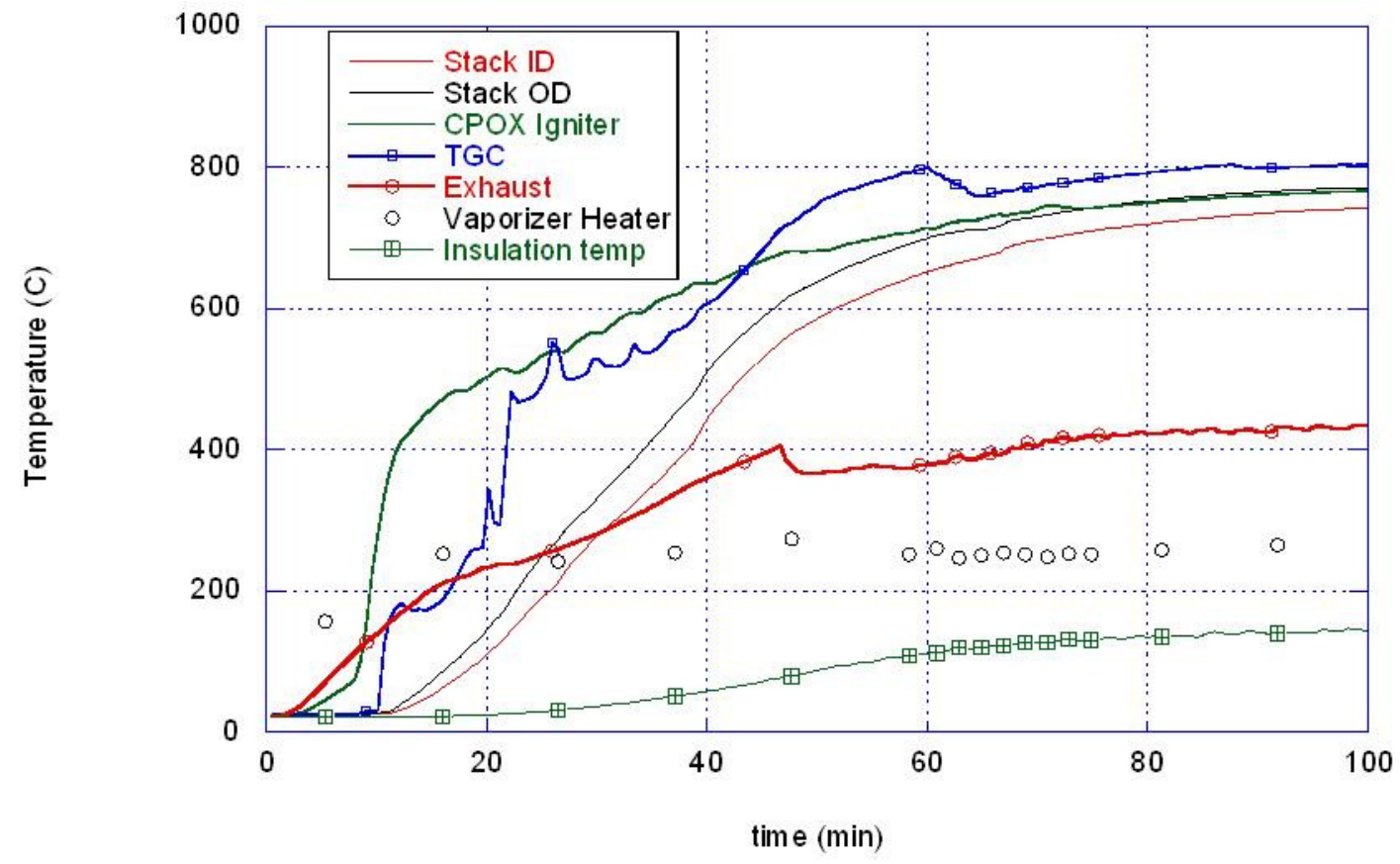

Figure 5-36. Startup temperatures.

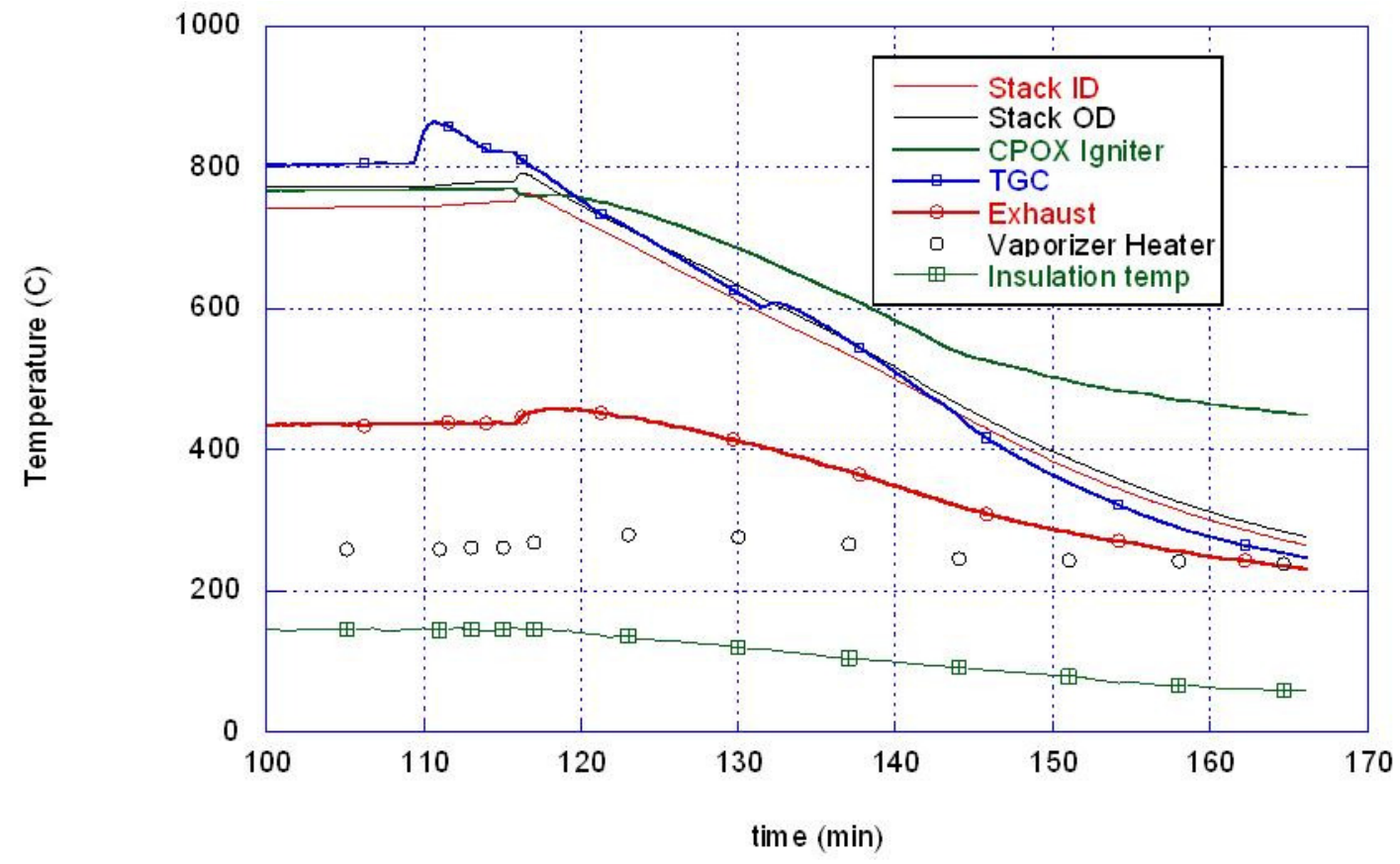

Figure 5-37. Shutdown temperatures. 


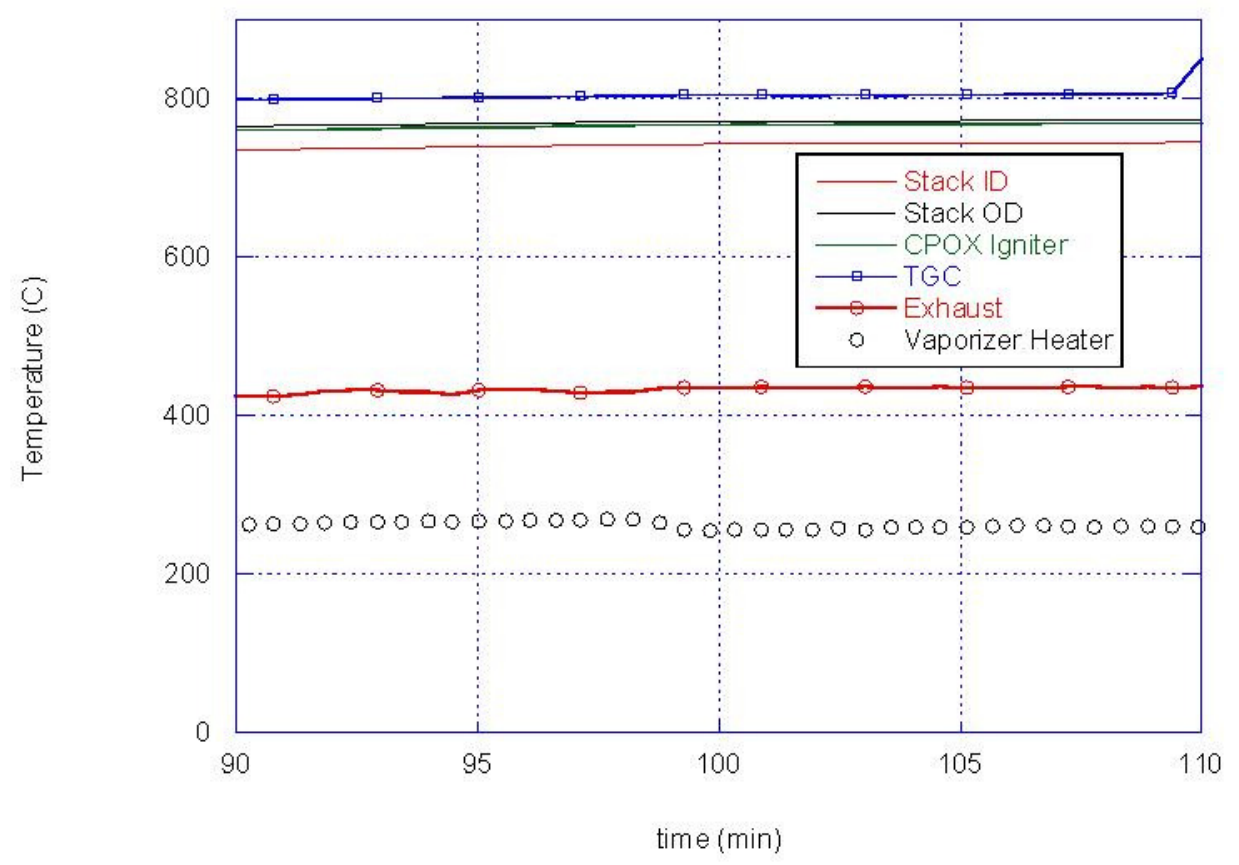

Figure 5-38. Steady state temperatures, $3.15 \mathrm{~g} / \mathrm{min}$ ULSD, O/C 1.35, 60 SLPM cathode air, $44 \mathrm{~V}, 320 \mathrm{~W}, 40 \%$ fuel utilization.

Module Performance In Integrated System Testing. The final four module deliverables were tested on ULSD integrated with the BOP control, power conditioning and mounting case developed at Cummins. Figure 5-39 shows the steady state power produced by the four modules as recorded at the power conditioning hardware. The power levels quoted in the following graphs would be 50-80 W higher if the plots were corrected for transmission losses. 


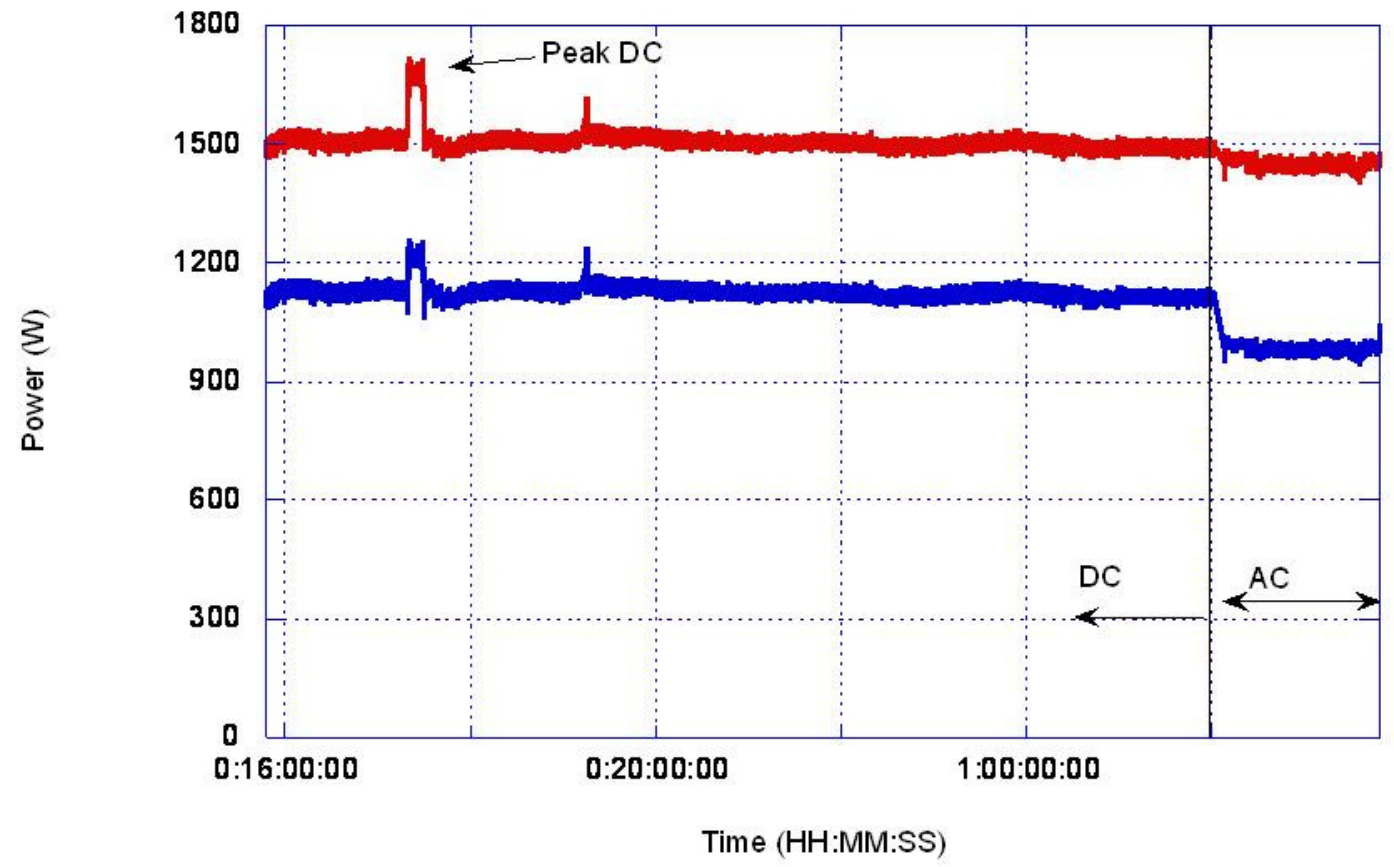

Figure 5-39. Total power production for final testing.

The test consisted of heating each module individually for convenient monitoring, and allowing the entire system to achieve a steady state. Note that the system is capable of starting all modules simultaneously if desired. The steady state DC power production was $1500 \mathrm{~W}$ gross with approximately $380 \mathrm{~W}$ of parasitic losses for a net production of 1120 W. A peak power loading of $1680 \mathrm{~W}$ with a net output of $1225 \mathrm{~W}$ was recorded for 10 minutes as seen in Figure 5-41. Higher peak loading of the modules is possible, the peak loading was not limited by inherent module capability, rather it was limited by the thermal balance. Future systems could be designed for higher firing rates and power production with moderate design modifications to the heat exchangers, fuel feed system and thermal insulation package.

After the peak loading, the system continued in steady state DC power operation for 10 hours, simulating the rest period over which a class 7/8 APU would operate. At the end of this time the power output was $1490 \mathrm{~W}$ gross and $1110 \mathrm{~W}$ net.

The system was then transitioned to AC loading for 1.5 hours. The AC loading required the modules to be connected in series electrically; thus forcing the same current through all modules and reducing total power by $3 \%$. The larger change in parasitic losses was due to the inverter efficiency of $~ 85 \%$. The power produced during this period is shown in Figure 5-42, $1460 \mathrm{~W}$ gross and $820 \mathrm{~W}$ net at the end of the test. This allowed the air conditioning, lighting and additional DC loading thus simulating a truck "hotel" load to all operate simultaneously from power generated by the SOFC sub-system. 


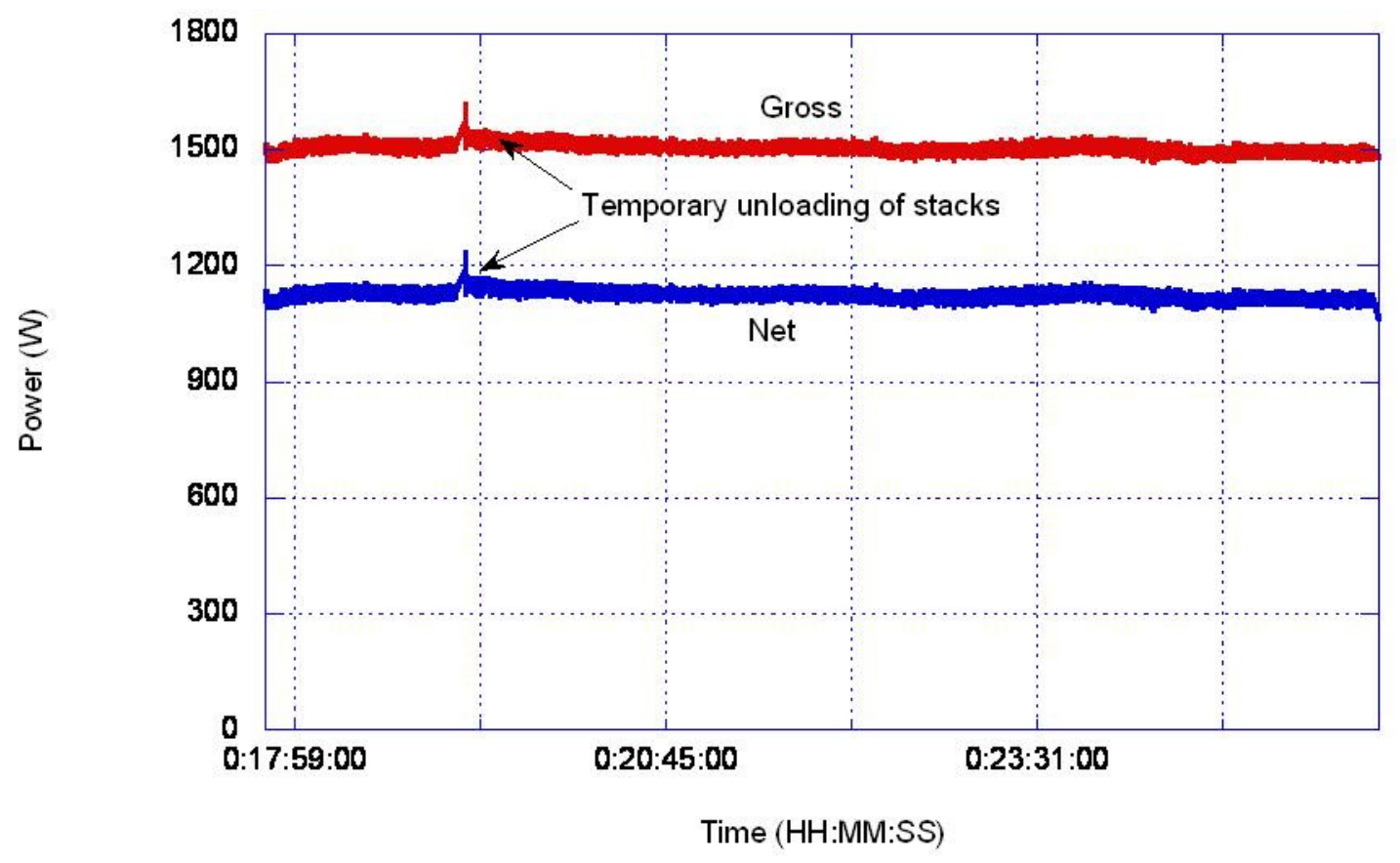

Figure 5-40. Average DC power produced by SOFC sub-system on ULSD during final testing at CPG.

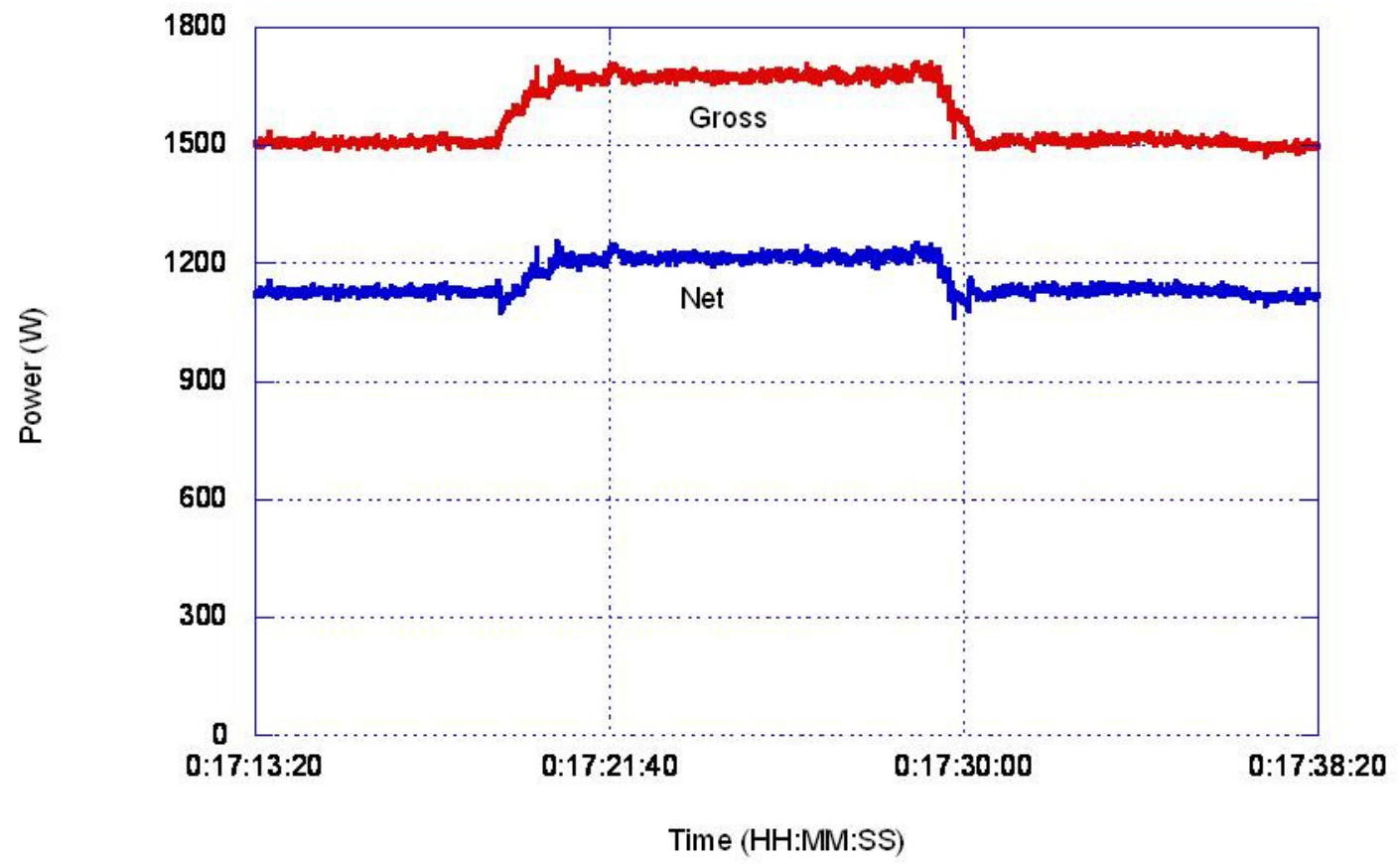

Figure 5-41. Peak DC power produced by SOFC sub-system on ULSD during final testing at CPG. 


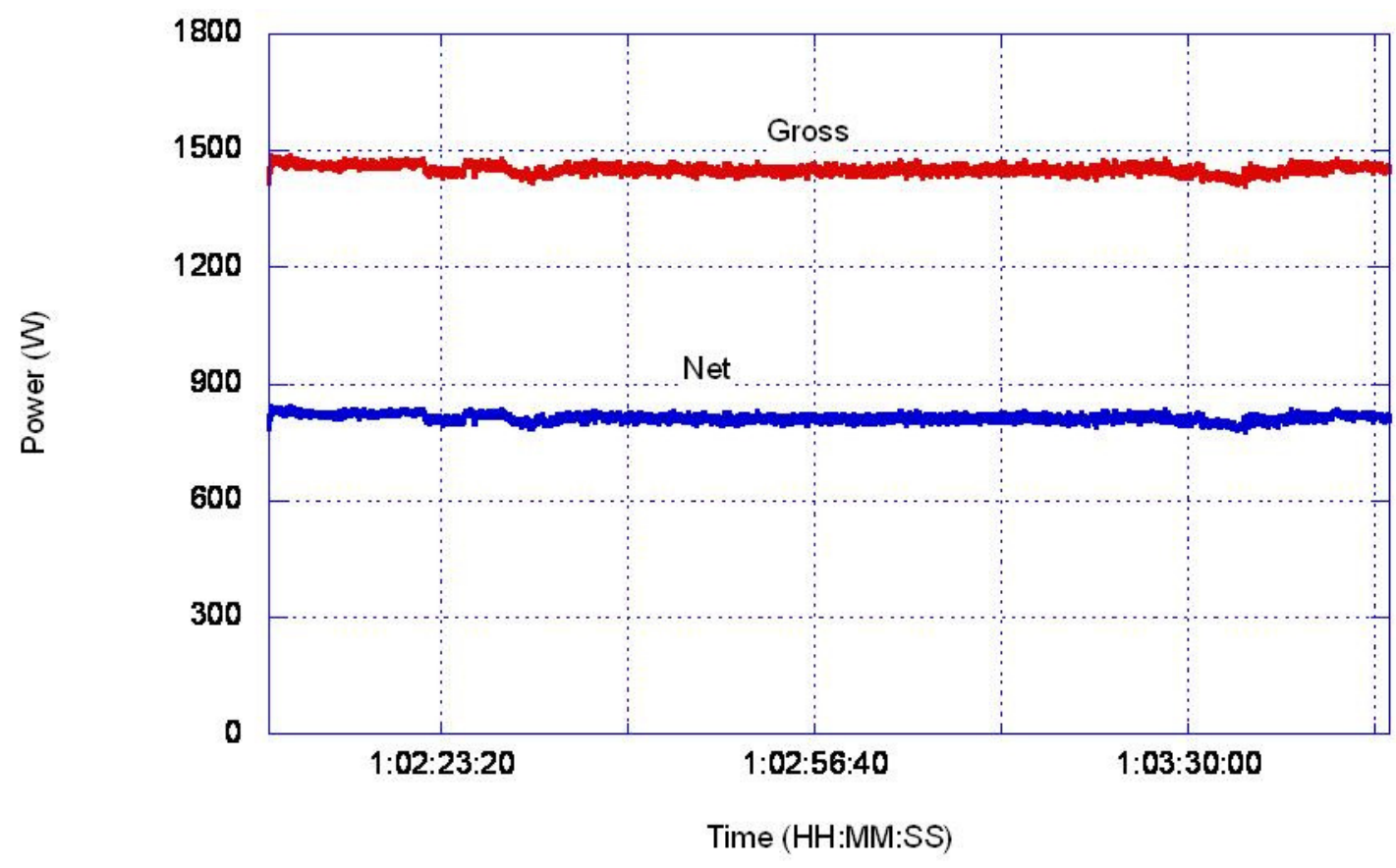

Figure 5-42. Average AC power produced by SOFC sub-system on ULSD during final testing at CPG. 


\section{Controls \& Power Electronics Development}

The controls for the SOFC APU unit were designed, programmed, and tuned at CPG. This was accomplished with five imbedded control modules (fig.8.1) designed by CPG. Communications between individual modules is via a CAN network. The modules are arranged such that there is an individual module for each SOFC module and one parent module that oversees the total operation of the SOFC APU system.

The electrical output of the SOFC APU can be processed directly through the CPG HQD inverter/battery charger to provide AC electrical power.

\subsection{Controls Development - CPG}

\section{SOFC Fuel Cell Control}

CPG developed an electronic fuel cell control card and software specifically for the operation of PTX fuel cell stacks. This complete system consisted of five individual modular control cards as shown in Figure 6-1.

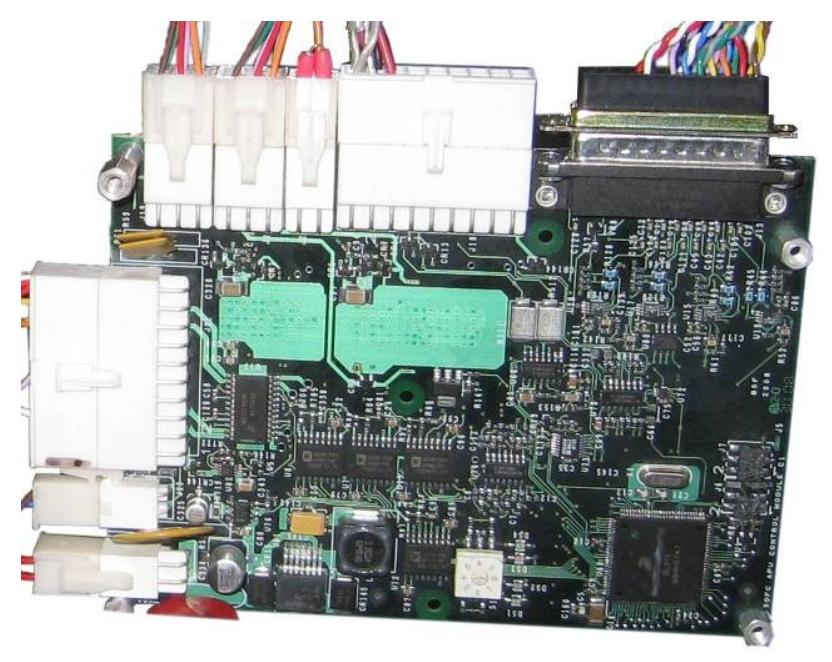

Figure 6-1 Modular Control Module.

Each of the four fuel cell stacks was paired with one child control module and the complete system is orchestrated by the parent control module. The physical control card and software are universal; with the actual placement in the system being defined by the position of a rotary switch on the card. Figure 6-2 provides a topological view of the complete control system. 


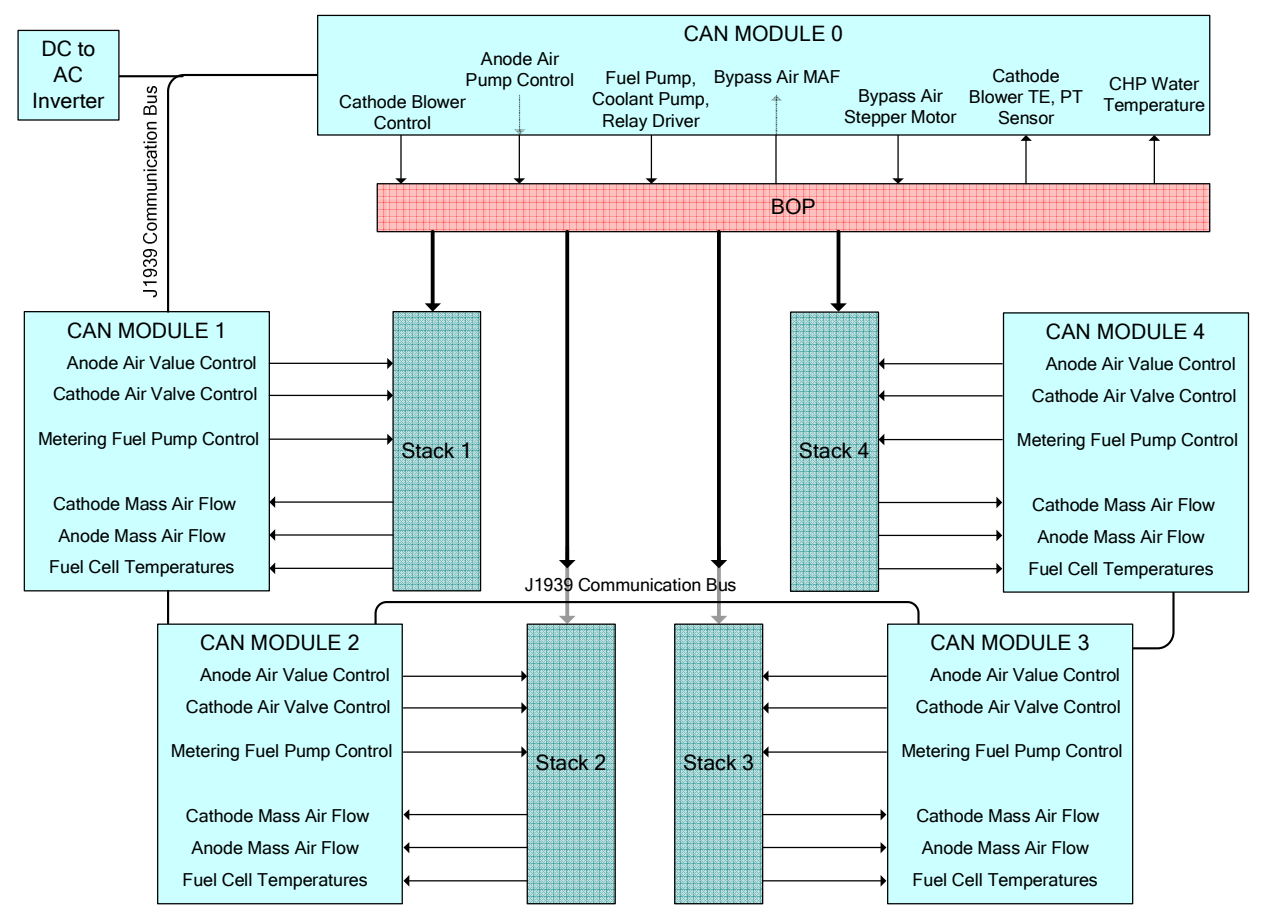

Figure 6-2 Topological view of the complete control system

Each child control card functions to maintain the inputs and outputs of one fuel cell stack.

\section{Anode Air Control}

A child control card regulates the anode air input into the fuel cell by controlling the position of a stepper motor actuated valve. The valve position is changed based on the amount of anode air measured via an automotive style mass air flow sensor and its compared value to the anode air set-point. The anode air set-point is set to a value such that the $\mathrm{O} / \mathrm{C}$ ratio of the fuel cell remains constant.

\section{Cathode Air Control}

Similar to anode air control, the child control card regulates the cathode air input into the fuel cell by controlling the position of a stepper motor actuated value. The valve position is changed based on the amount of cathode air measured via an automotive style mass air flow sensor and its compared value to the cathode air set-point. The cathode air set-point is set to a value based on the output of the stack temperature control algorithm.

\section{ULSD Fuel Control}

Each control card interfaces with a metering fuel pump, with the actual fueling valve being determined by current output and stack recuperator temperatures. 


\section{Electrical Pre-Heater Control}

Each control card interfaced with two separate electrical pre-heaters. These electrical heaters provided the required thermal energy to start the fuel cell system before it reaches operational steady state. Once operational, the fuel cell required no auxiliary electrical heating to function. The control managed the on and off states of the electrical heaters based on state based and fuel cell inputs.

The parent control card is responsible for orchestrating the children control cards as well as managing the BOP components common across all fuel cell stacks. The parent control card and its four children are linked together via a common J1939 CAN based communication bus.

\section{Child Control Card Control}

Each child control card has the ability to startup independently. Once all four fuel cell stacks are at operational temperature the child control cards look to the parent for definition of their individual fueling values. Under typical operation, the desired current output of the fuel cell is used to determine the fueling values for the complete system. Only those control cards that are having thermal limitations will deviate from the parent's instructed fueling value, ultimately bringing the complete system down to that current output level in which all four modules are thermally stable.

\section{Anode and Cathode Blower Control}

Both the anode and cathode air blowers are variable speed. As such, the parent control card interfaced with these motor controllers adjusting the speed of the blowers based on system requirements. The blower speed was adjusted with a closed-loop algorithm using the stepper motor position of the children boards as feedback. The cathode blower was adjusted to minimize BOP power draw while still ensuring enough pressure capacity for the need flow. The anode blower speed was adjusted to keep the anode stepper air valves in the linear of operation in order to aid in successful O/C ratio control.

\section{Cathode Blower Control}

A need existed to bypass a portion of the air generated by the cathode blower during stack startup because of the low mass flow, relatively high back pressure requirements. In order to achieve this, the parent module controlled the amount of bypass air via a stepper motor actuated air valve. The actual amount of air bypassed was dependant on the total sum of the cathode air flows from the four children.

\section{Hybrid Inverter Control}

The parent control card interfaced with the Onan HQD inverter via the same common J1939 CAN communication bus as the children. Over this communication bus the parent control card instructed the HQD inverter when to turn on/off, and how much current to draw from the fuel cell stack. The parent control card also read from the HQD the $120 \mathrm{Vac}, 60 \mathrm{~Hz}$ output power and automotive battery bank voltage for diagnostic purposes.

\section{Stack Temperature Control}

One important role of the control system is the regulation of the cathode air plumbed into each of the four fuel cell stacks. Each fuel cell must have enough cathode air to complete the electrochemical reaction and keep the internal stack temperature at the correct set point. 
Figure 6-3 shown below illustrates a test case performed during the final test. At approximately 7:10:00 PM the complete fuel system was brought to OCV from a full power condition. While at the OCV the internal stack temperature dropped because less heat was being generated internally. In response to this decrease in temperature the control system began to decrease the cathode air in an attempt to increase the internal stack temperature. After a few minutes, the system power was increased back to full power. As a result the internal stack temperature increased due to latent heating caused by an increase in tail gas recuperator temperature caused by going to OCV, resistive losses, and heat generated from the electro-chemical reaction. In response to an increase in internal stack temperature the control system increased the cathode air, finally leveling out at the same mass air flow it began at before going to OCV.

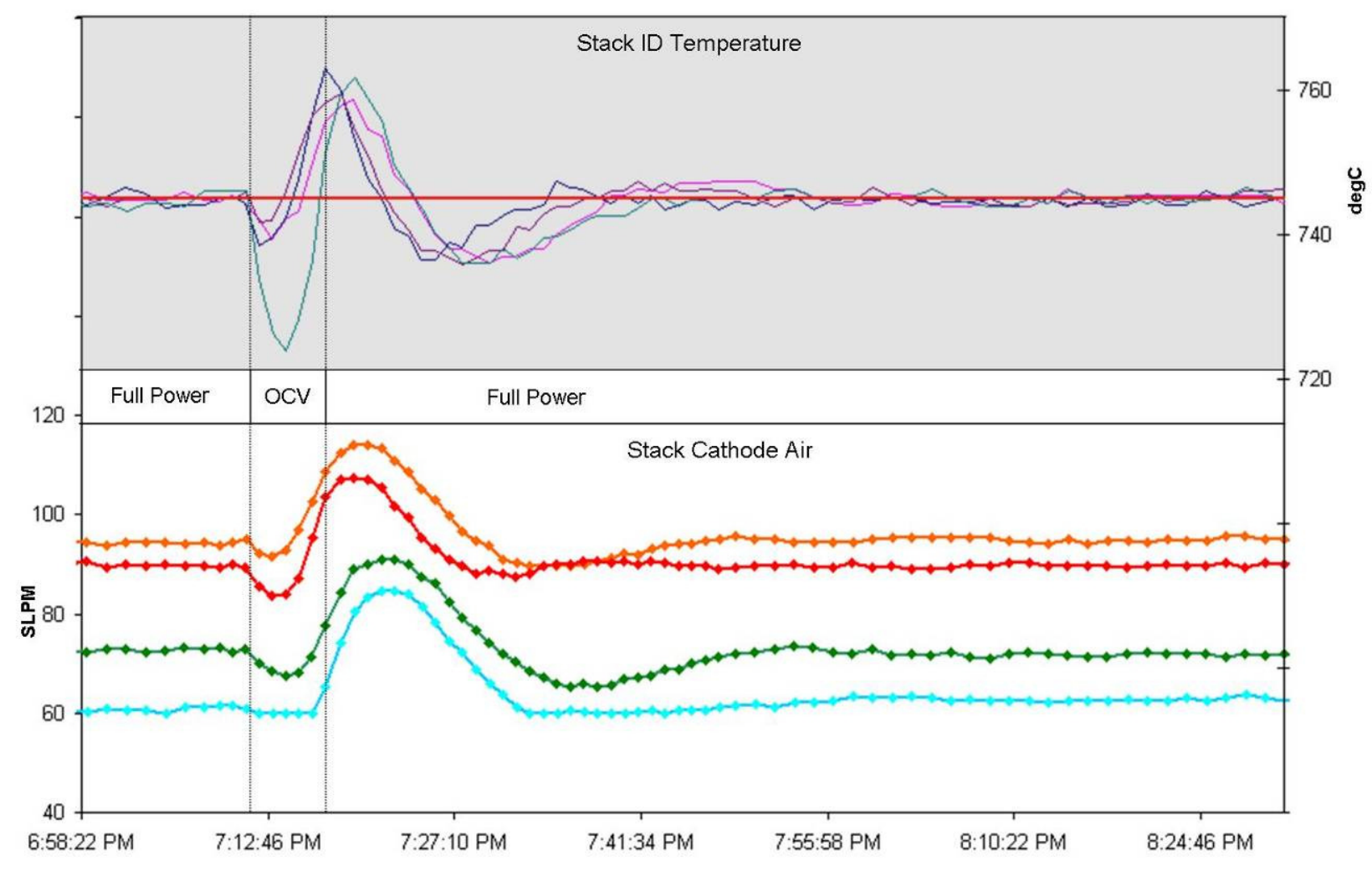

Figure 6-3 Test case for cathode air controlled Stack temperature.

\section{O/C ratio control}

An important component of the BOP system is maintaining a desired $\mathrm{O} / \mathrm{C}$ ratio in the fuel cell stack reformer. First, the anode mass air flow sensors were calibrated with an external sensor and their calibration data was entered in the child control cards. The metering pumps were also calibrated and their calibration data was entered in the child control cards. Additionally, both anode air fuel metering systems were checked for closed-loop operation in a cold fuel cell stack. Second, the anode mass air flow was as tightly as possible regulated around a set-point defined by anodeAirSetpoint $=O / C_{-}$Ratio $* A *$ FuelFlow, where $A$ is a constant defined by fuel specifics and other system inputs. 
Figure 4 shows the O/C ratio error in percentage for all fuel cell stacks throughout the complete testing period. During the complete test the $\mathrm{O} / \mathrm{C}$ ratio stayed below the five percent maximum error specified by PTX for proper operation of the CPOX.

OIC Ratio Control

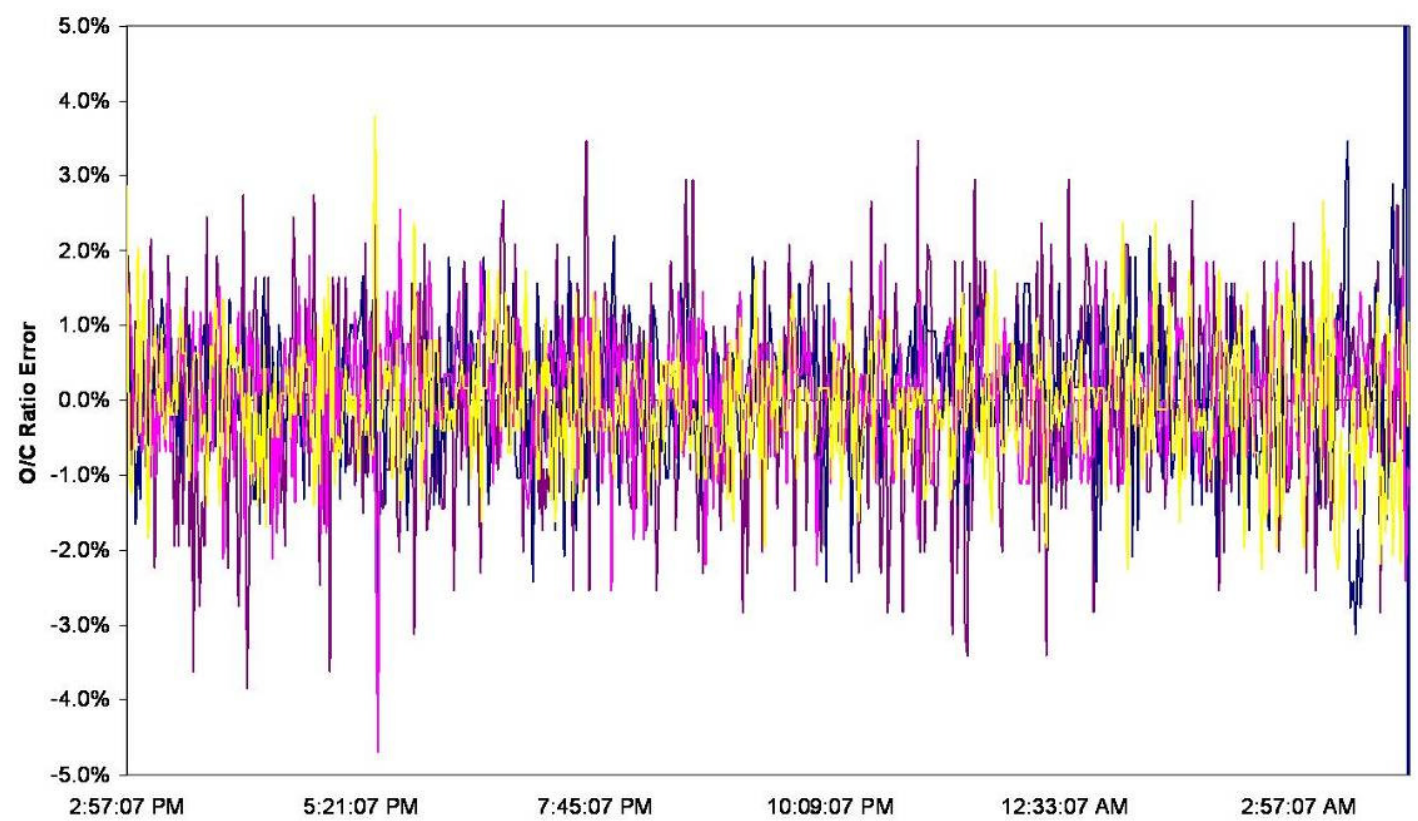

Figure 6-4 O/C ratio error in percentage for all fuel cell stacks

For initial development a control hardware and simulator system was constructed as shown in figure 6-5 (ref. 14318R04.pdf). 


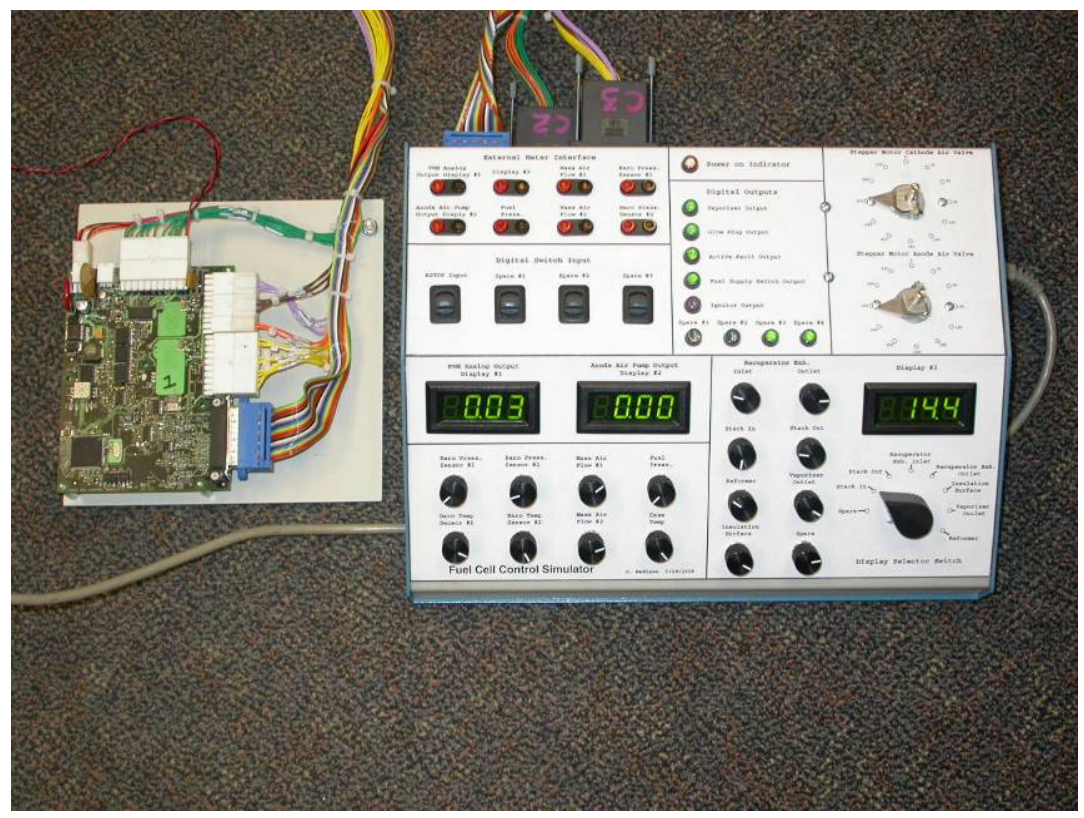

Figure 6-5 - Fuel Cell Control and Simulator

All sensor inputs into each module are filtered digitally in order to minimize the effects of noise. Initial filter designs used a $1^{\text {st }}$ order low pass filter which proved to contain a hysteresis band caused by the digital core's fixed point arithmetic unit. This issue caused controllability issues which forced the need for a hysteresis-less filter design. Using MATLAB Simulink as a simulation tool, a $1^{\text {st }}$ order filter was designed with a variable gain. The variable gain reduced the hysteresis band from 8 digital counts to .25 digital counts.

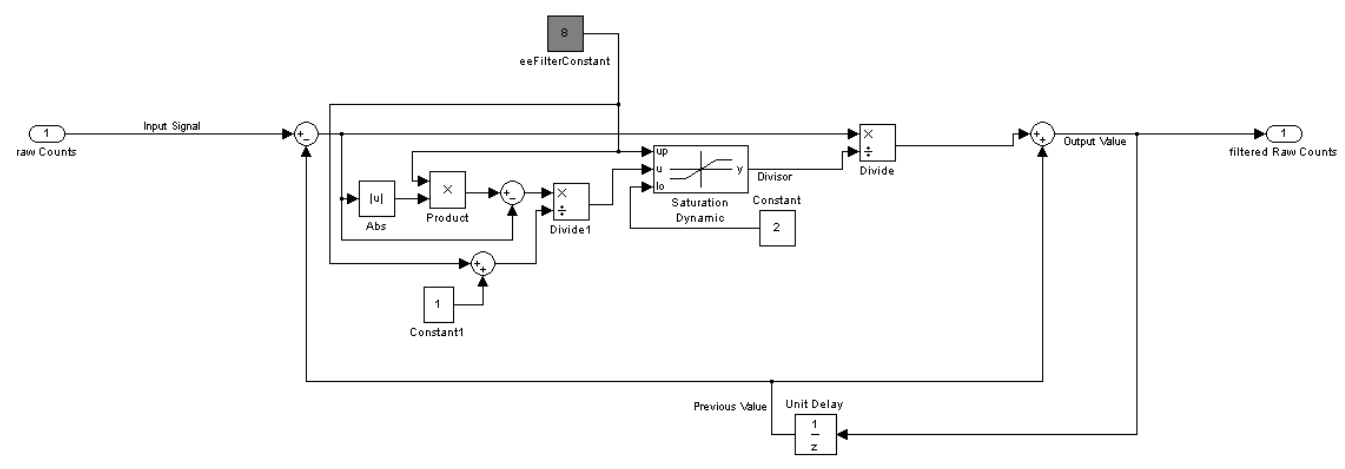

Figure 6-6 - SIMULINK model of digital filter

After proper Simulink simulations results were obtained, the model was converted in microcontroller $\mathrm{C}$ code. With the improved filter design closed loop steady state performance improved when tested on the fuel cell test system in the laboratory (ref. 14318R05.pdf). 


\subsection{Power Electronics Development}

Initial power electronics development was centered around interfacing the SOFC system with CPG's commercially produced HQD hybrid inverter. The inverter is a system that is capable of five distinct operational modes. The first mode strictly boosts up to $3.0 \mathrm{kWs}$ of power from a bank of automotive batteries to produce $120 \mathrm{Vac} 60 \mathrm{~Hz}$ power. The second mode uses power from the SOFC fuel cell system to recharge the bank of automotive batteries using a 4-mode charging algorithm. The third mode takes all of the power from the SOFC fuel cell system and converts it into $120 \mathrm{Vac} 60 \mathrm{~Hz}$ power. The fourth mode operates in a hybrid fashion, combining energy from both the SOFC fuel cell system and automotive battery bank to provide up to 4.2 $\mathrm{kWs}$ of $120 \mathrm{Vac}, 60 \mathrm{~Hz}$ power. In hybrid mode, the system can provide $4.2 \mathrm{kWs}$ of power for up to several hours based on the available capacity stored in the battery bank. The final operational mode takes power from the SOFC fuel cell system to provide both $120 \mathrm{Vac} 60 \mathrm{~Hz}$ power and recharging of the batteries simultaneously.

Interfacing the SOFC fuel cell system with the hybrid inverter system is simpler then previous fuel cell programs at CPG. Originally designed to accept $200 \mathrm{Vrms}$ power from a variable speed PMA generator, the inverter readily accepted the nominal 240 Vdc power from the fuel cell stack. No additional power conditioning was needed and current limiting of the fuel cell stack was achieved using a closed loop software algorithm.

As part of CPG's initial trade studies, we explored the tradeoffs between three candidate system voltages. With approximately 60 cells per stack, logical choices for the multi-module output voltages are approximately $40 \mathrm{~V}, 80 \mathrm{~V}$ and $160 \mathrm{~V}$ under load, corresponding to configurations with all modules in parallel (1s4p), two modules in parallel (2s2p) and all modules in series (4s1p).

CPG has tested a prototype DC-DC boost (fig. 6-7). A $250 \mathrm{~V}$ DC power supply with 3 Ohm impedance is used to simulate the PTX fuel cell stack. The DC-DC converter prototype will boost the stack output voltage from $150 \mathrm{~V}-250 \mathrm{~V}$ to $290 \mathrm{~V}$ and the efficiency is $>90 \%$. The current ripple was controlled below 10\% @ normal running mode. The DC-DC converter will connect with CPG's hybrid power system and a battery bank to provide $120 \mathrm{~V}$ AC to truck cabin's end user and all the parasitic power consumption by fuel cell system. A new DC-DC boost enclosure was designed and manufactured.

Figure 6.8 illustrates the complete truck electrical and CHP system simulated by the demonstration set-up. The CHP heat was dissipated to the external ambient air. While the air conditioning was utilized in the test cell. 


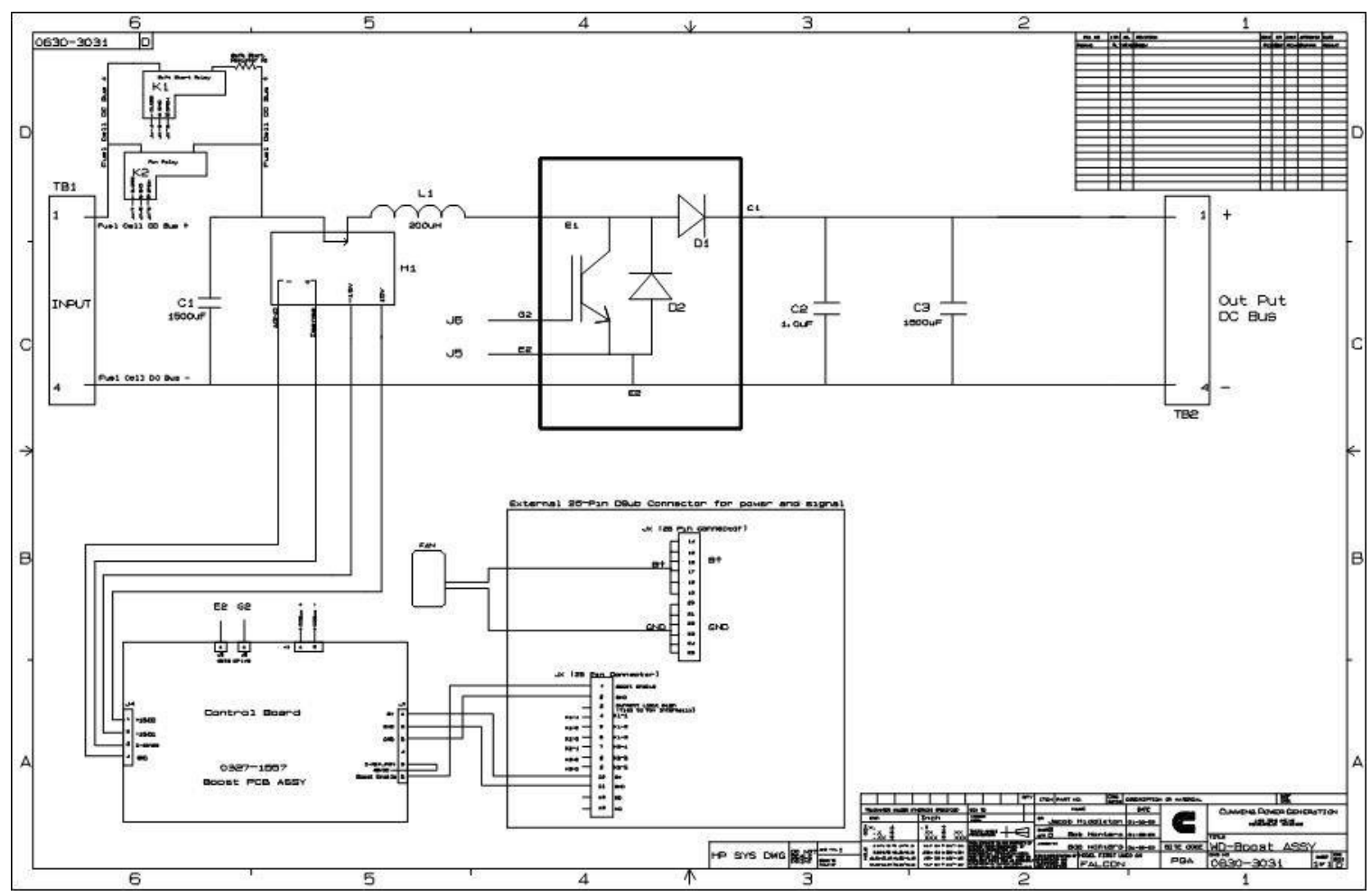

Figure 6-7, Schematic of the Simple Inductor Based Boost

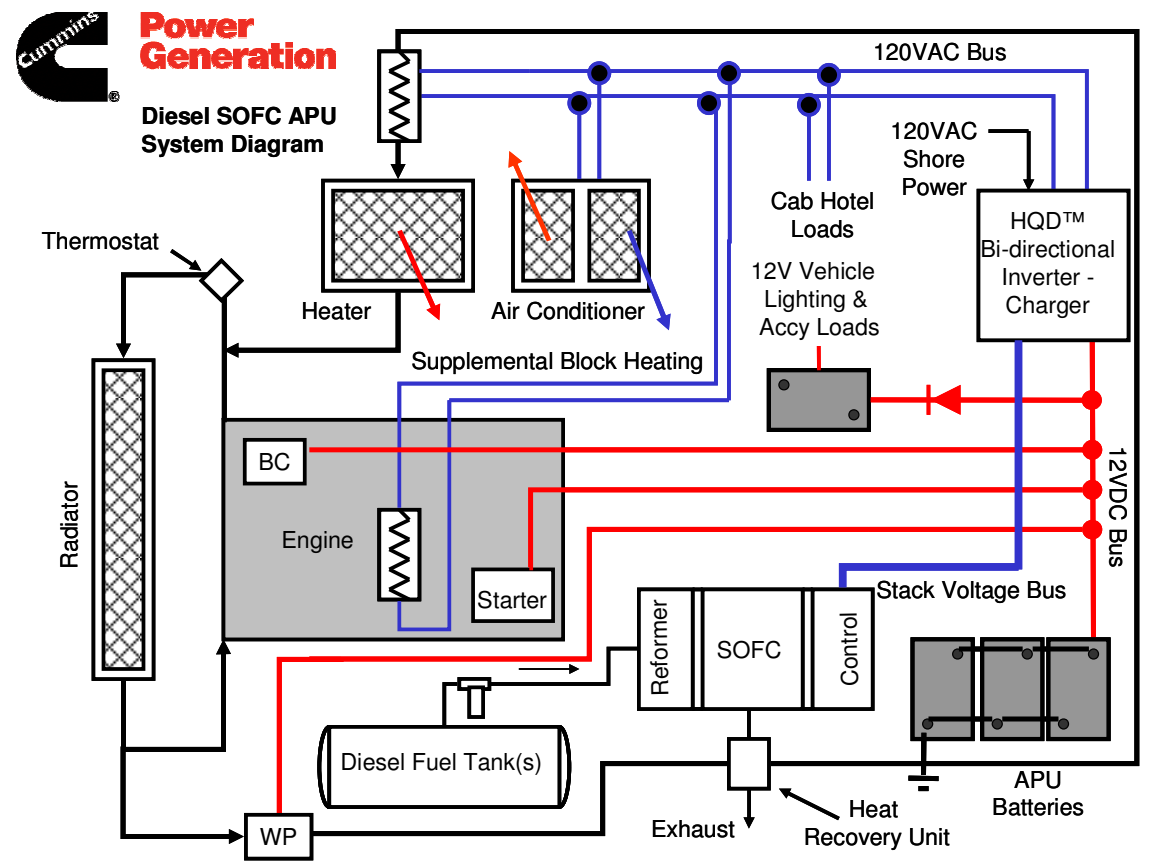

Figure 6-8, Schematic of SOFC APU Truck Auxiliary Power 


\section{Operational Modes}

During the final test of the SOFC fuel cell system CPG demonstrated all five operational modes (see Section 6.2) of the inverter system. Shown in Figure 6-8 is a time-based view of this portion of the test.

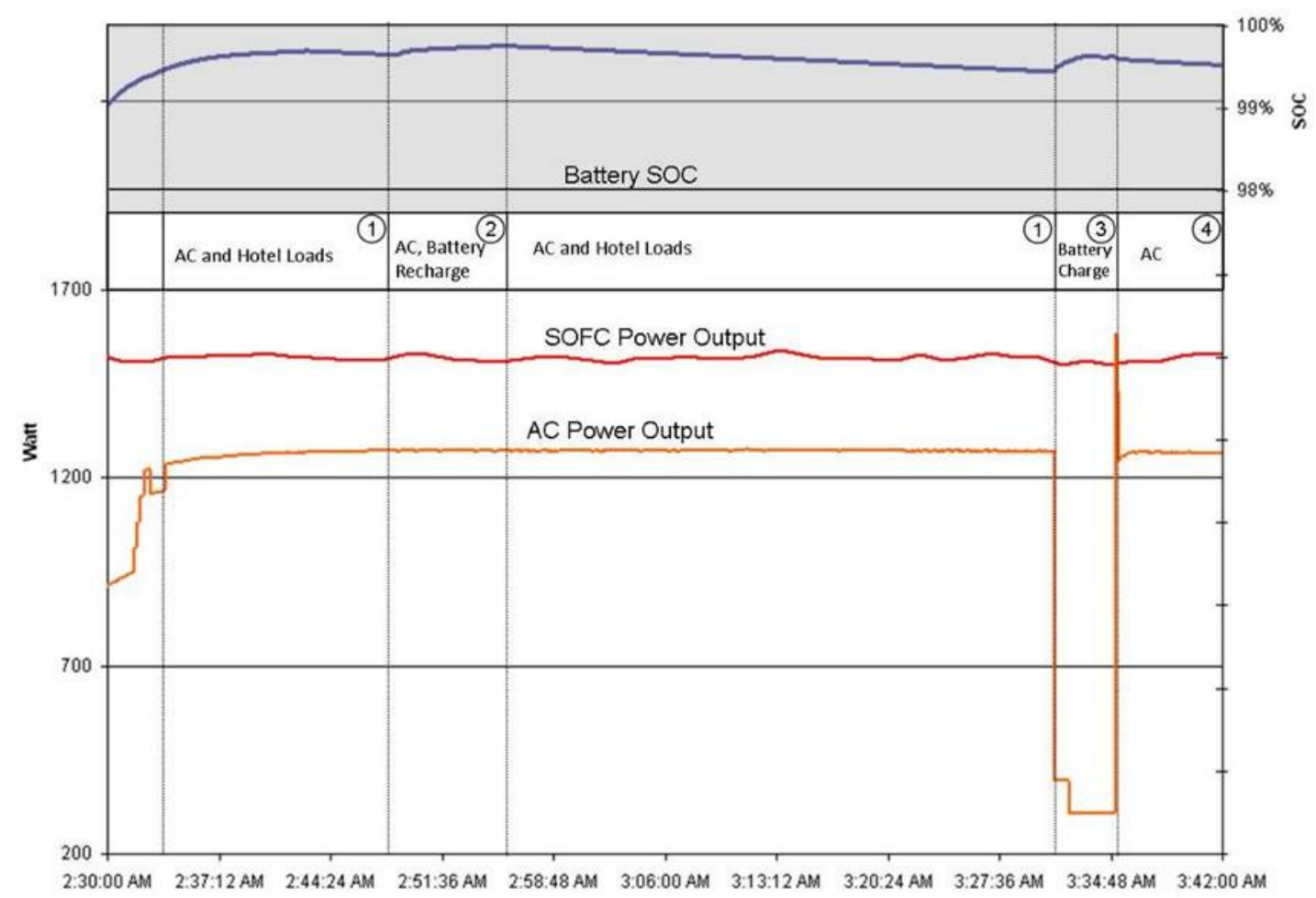

Figure 6-9 AC power output period.

The time periods designated 1 in Figure 6-8 are time periods where the fuel cell system was powering the complete cab air conditioning system, 300 Watts of simulated hotel loads, and approximately 200 Watts of external DC loads. Hotel loads consist of in-cab lighting, televisions, or other conveyance loads. During the time period designated 2, the hotel loads were removed and the 300 Watts of extra fuel cell capacity was used to recharge the automotive battery bank. Once battery state of charge (SOC) indicated a charged battery bank, battery charging current was automatically minimized and the hotel loads were turned back on, fully loading the fuel cell system and halting battery charging. During time period 3 the air conditioning turned was turned off and the full output of the fuel cell was used to recharge the automotive battery bank. Once charging was complete, the air conditioning was turned back on. Hybrid mode was automatically entered between time period 3 and time period 4 when the motor starting current of the air conditioning system was larger then the fuel cell output power. Once the air conditioning compressor was started, the inverter system transitioned back into powering the air conditioning and hotel loads completely from the fuel cell stacks. 


\section{SOFC APU BOP and System - Overview}

The system architecture built on Protonex strengths of building sub-kilowatt hot zones which would be operated in series electrically to generate appropriate voltages to interface with CPG power conditioning and balance of plant hardware. The direction of the BOP design was to create a compact package that met the total system requirements while utilizing concepts and components that demonstrated reaching the cost targets for a commercial product. Many automotive sensors and electro-mechanical devices were utilized to accomplish this task. The implementation of a rapid prototyping printer expedited the process and provided more than a dozen functional components used in the final demonstration.

\subsection{SOFC APU BOP and System Analysis and Design}

An important goal of CPG's design study was to fit the APU in package envelope similar to the size of the Cummins ComfortGuard production APU (Figure 7-1). The main advantage of the conceptual case design is easier access to the inside of the APU. These case options formed the basis for all module configurations that were considered.

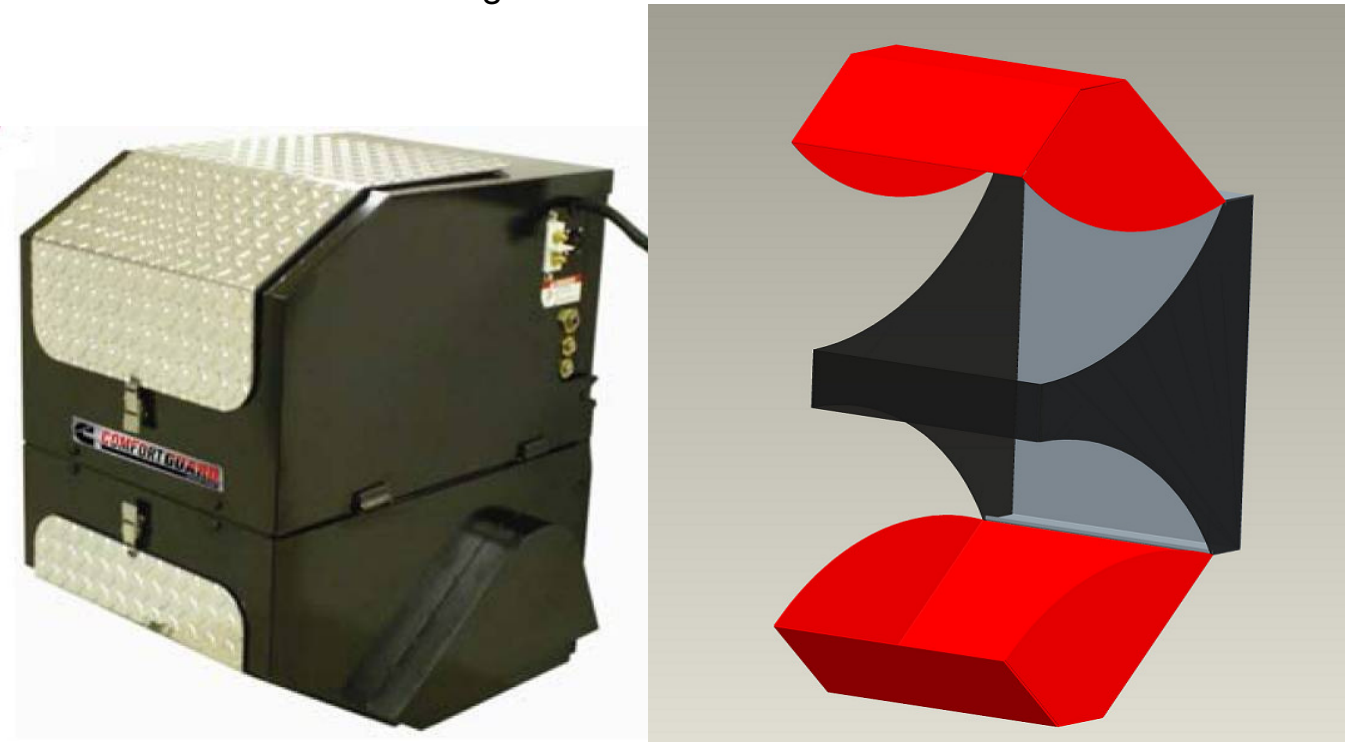

Figure 7-1. ComfortGuard case and conceptual APU case.

Figure 7-2 gives representative examples of the possible module orientations that were considered. The first two options show "cuts" in the module walls where they would theoretically extend beyond the ComfortGuard case walls. The third option fits better inside the case, although it is possible that minor modifications to the case envelope might still be required. The third configuration also has easier access for the replacement of individual modules. Access is gained by hinging the top and bottom of the case as shown in Figure 7-1. Options 2 and 3 would make disconnecting the plumbing and electrical connections much easier during replacement than option 1. 

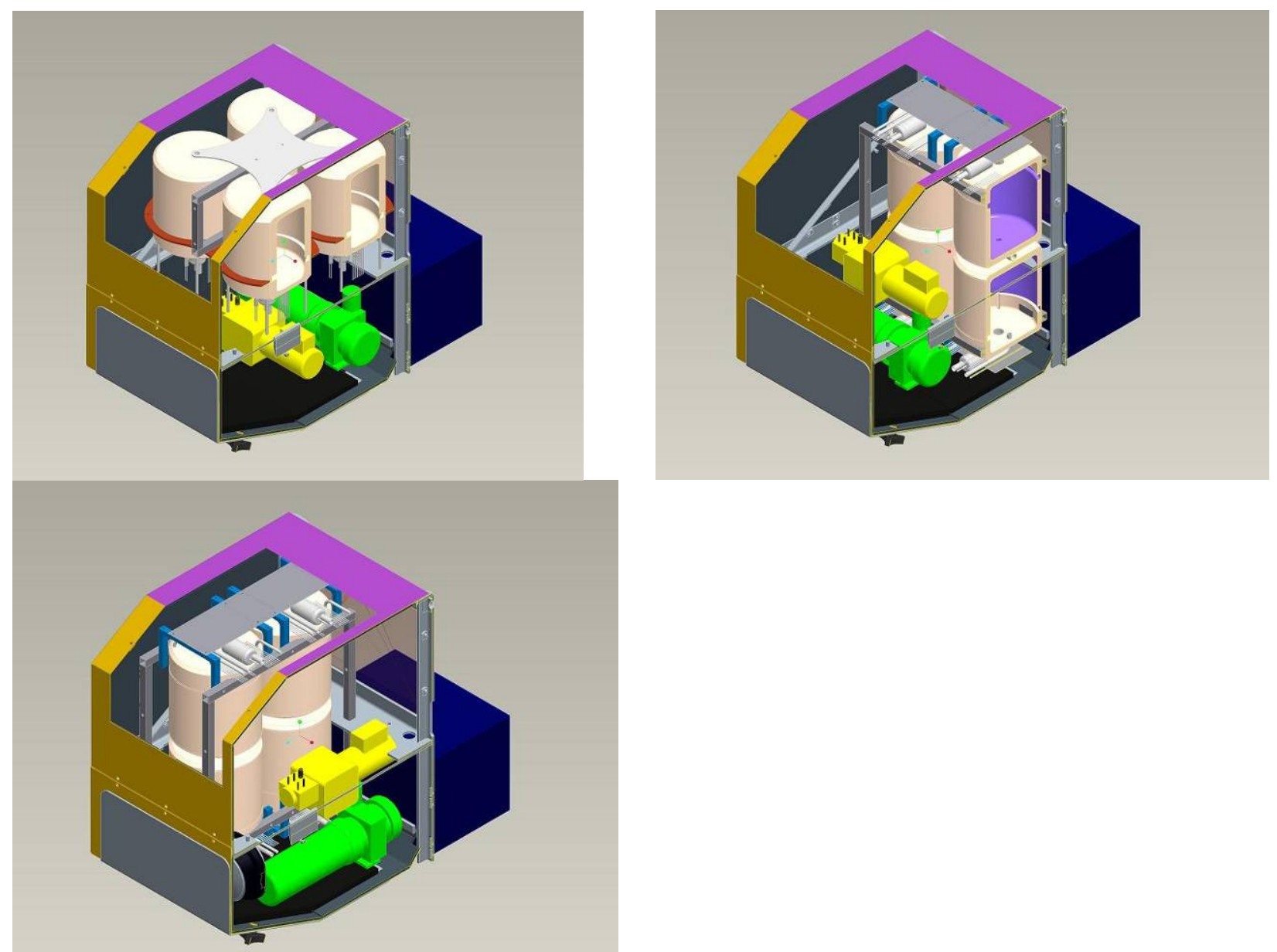

Figure 7-2. Selected hot zone arrangements that were considered. The hot zone containment case is omitted for clarity. The bottom orientation was determined to be the most appropriate.

The orientation of each module in option 3 of Figure 7-2, with the plumbing and electrical connections near the top or bottom of the case, makes assembly and module replacement significantly more convenient than having all connections near the center (vertically) of the case. It also simplifies the structure used to support and isolate the modules from the balance of plant. Most of that structure is omitted for clarity.

An additional benefit of option 3 is that it allows for easier collection and routing of the module exhaust than the other designs. A relatively simple and light exhaust manifold can be used and the exhaust heat can effectively be channeled away from the balance of plant for possible use elsewhere on the vehicle. 


\subsubsection{System Development - Packaging}

The design of the inner sheet metal enclosure that houses the four modules and the BOP components was reviewed. The main considerations were for the BOP components with respect to accessibility, ease of maintenance, thermal management and ease of assembly and disassembly. Taking the above factors into consideration the components were relocated and an improved solid model was made in ProE. Figure 7-3 shows the revised model of the inner sheet metal frame.

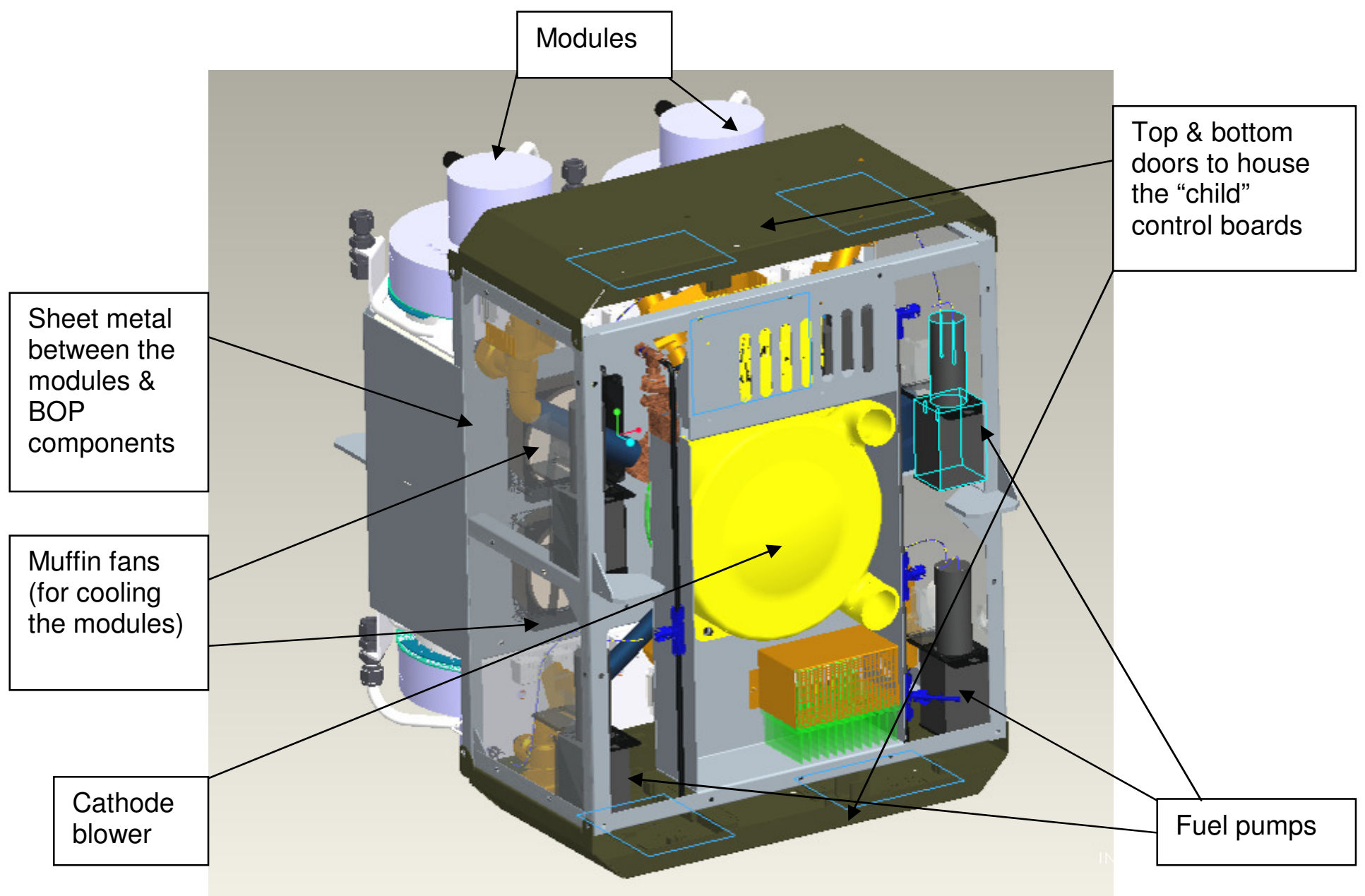

Figure 7-3: Inner frame of SOFC APU

The electrical hardware consists of a total of five control boards and a truck interface board. Each module has its own control board (referred to as "child" board) and there is a "parent" board which controls the four "child" boards. These five control boards are located inside the APU. The truck interface board, which is the link between the APU and the "outside world" (i.e. the truck cab) is located on the outer frame (Fig 7-4). The four "child" boards are housed in the top and bottom doors of the frame (two boards on top and two on bottom) as shown in figure 7- 
3. The doors can swivel about a horizontal axis and enable an operator to work on the unit while performing maintenance and during troubleshooting. The doors also house the different relays for the modules (such as muffin fan relays, reformer glow plug relays, vaporizer relays and a boost pump relay).

The mechanical components include the fuel pumps (total of four, one for each module), a cathode air blower (also called the "primary blower") and an anode blower (also called the "secondary blower"). The fuel pumps are located on the four corners of the inner frame as shown in figure 7-3. The fuel supply line to the SOFC APU comes from the main fuel tank of the truck via a boost pump which is mounted on the outer frame (refer Fig 7-4). There is a fuel filter downstream of the boost pump. The fuel line then connects via a fitting and a flexible tube connection to the four fuel pumps.

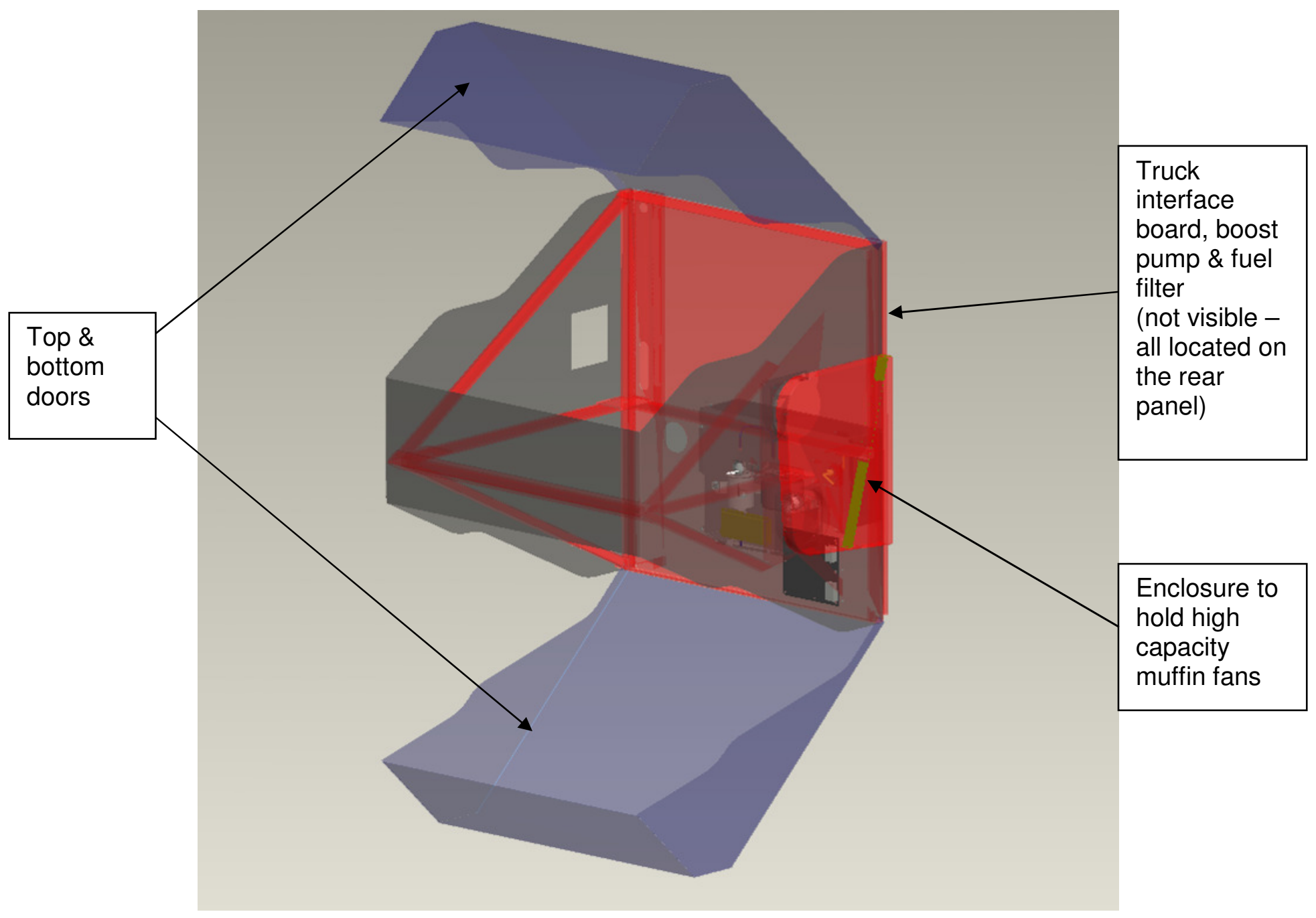

Figure 7-4: $\quad$ Outer frame of the SOFC APU

The cathode blower is mounted on a sheet metal bracket and is connected to the inner frame by bolts. The sheet metal bracket also houses the "parent" control board, cathode controller and the anode blower (shown in figure 7-5). The anode blower is located on a plate adjacent to the cathode blower. 


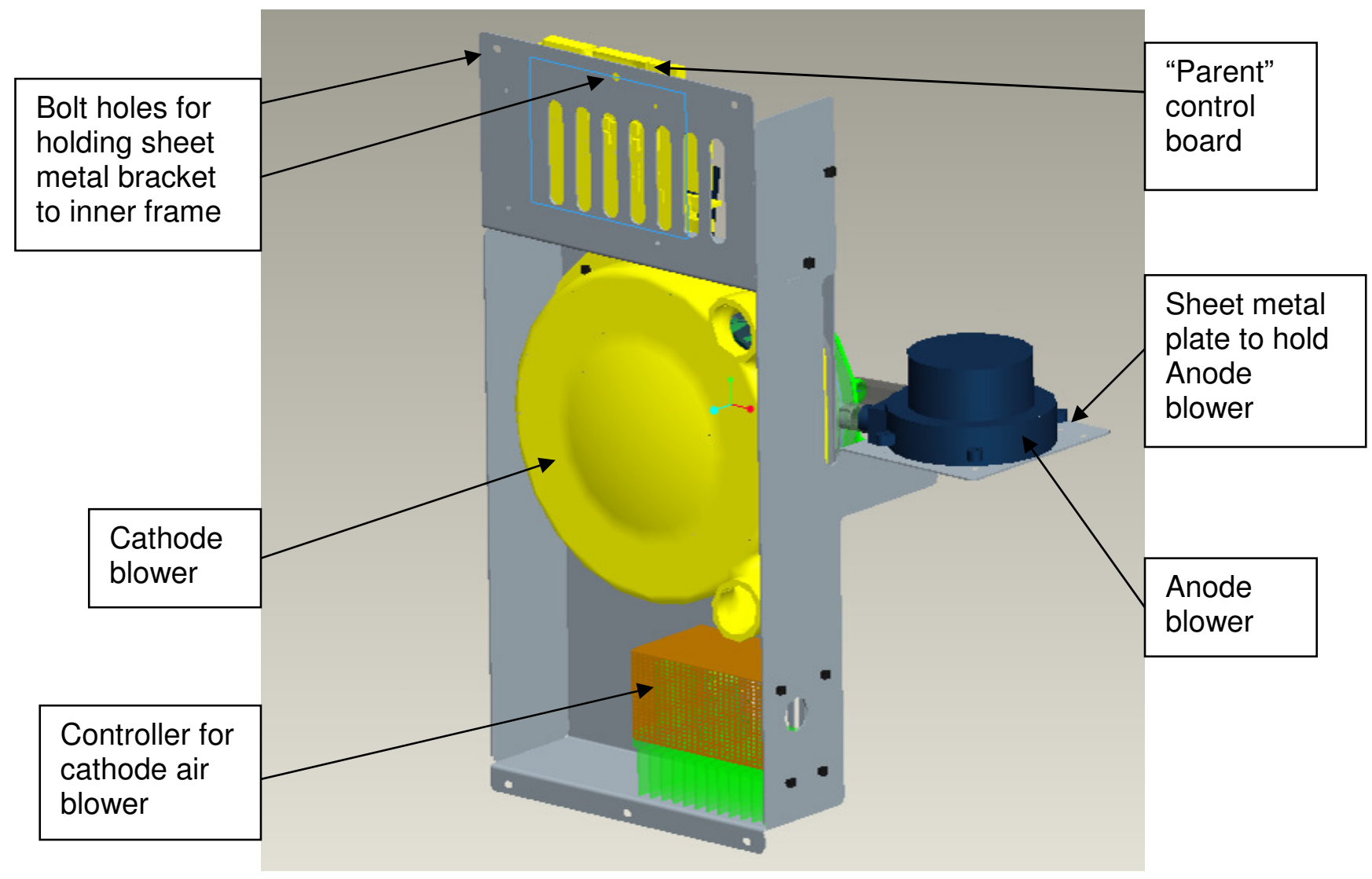

Figure 7-5: Sheet metal bracket for supporting cathode and anode blowers

The four fuel cell modules are located on the side opposite to BOP components. There is a piece of sheet metal that separates the module side and the BOP side (refer Figure 7-3). This sheet metal also houses four muffin fans. The function of the muffin fans is to provide forced air cooling to the modules at high load conditions (the surface temperature of the modules at full load can be as high as $200^{\circ} \mathrm{C}$ ). In order to supply the air to the four muffin fans, there are two additional high capacity muffin fans located on the outer sheet metal frame (refer Figure 7-4).

The outer frame of the SOFC APU is being redesigned (refer Figure 7-6). Stiffer square tubes are used in place of bulky channels and thick sheet metal as in the first generation design. 


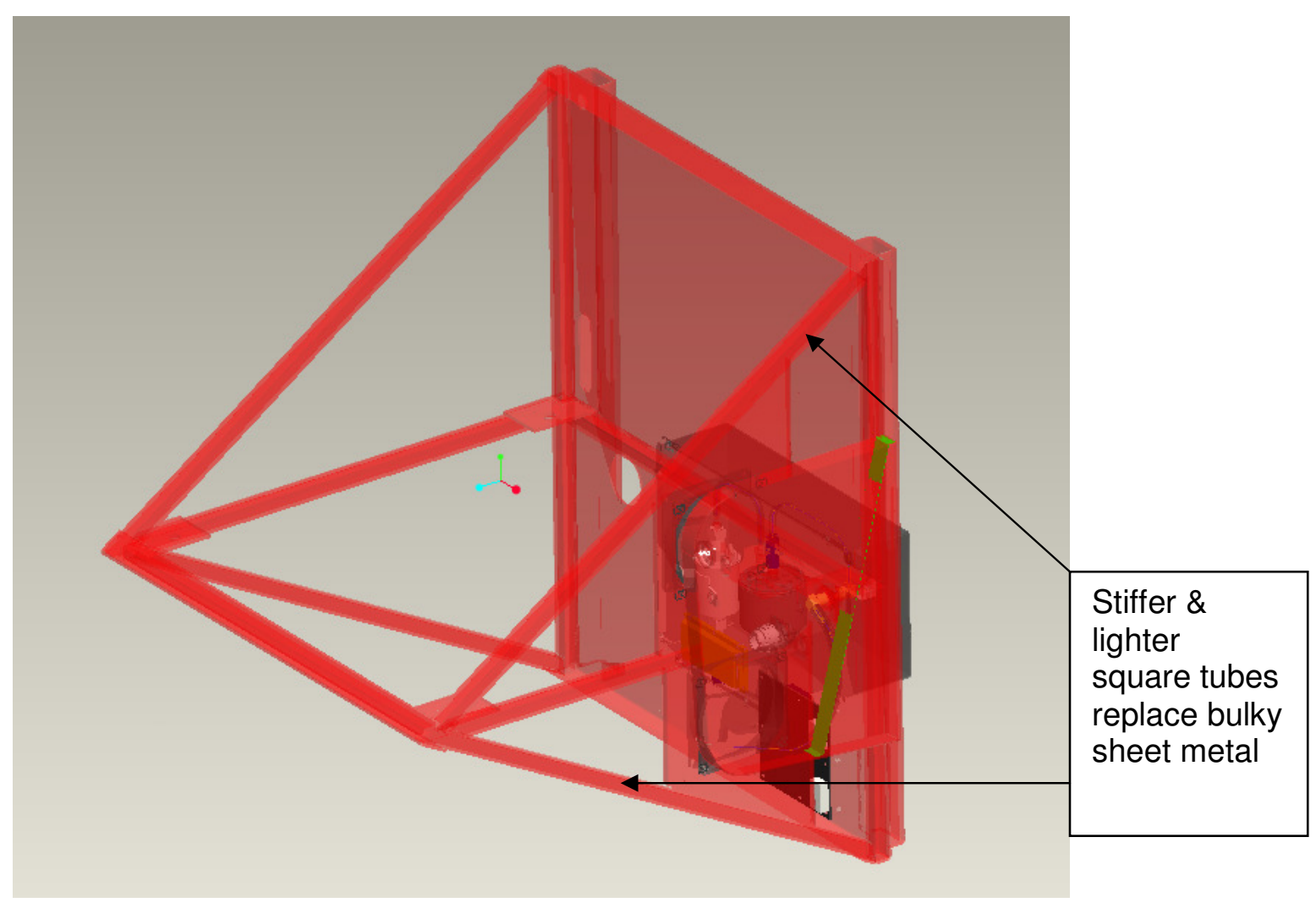

Figure 7-6: Outer frame of SOFC APU (structural members)

Sway space between the inner and outer frames was defined using the acceleration spectral density versus frequency data for a US highway truck as provided in MIL810 standard. The deflections produced by this input in the longitudinal, transverse and vertical directions are being analytically determined. The maximum value of the displacement at the extreme points will decide the sway space that needs to be provided between the inner and outer frames. Vibration isolation mounts will be chosen accordingly. The analytical process will also tell us the " $\mathrm{g}$ " levels that the inner frame and its components will experience in all three directions. The analytical values will be used as a basis to fabricate the inner and outer frames of the SOFC APU. 


\subsection{System Development - Low cost integrated BOP}

CPG redesigned the air supply system as shown in figure 7-7. The new design makes the air supply manifold more compact. Also, CPG used a 3D printer to fabricate the new air manifold system and flow controller(s) as shown in Fig. 7-8 and Fig. 7-9.

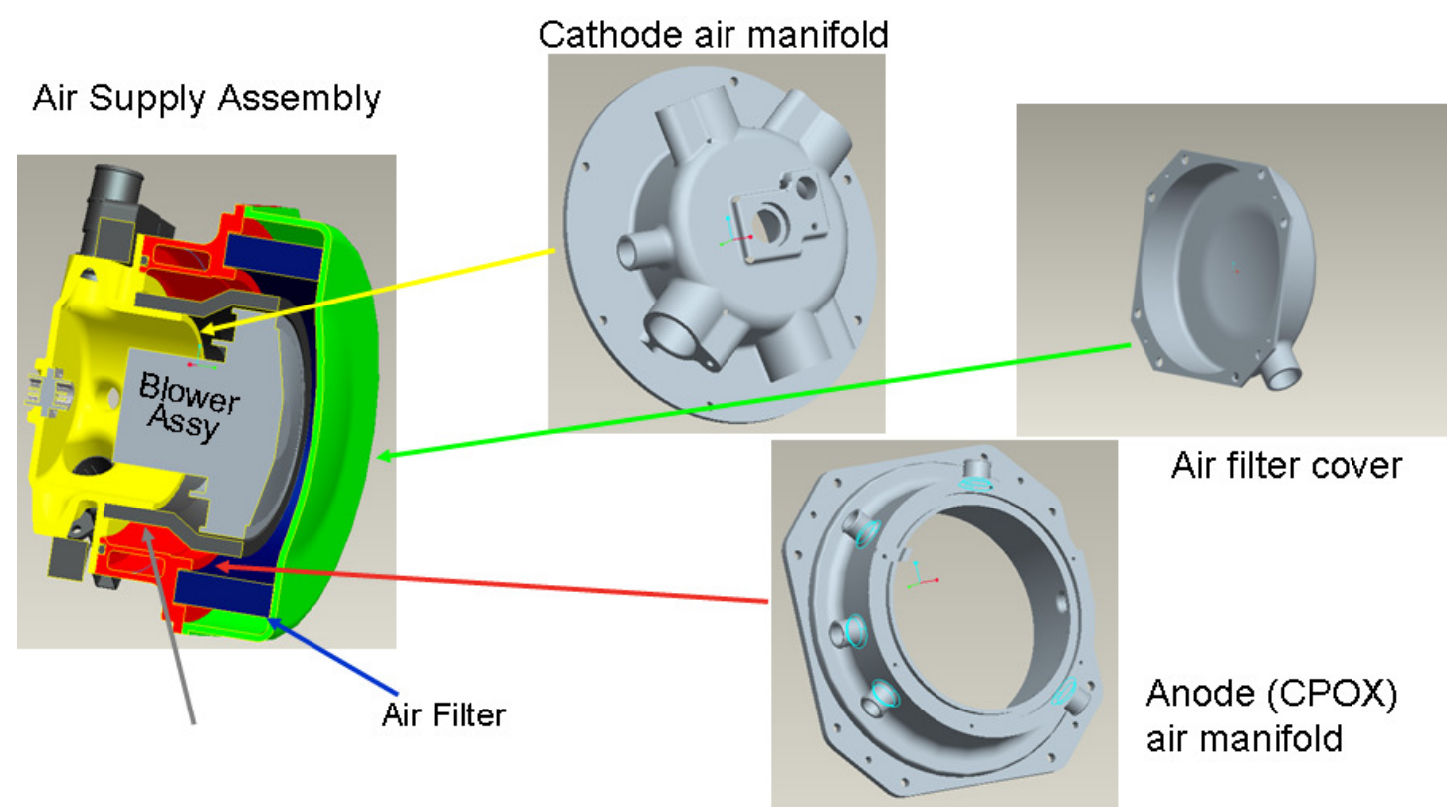

Figure 7-7. Integrated Cathode/Anode blower/distribution manifold

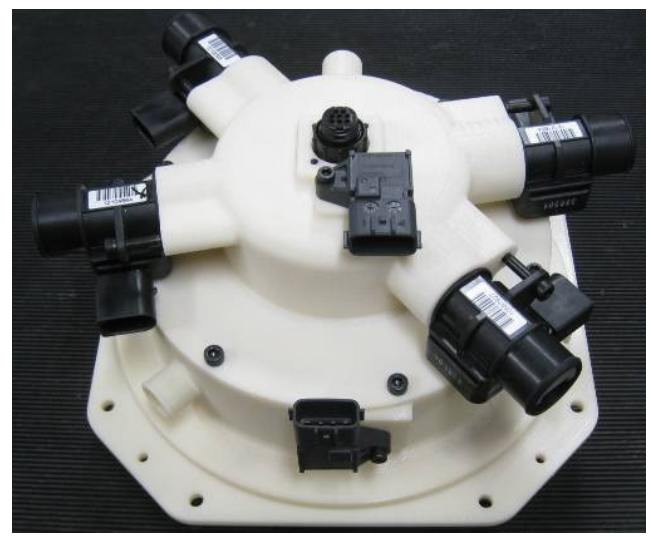

Figure 7-8. Integrated manifold prototype 


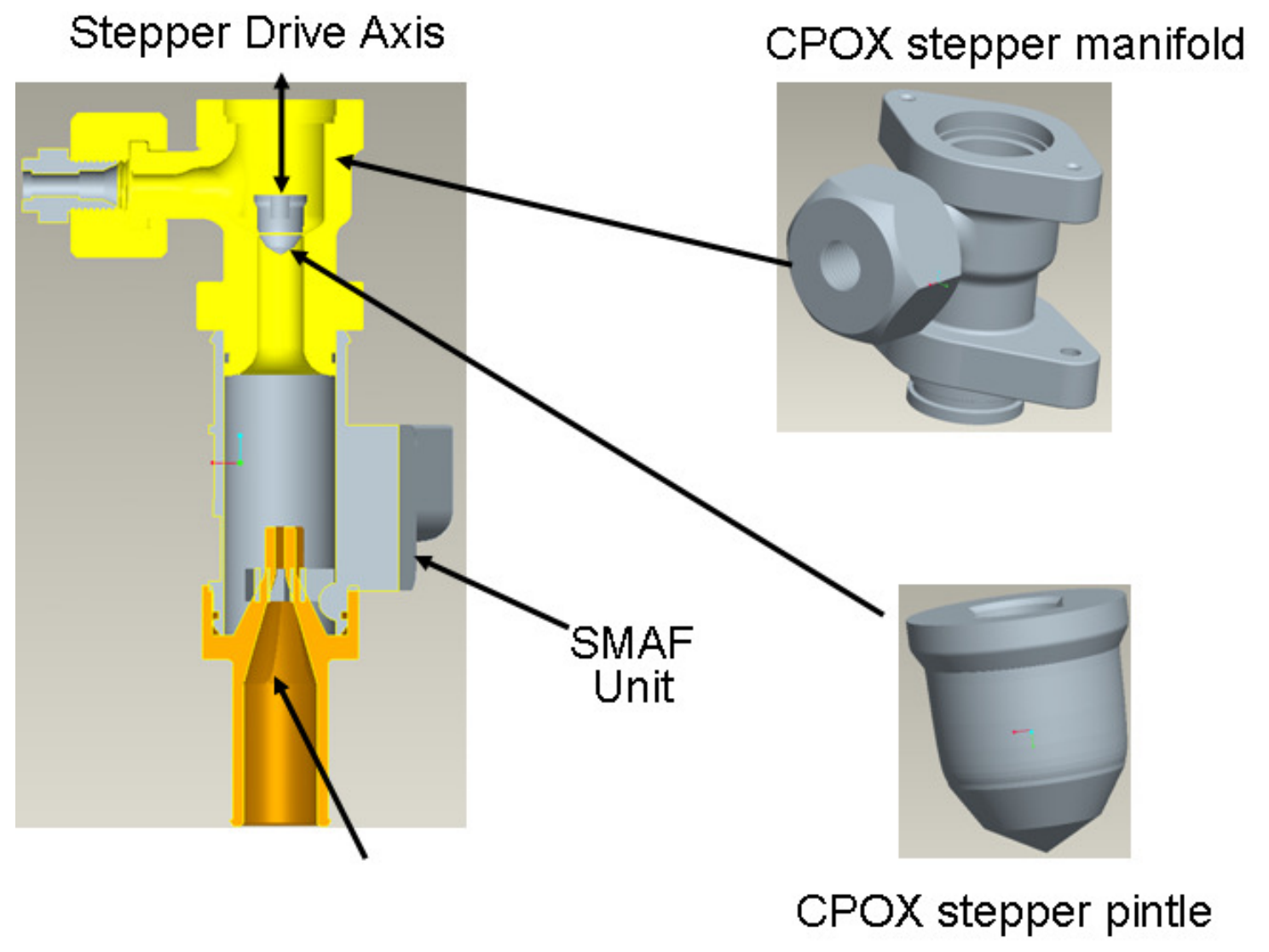

Figure 7-9. Stepper controller

A key process to the rapid development of the BOP mechanical controls was the implementation of an SLA rapid prototyping printer. Most of the control devices were iterated designs to achieve the performance requirements. An example is in figure 7-9 the orange colored SMAF inlet flow adaptor was developed to modify the original automotive sensors range, from $1000 \mathrm{~g} / \mathrm{min}$ to $80 \mathrm{~g} / \mathrm{min}$ cathode and $20 \mathrm{~g} / \mathrm{min}$ anode, to improve resolution. This SLA process was also used for the integrated air manifolds and blower housing and air cleaner cover. The use of the modified SMAF sensor demonstrates the ability to utilize a $\$ 20$, including the adaptor parts, automotive component effectively in an SOFC application.

MiliGat metering pumps with drivers were procured and calibrated. Through calibration of control board clock signal, the accuracy of delivered diesel fuel flow was improved to $\pm 1 \%$, as shown in Fig. 7-10. 


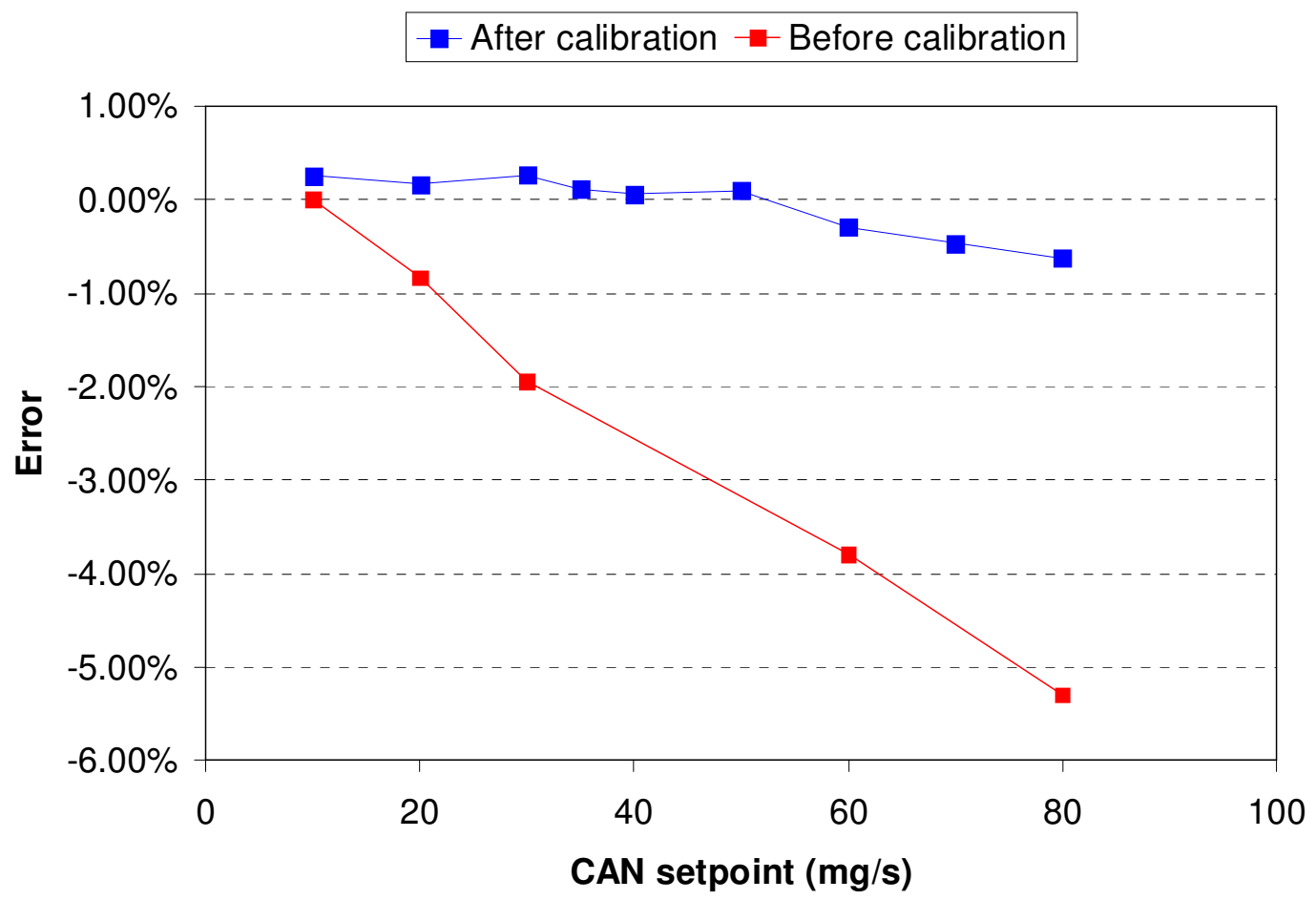

Figure 7-10. Improvement of delivered fuel flow accuracy

The mechanical fuel delivery subsystem was operated with the anode air supply subsystem. The mechanical system is capable of being controlled to maintain the $\mathrm{O} / \mathrm{C}$ ratio within the requirements. As shown in Fig. 7-11, over $25 \% \sim 100 \%$ of operation load range, O/C ratio is controlled within $\pm 3 \%$ of target range, which meets the PTX requirement of $\pm 5 \%$.

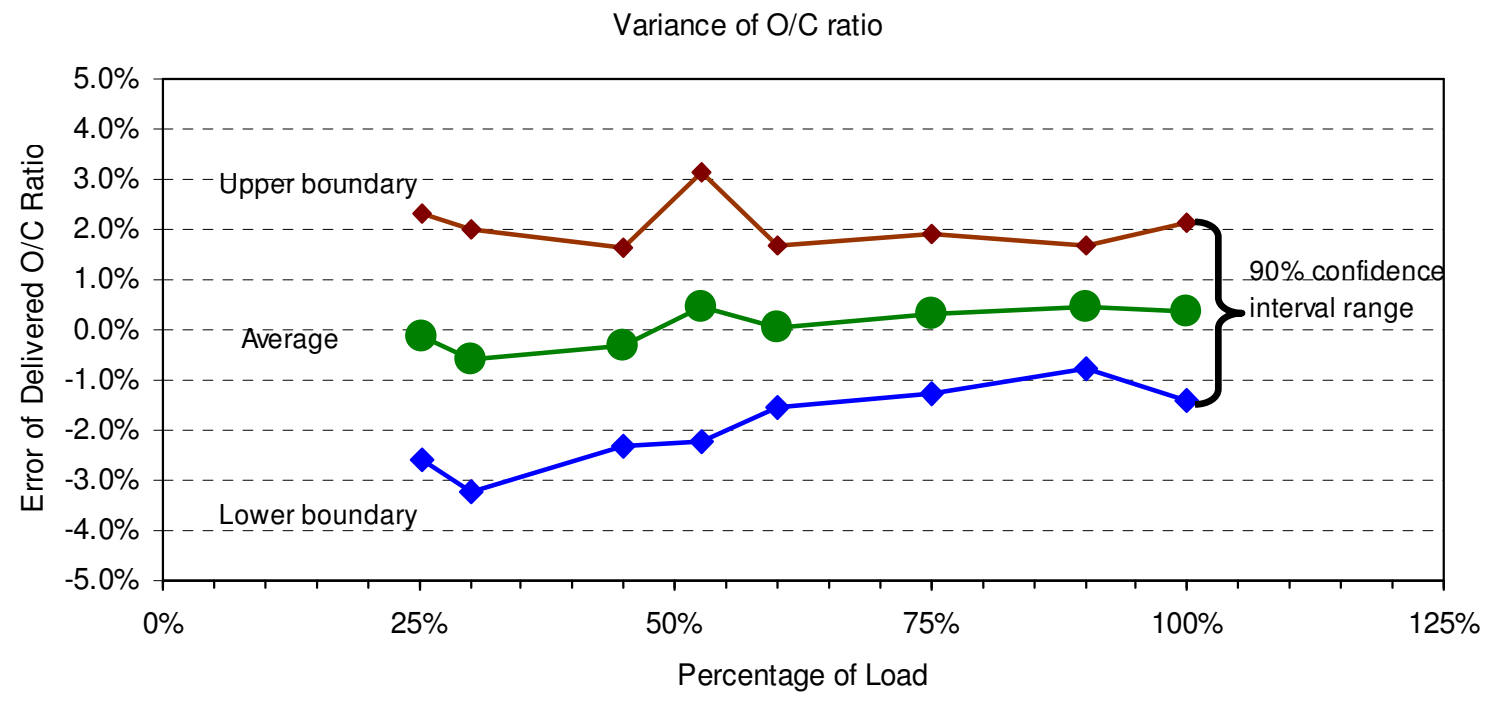

Figure 7-11. Accuracy of controlled $\mathrm{O} / \mathrm{C}$ ratio in operation range. 


\section{Complete Air System Control}

A complete air manifold system consisting of 4 child modules and one parent module was tested and optimized. Each child module contained control of one cathode air valve using one cathode mass air flow sensor as feedback, and control of one anode air valve using one anode mass air flow sensor as feedback. The parent module controlled the anode blower speed by commanding a 0-10VDC signal to the anode blower motor control module using the RMS position of the children's anode air valve(s) as feedback. The parent module also controlled the cathode blower speed by commanding a targeted PWM signal to the cathode blower motor module using the RMS position of the children's cathode air valve(s) as feedback. By optimizing the controller gains and RMS valve positions, a reactive yet stable system was realized.

Figure 7-12 illustrates an air system startup sequence starting form no air flow to 10SLPM on each of the four children. Following the optimization of the controller gains a steady state air system error of less than $\pm 2 \%$ was achieved, meeting the design objective of $\pm 3 \%$.

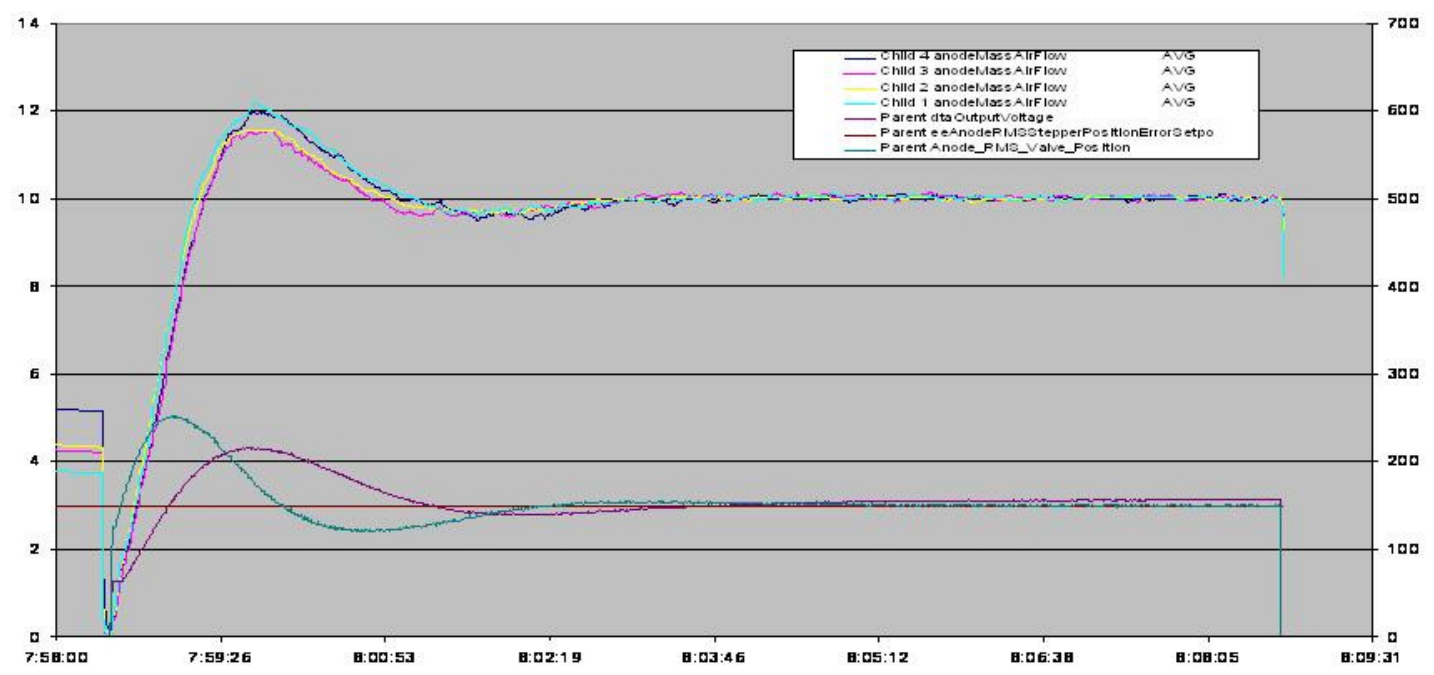

Figure 7-12. Air system startup sequence.

\section{O/C Ratio Control}

Following successful control of the air system, the next step in sub-system development was mating the fuel and air control logic for the purpose of achieving a stable and steady $\mathrm{O} / \mathrm{C}$ ratio during both steady state and transient operational modes. In order to maintain the required +/$5 \%$ control of OC ratio, during steady state operation the ULSD fuel set-point was used to set the anode air control set-point. During transient events, the fueling was incremented a small amount and the air system set-point was changed. By breaking up a large transient event into many smaller fuel and air steps the O/C ratio was controlled to a $+/-3 \%$ error window with a $90 \%$ confidence.

Figure 7-13 illustrates the fuel, air, and OC ratio of the control system during both steady state and transient fuel events. 


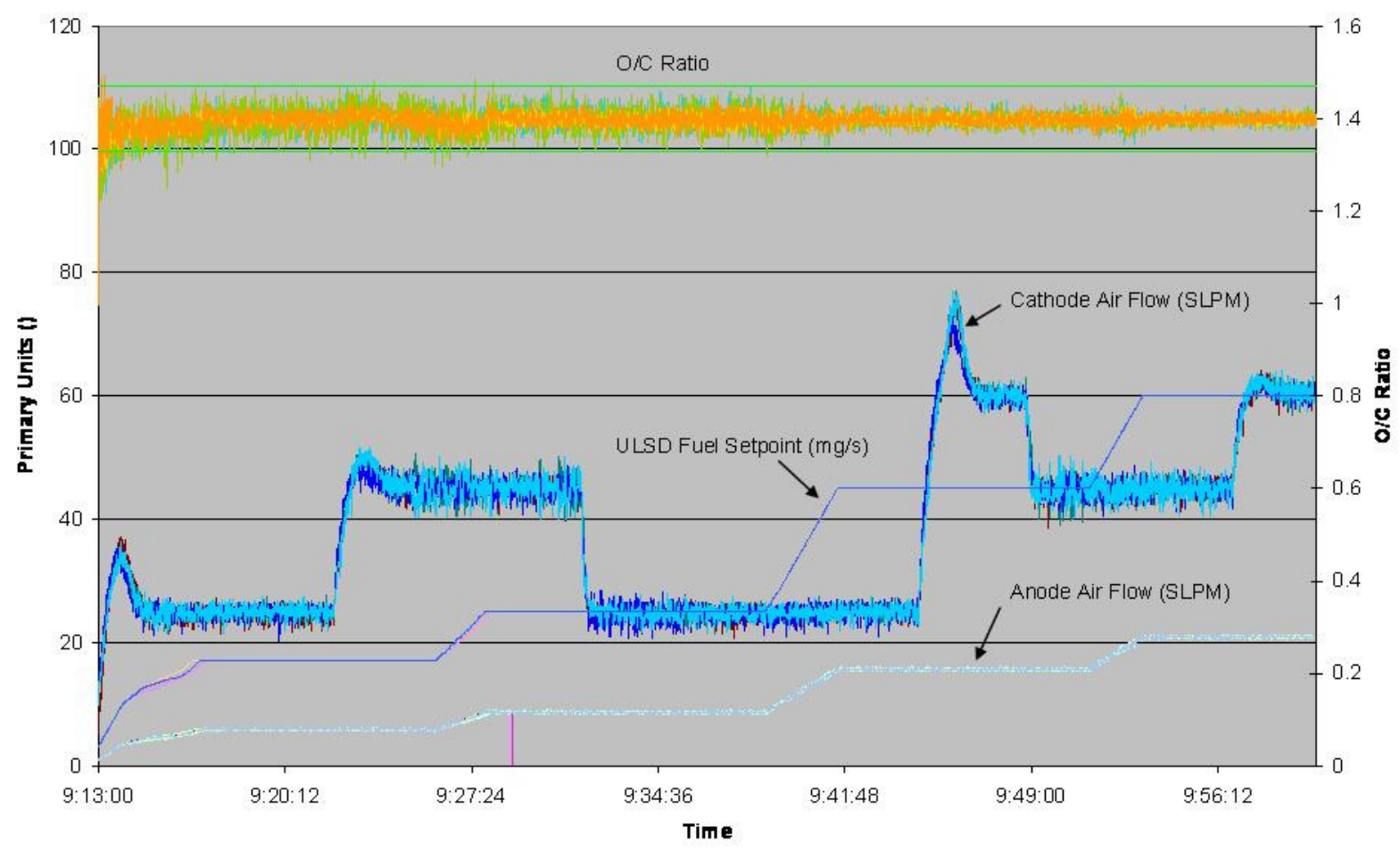

Figure 7-13. Steady state and transient fuel, air, and $\mathrm{O} / \mathrm{C}$ ratio control response.

\section{Other components}

A heat exchanger developed for waste heat recovery from the SOFC APU exhaust was tested for heat transfer and fluid flow performance. The SOFC exhaust of all four modules combined was simulated by a natural gas burner.

The inner frame was assembled inside the outer frame with vibration isolators in between the two. The four fuel cell modules and the various BOP components which included the following were assembled:

- Fuel subsystem:

○ Four fuel pumps (four)

- One boost pump (draws fuel from the main tank and supplies to the individual pumps)

- Fuel pump controllers (four) and fuel lines

- Air subsystem:

- Cathode air blower (one) and corresponding mass flow sensors and controls

- Anode air blower (one) and corresponding mass flow sensors and controls

- Plastic tubing for anode and cathode air handling

- Controls 
- Four individual (“child”) boards (one for each module)

- One main ("parent") board

- One truck interface board (interface between the main truck controls and the SOFC APU)

- Waste heat recovery subsystem:

- Two waste heat exchangers

- High and low temperature exhaust bellows

- Coolant pump

- Radiator, fan and coolant piping

- Miscellaneous items:

- brush seals (for sealing all the air gaps inside the APU box)

- Muffin fans (total of six) for external cooling of the modules

There were no major assembly/packaging issues. The outer panels were spray painted with the customary Cummins red and black .

Figure 7-14 illustrates the final CHP heat exchangers and plumbing that is capable of over 8kW of heat recovery. Figure 7-15 to 7-18 show the various views of the SOFC APU demonstration unit.

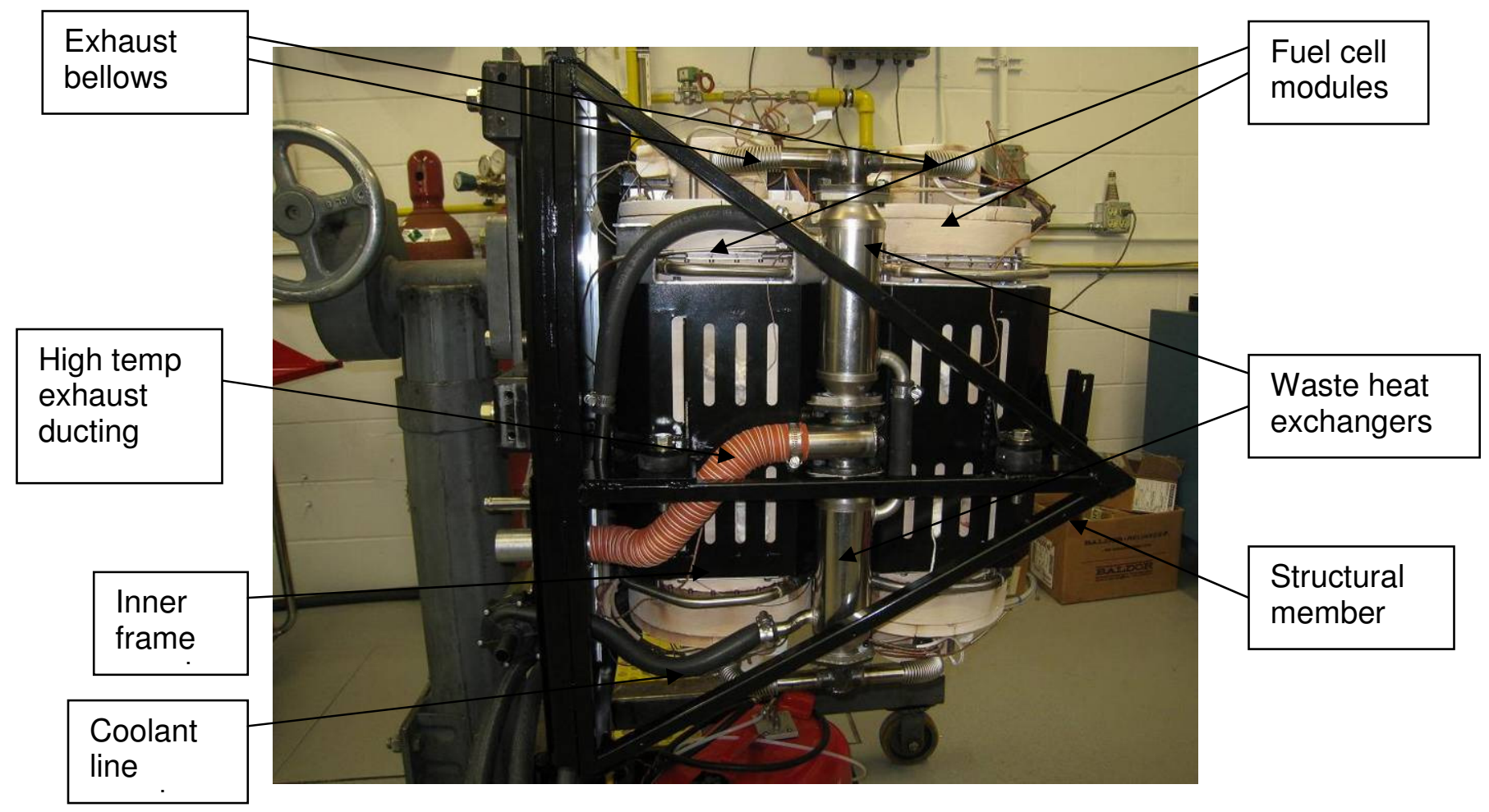

Figure 7-14: Fuel cell frame with the four modules and waste heat recovery subsystem 


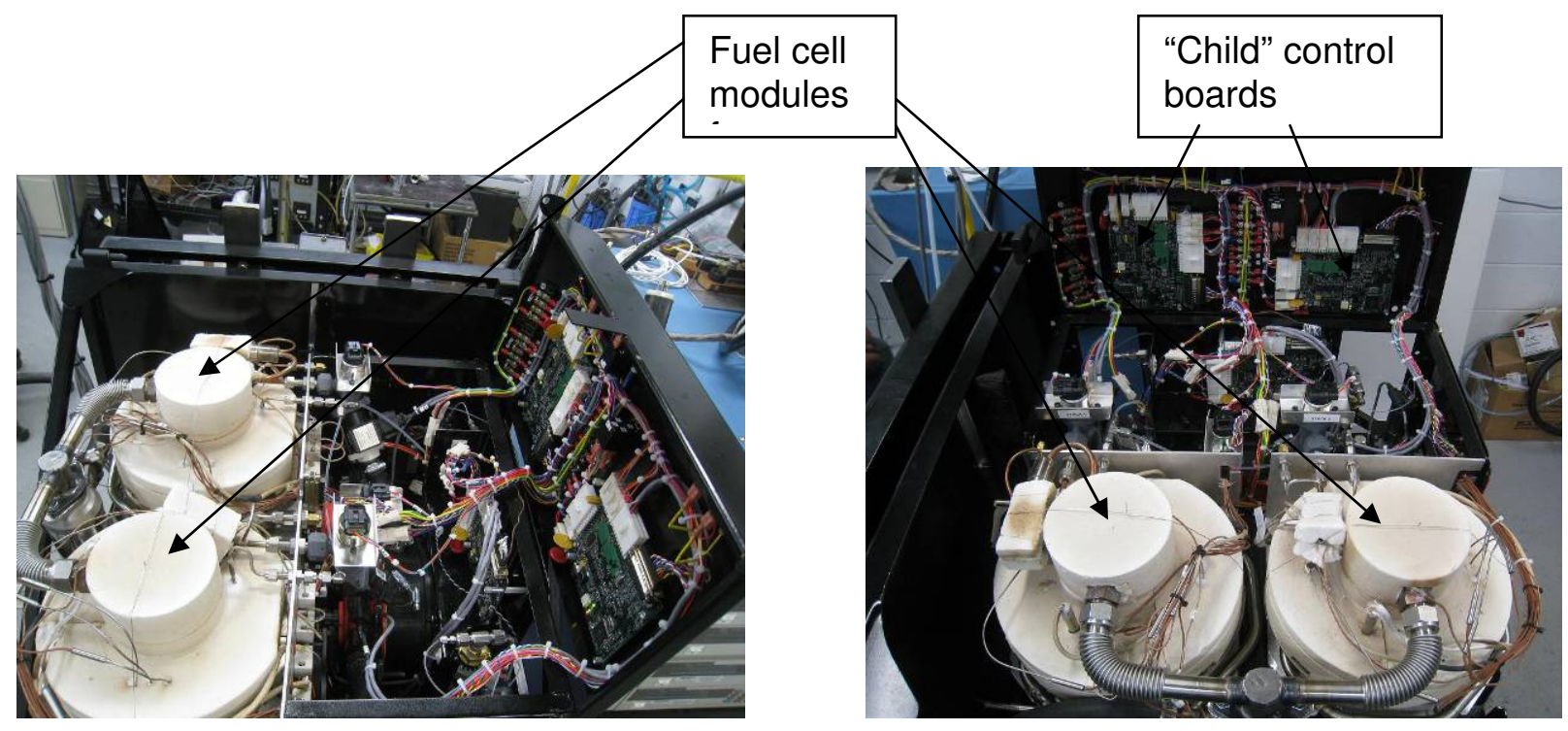

Figure 7-15: Top and side view of the inner assembly

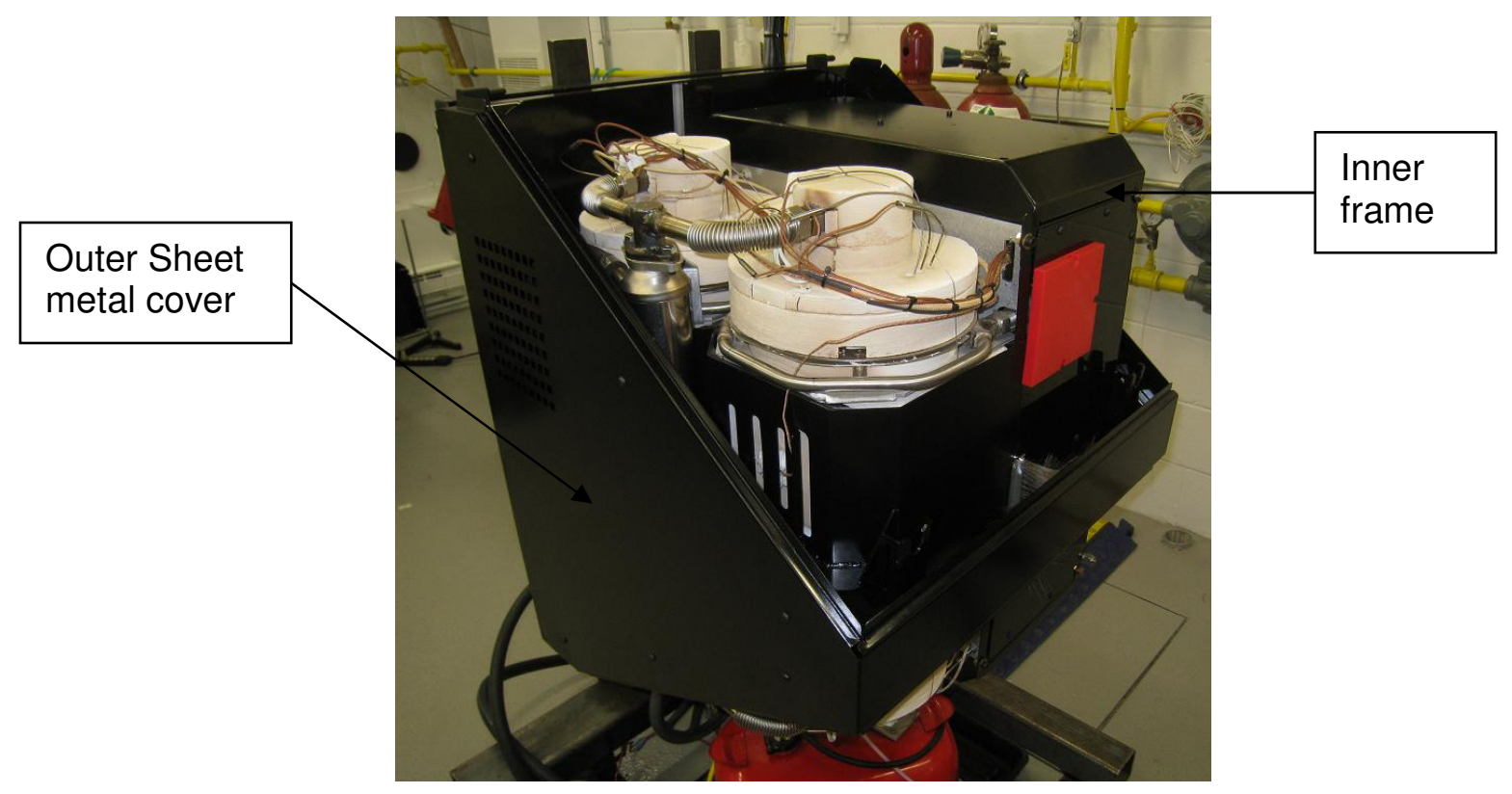

Figure 7-16: Another picture of the assembled modules and BOP components 

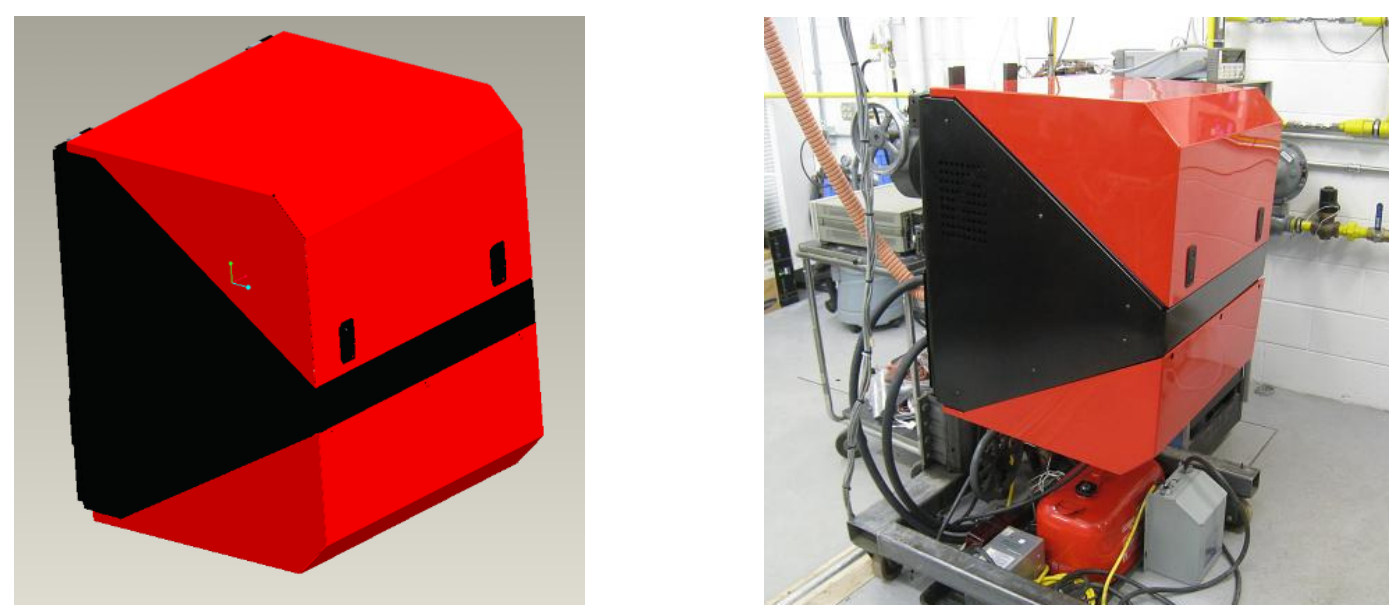

Figure 7-17: Solid model of SOFC APU assembly and associated hardware

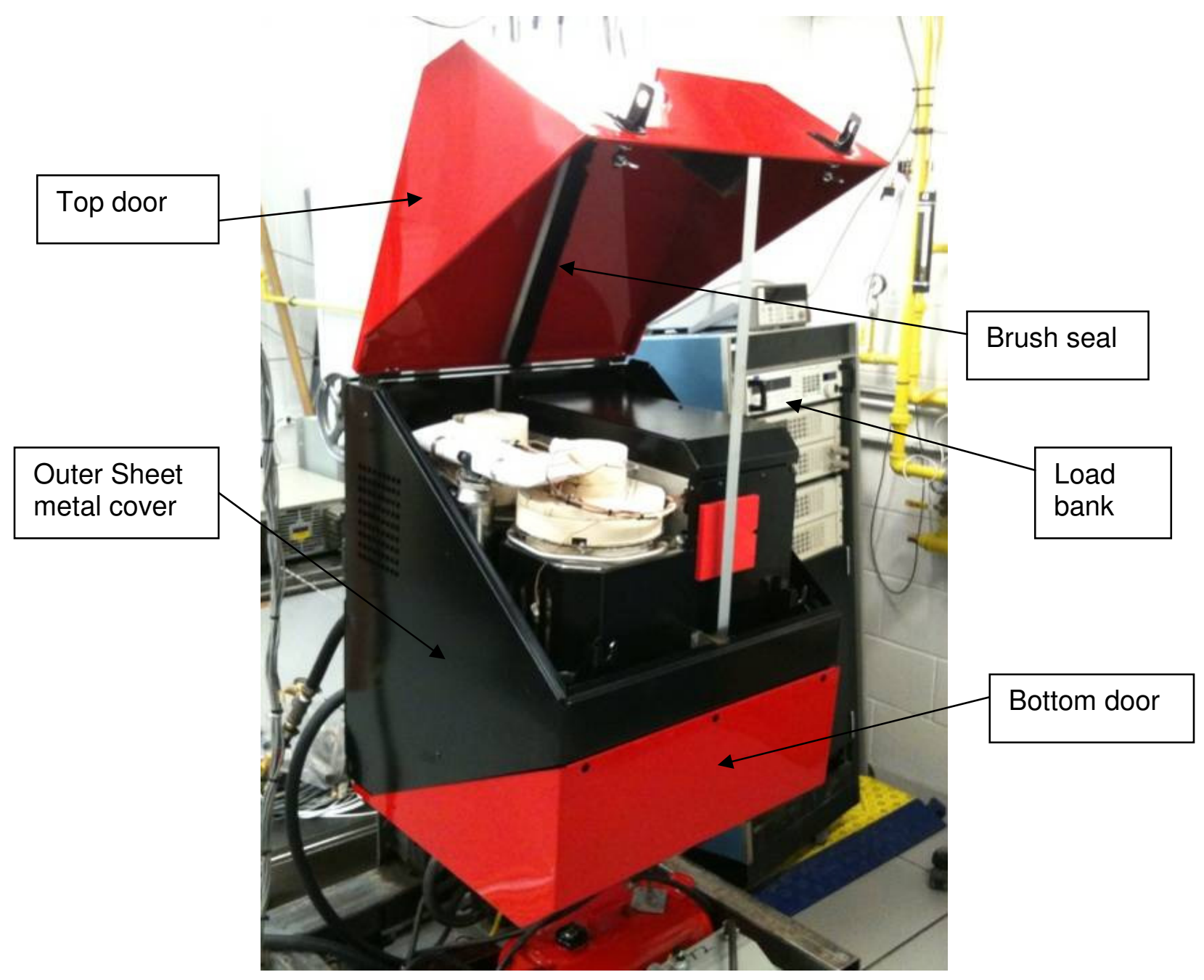

Figure 7-18: Final assembly with top door open 
The SOFC APU housing and the components within are subjected to vibrations coming from the truck while the truck is in motion. Mechanical vibrations are also transmitted while the APU is being shipped for delivery. The APU housing and the inner components must be able to sustain the vibrations without any electrical or mechanical failure. In order to determine the stresses on the housing and the components, a stress analysis was conducted using ANSYS®. A Finite Element (FE) model of the housing and the sheet metal bracket that holds the four can modules was created. In the previous quarter a preliminary FE analysis of the bracket was carried out. In the present quarter a similar analysis was conducted for the housing. The housing was subjected to transportation loads in lateral, longitudinal and vertical directions as per Cummins Power Generation's Engineering Standard Work document 0021 (ESW-21) [1]. For consumer sets such as the APU, the criteria is to sustain 5 ' $\mathrm{g}$ ' $\mathrm{s}$ of acceleration in all three directions.

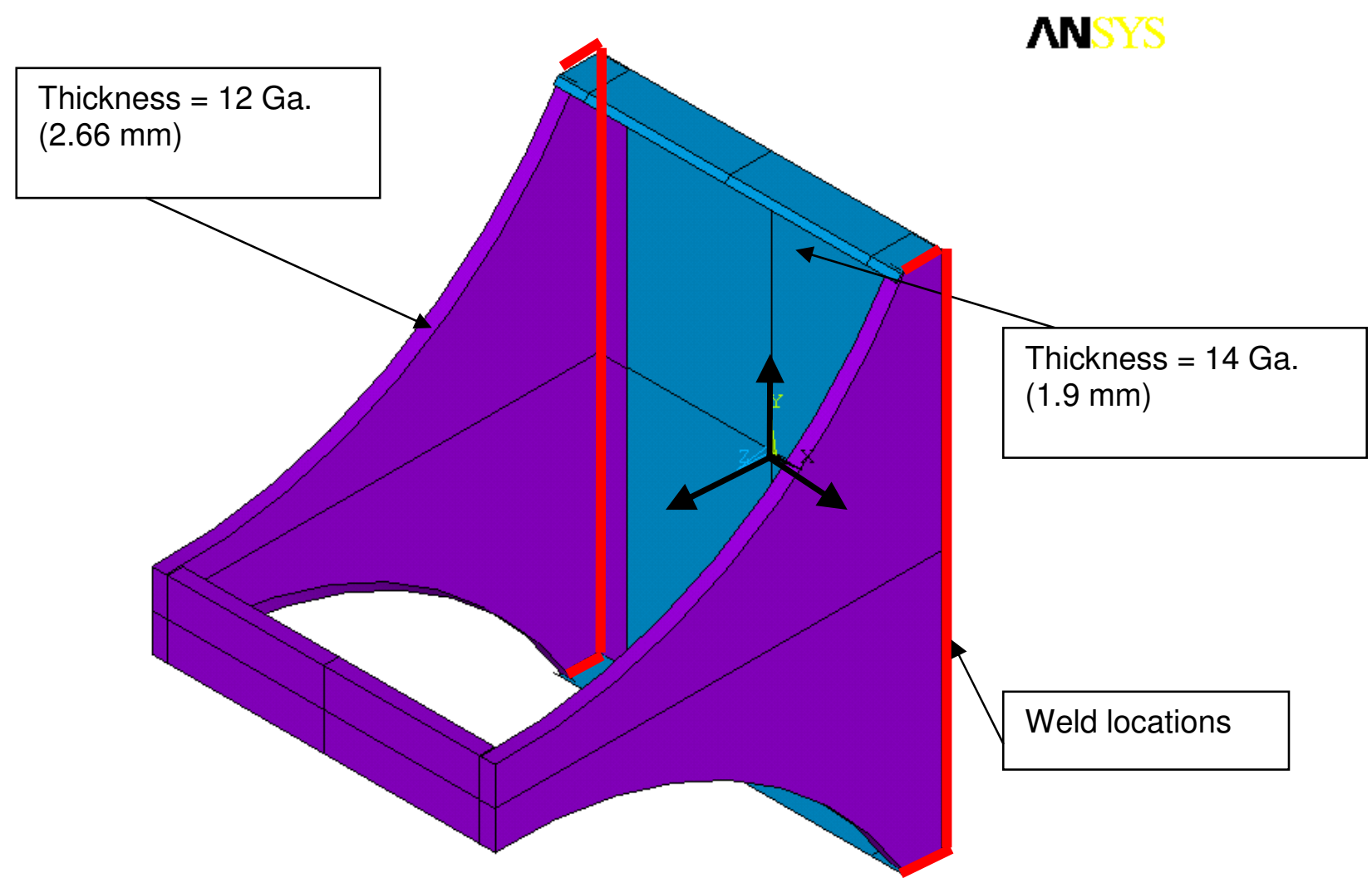

Figure 7-19: Solid model of APU housing

The model was generated in ANSYS 10.1. Metric units are used in the entire analysis and in the report.

Shell (SHELL93) elements were used to model the sheet metal structure. A point mass (MASS21) element was defined to represent the mass of the rest of components supported by the housing. The point mass is attached to housing using the 'rbe3' method in ANSYS such that the forces are transferred from the point mass to the housing but the housing does not see any additional stiffness. This is to represent the fact that the components will be suspended on / supported by the housing using rubber mounts rather than being bolted/ welded rigidly to the housing. 
The back plate (14 Ga.) is connected to the rest of the housing (12 Ga.) with 'cp's (coupled degrees of freedom) similar to having a stitch welded structure. The lids were not modeled since they do not add significant stiffness to the structure.

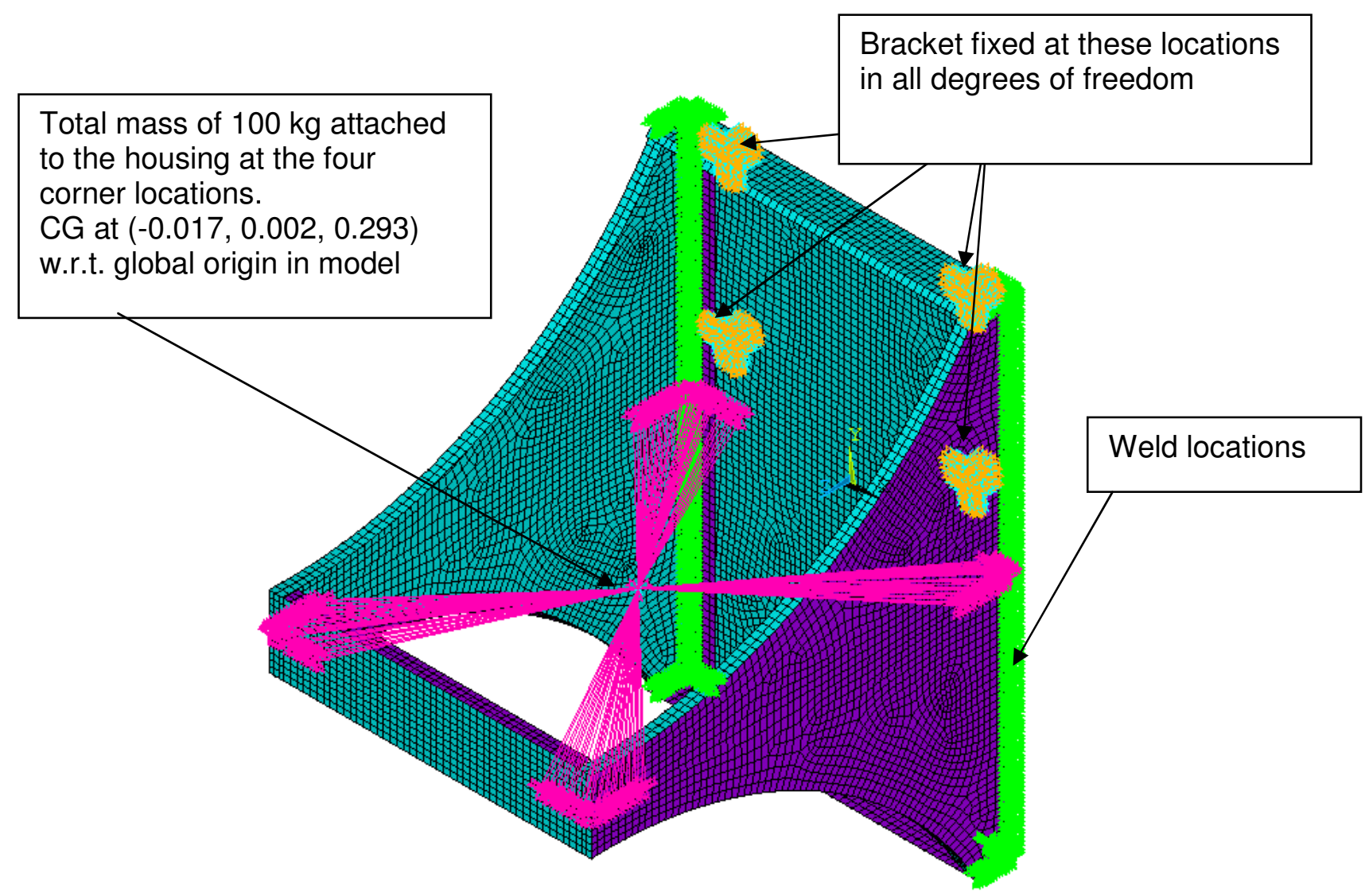

Figure 7-20: FE model of APU housing showing CG of housed components

The housing is made of sheet steel. The yield strength of steel (250 MPa) is used as the allowable design stress. The stresses in the bracket exceed allowable design stress limit in the first of the three load-cases tested. The results for the three load cases are documented here (ref. 14318R03.pdf).

A 66-cell stack was tested at room temperature as a preliminary test to capture the module' vibration behavior, as shown in Fig 7-21. The tests were performed in the 5 200 Hz frequency range in three directions with vibration level of $0.5 \mathrm{~g}$. Test results showed the fuel cell stack module had fairly symmetric vibration behavior about its vertical axis. With current mounting design, module demonstrated resonant peak at frequency about $75 \mathrm{~Hz}$ (ref. 14318R07.pdf). 


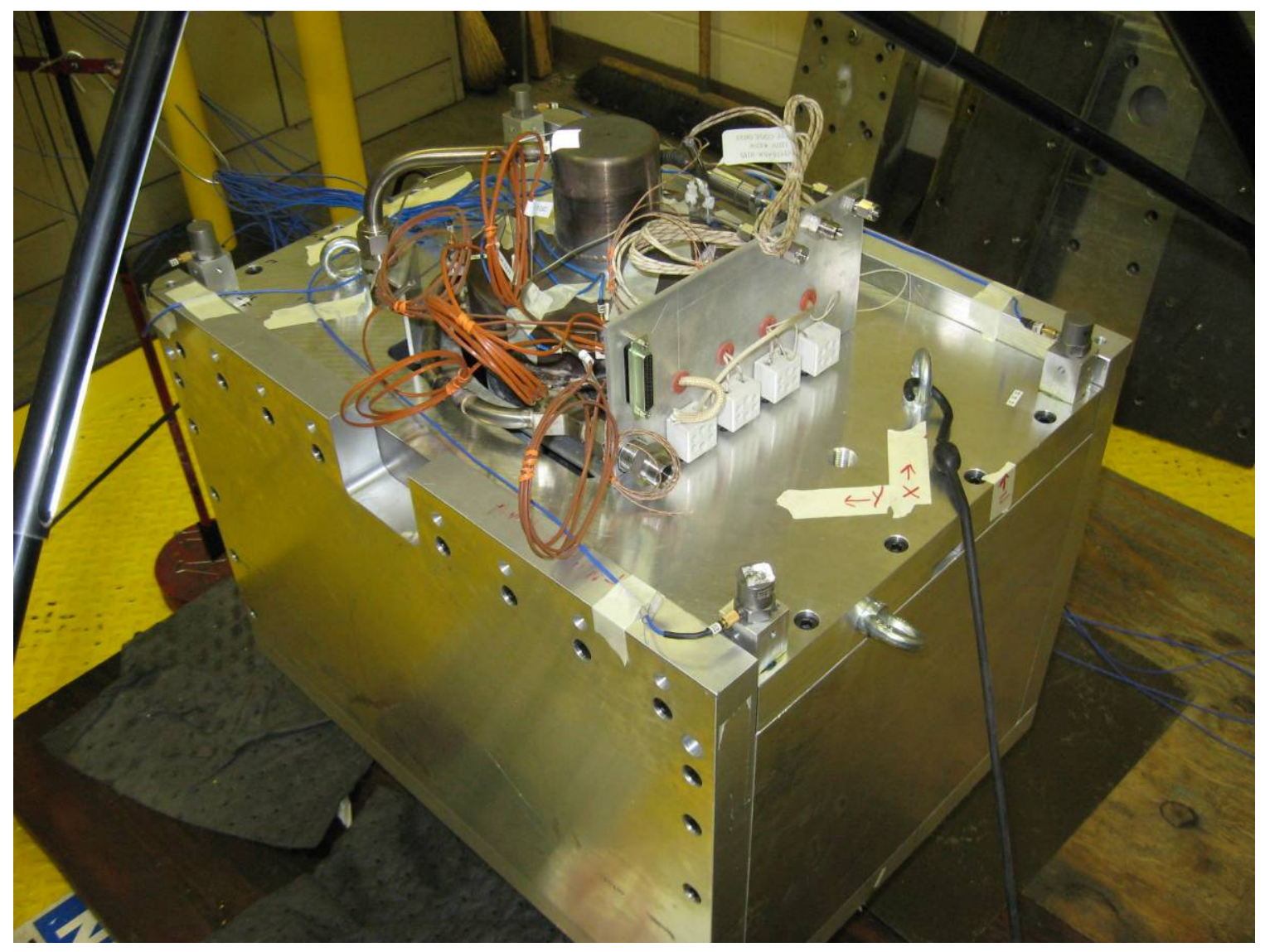

Figure 7-21. Vibration test setup of fuel cell stack module.

Test plan of the fuel cell system vibration test was under development. Fixture to mount APU system on the shacking table was selected. Vibration input profile and sensor positioning were under discussion (ref. 14318R09.pdf). 


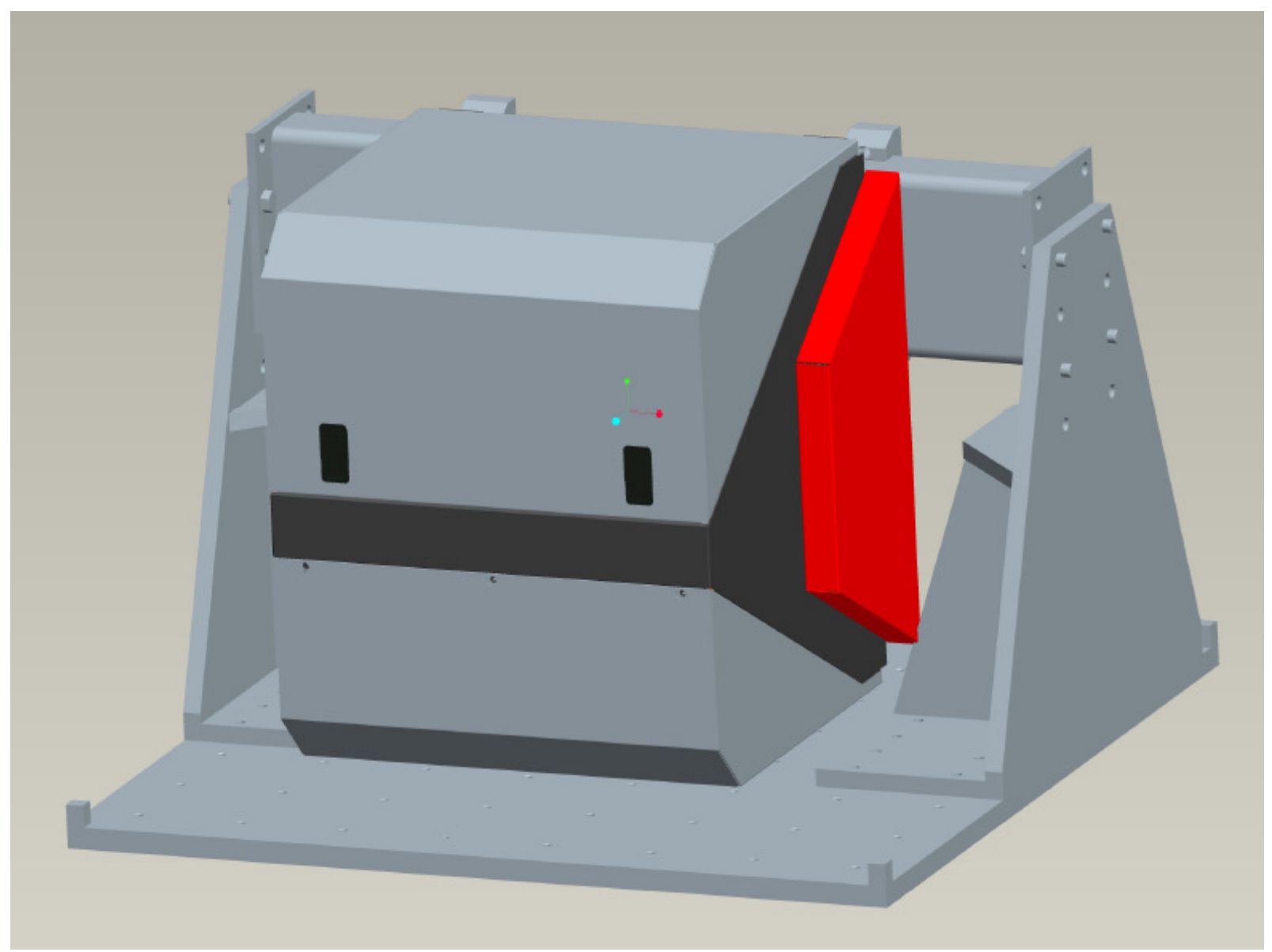

Figure 7-22. Vibration test setup of fuel cell system. 


\section{SOFC APU Demonstration Results}

The following section details the results of the SOFC APU demonstration. It is shown that the SOFC APU unit demonstrated the key technology goals (Table 8.1).

Vehicle simulator integration was planned for in calendar Q4 of 2009. However, the purchase and up-fit of a test vehicle was predicated on the SOFC APU system demonstrating the program requirements in lab testing. Delays and delivered module performance levels shifted testing from a complete vehicle installation to a test cell implementation that consisted of vehicle sub-systems operating as though mounted to a real vehicle. These subsystems included:

1) Commercial ULSD operation from a remote tank.

2) CHP heat exchanger to simulate engine heating and hotel load heating.

3) Hotel air conditioning/climate control unit (production unit from CPG's Comfortguard product line with a cooling capacity of $12,000 \mathrm{BTU}$ ). The unit provided a continuous level of cooling during the AC output portion of the demonstration.

4) Hotel electrical loads including lighting, microwave, TV, etc.

5) Vehicle marker lighting loads.

6) CPG HQD hybrid inverter/battery charger.

The in vehicle demonstration was changed to a simulated vehicle system set-up in calendar Q4 of 2009. The final demonstration was attempted on December $17^{\text {th }} 2009$ with the following results:

1) All four modules had significant leakage and were repaired prior to the demonstration attempt.

2) Two of the stacks were found to be damaged during inspection while performing repairs.

3) The four modules were assembled into the SOFC APU and the demonstration started with the understanding that there would be very limited performance available due to the stack condition.

4) The start-up(s) were aborted due to the following shutdowns:

a) The CHP cooling loop experienced a vapor lock in the pump (issue resolved).

b) Blower over temperature shutdown (revised to alarm only without shutdown).

c) Recuperator input over temperature shutdown due to operating procedure (corrected).

d) Revised individual module start-up procedure reduced cathode blower flow to a degree that precipitated a blower failure (corrected by implementation of a bypass feature). 
5) During these attempts three of the modules had light-off of the tail gas combustor. One produced limited power before degrading to no OCV. One module was operating at 250 Watts (limited to the isolated DC load bank utilized for start-up).

6) Due to the issues with the modules and the BOP revisions required the demonstration attempt was aborted for 2009 and completed in February 2010.

7) Four new modules of stable design and components were built for the demonstration unit.

8) The APU was updated with a cathode bypass feature to allow the BOP to perform as required.

The final demonstration occurred on February $26^{\text {th }}, 2010$ with the results shown in Table 8-1. The key performance parameters are:

1) Operation meeting SOFC APU requirements on commercial Ultra Low Sulfur Diesel (ULSD) fuel.

2) SOFC systems operating on dry CPOX reformate.

3) Successful start-up and shut-down of SOFC APU system without inert gas purge.

4) AC power output sufficient to operate 12,000 BTU air conditioning system.

Table 8.1 - Performance Results

\begin{tabular}{|l|l|l|}
\hline \multicolumn{2}{|l|}{ RESULTS AGAINST PROJECT OBJECTIVES } \\
\hline OBJECTIVE & TARGET & DEMONSTRATED \\
\hline Operation on Liquid Fuel & ULSD & ULSD \\
\hline Average Power (Net DC) & & 1100 Watts \\
\hline Average Power (Net AC) & & 820 Watts \\
\hline Combined Heat and Power (CHP) & & $>4 \mathrm{kWatts}$ \\
\hline Peak Power (Net DC) & & $1250 \mathrm{Watts}$ \\
\hline Specific Power (Net DC) & $17 \mathrm{~W} / \mathrm{kg}$ & $9 \mathrm{~W} / \mathrm{kg}$ \\
\hline Power Density & $8 \mathrm{~W} / \mathrm{L}$ & $3 \mathrm{~W} / \mathrm{L}$ \\
\hline Start-up Time (Cold) & 1 hour & 1 hour \\
\hline Efficiency @ Rated Power & $25 \%$ LHV & $11 \%$ LHV \\
\hline In Vehicle Demonstration & $\begin{array}{l}\text { Operation on a Class } 8 \\
\text { Truck }\end{array}$ & $\begin{array}{l}\text { Operation on } \\
\text { Hardware in Lab }\end{array}$ \\
\hline
\end{tabular}

As delivered prototype PTX modules did not meet initial power projections. Modules as delivered produced approximately half of the originally predicted power. Had the modules met the original performance targets, Specific power, Power density, and efficiency would have been approximately at the original target values. In addition the BOP parasitic power was relatively high due to being designed for the higher power levels. 


\subsection{SOFC APU Test Article}

Figure 8-1 is the final SOFC APU test article during the demonstration test evaluation in cell 134 at CPG.

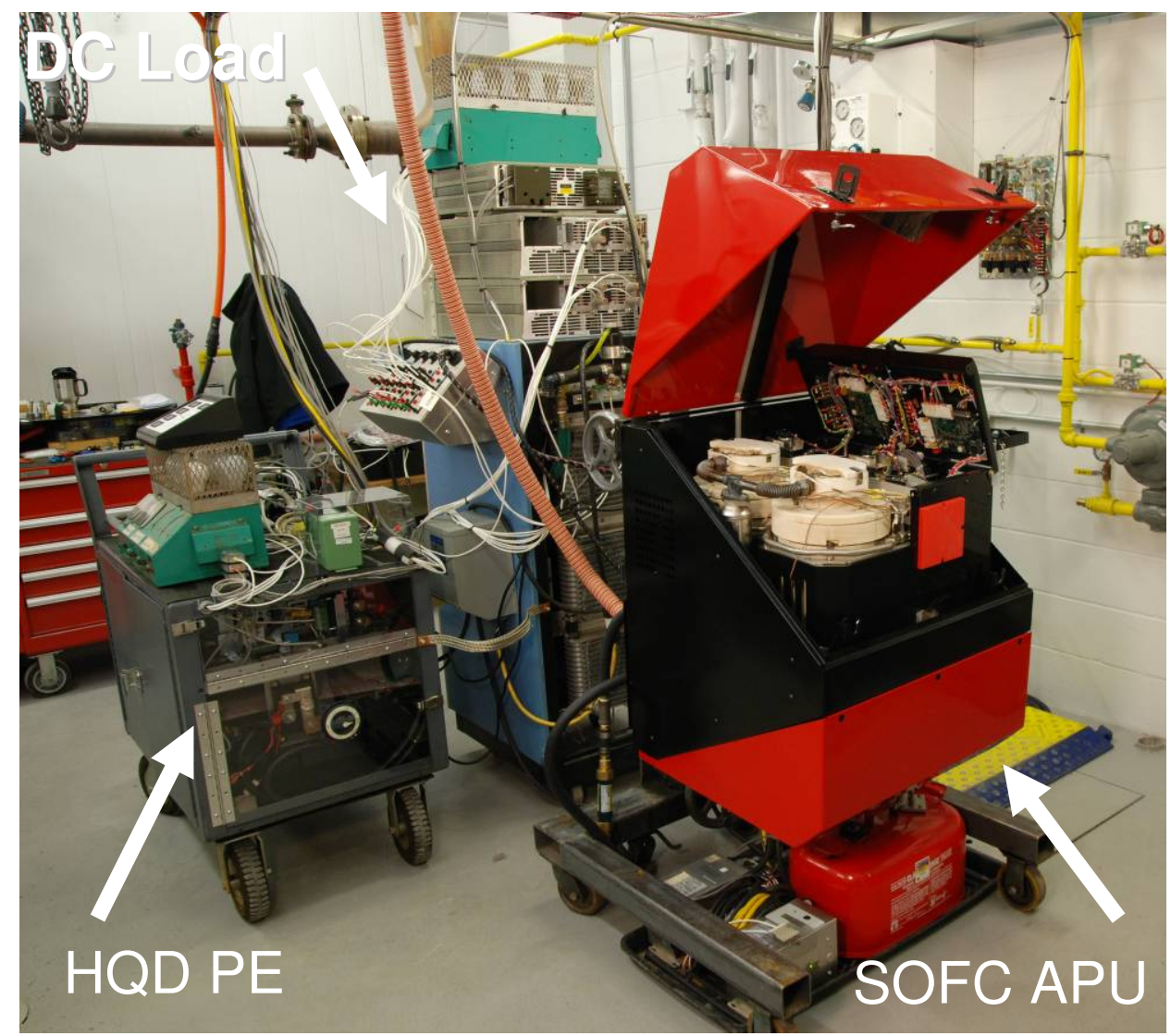

Figure 8-1 SOFC APU Demonstration Article at CPG 


\subsection{SOFC APU Performance Results}

The final four module deliverables were tested on ULSD integrated with the BOP control, power conditioning and mounting case developed at Cummins. Figure 5-392 shows the steady state power produced by the four modules as recorded at the power conditioning hardware. The power levels quoted in the following graphs would be 50-80 W higher if the plots were corrected for transmission losses.

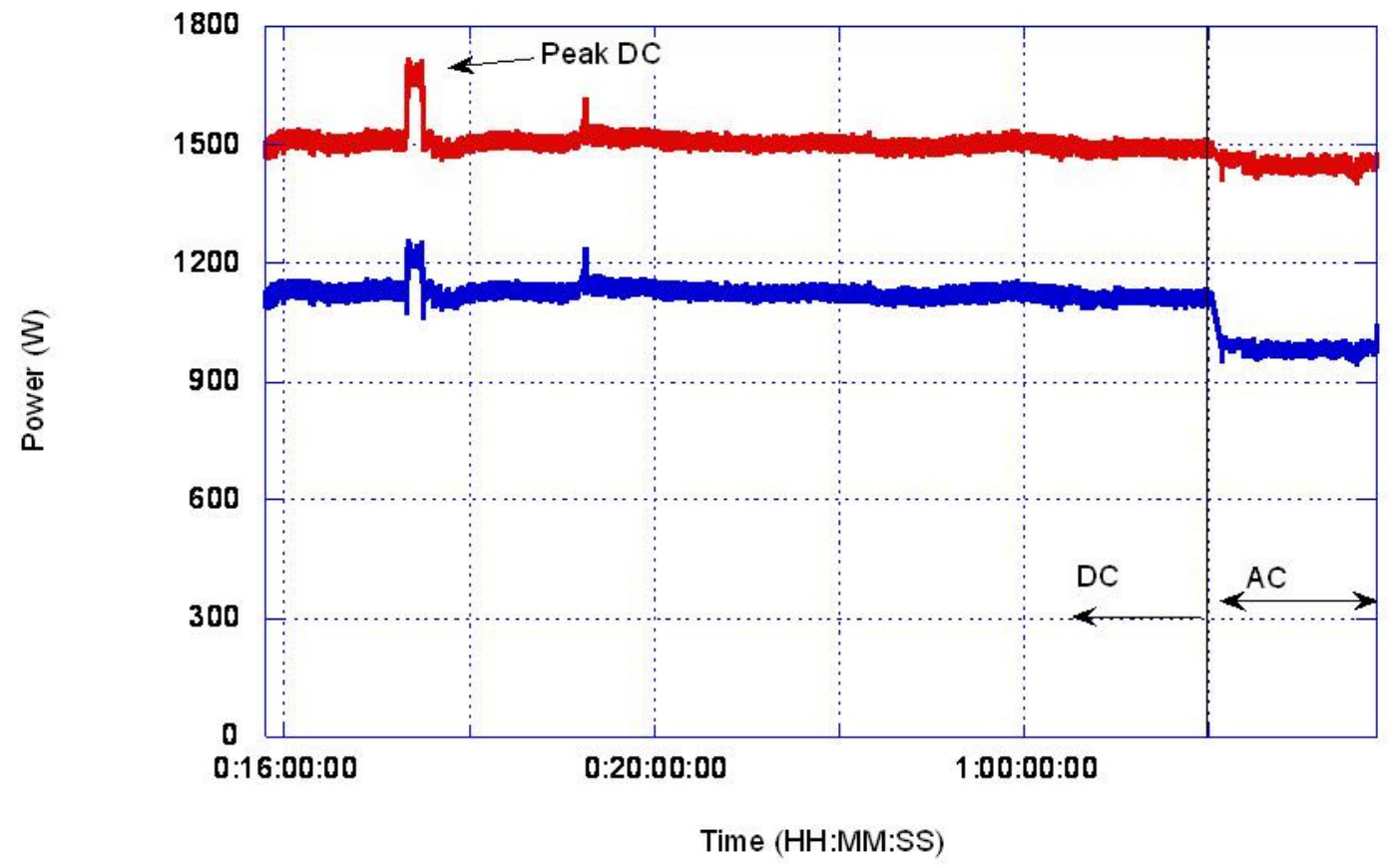

Figure 8-2. Total power production for final testing.

The test consisted of heating each module individually for convenient monitoring, and allowing the entire system to achieve a steady state. Note that the system is capable of starting all modules simultaneously if desired. The steady state DC power production was $1500 \mathrm{~W}$ gross with approximately $380 \mathrm{~W}$ of parasitic losses for a net production of 1120 W. A peak power loading of $1680 \mathrm{~W}$ with a net output of $1225 \mathrm{~W}$ was recorded for 10 minutes as seen in Figure 8-2. Higher peak loading of the modules is possible, the peak loading was not limited by inherent module capability, rather it was limited by the thermal balance. Future systems could be designed for higher firing rates and power production with moderate design modifications to the heat exchangers, fuel feed system and thermal insulation package.

After the peak loading, the system continued in steady state DC power operation for 10 hours, simulating the rest period over which a class 7/8 APU would operate. At the end of this time the power output was $1490 \mathrm{~W}$ gross and $1110 \mathrm{~W}$ net.

The system was then transitioned to AC loading for 1.5 hours. The AC loading required the modules to be connected in series electrically; thus forcing the same current through all modules and reducing total power by $3 \%$. The larger change in parasitic losses was 
due to the inverter efficiency of $\sim 85 \%$. The power produced during this period is shown in Figure 5-42, $1460 \mathrm{~W}$ gross and $820 \mathrm{~W}$ net at the end of the test. This allowed the air conditioning, lighting and additional DC loading thus simulating a truck "hotel" load to all operate simultaneously from power generated by the SOFC sub-system.

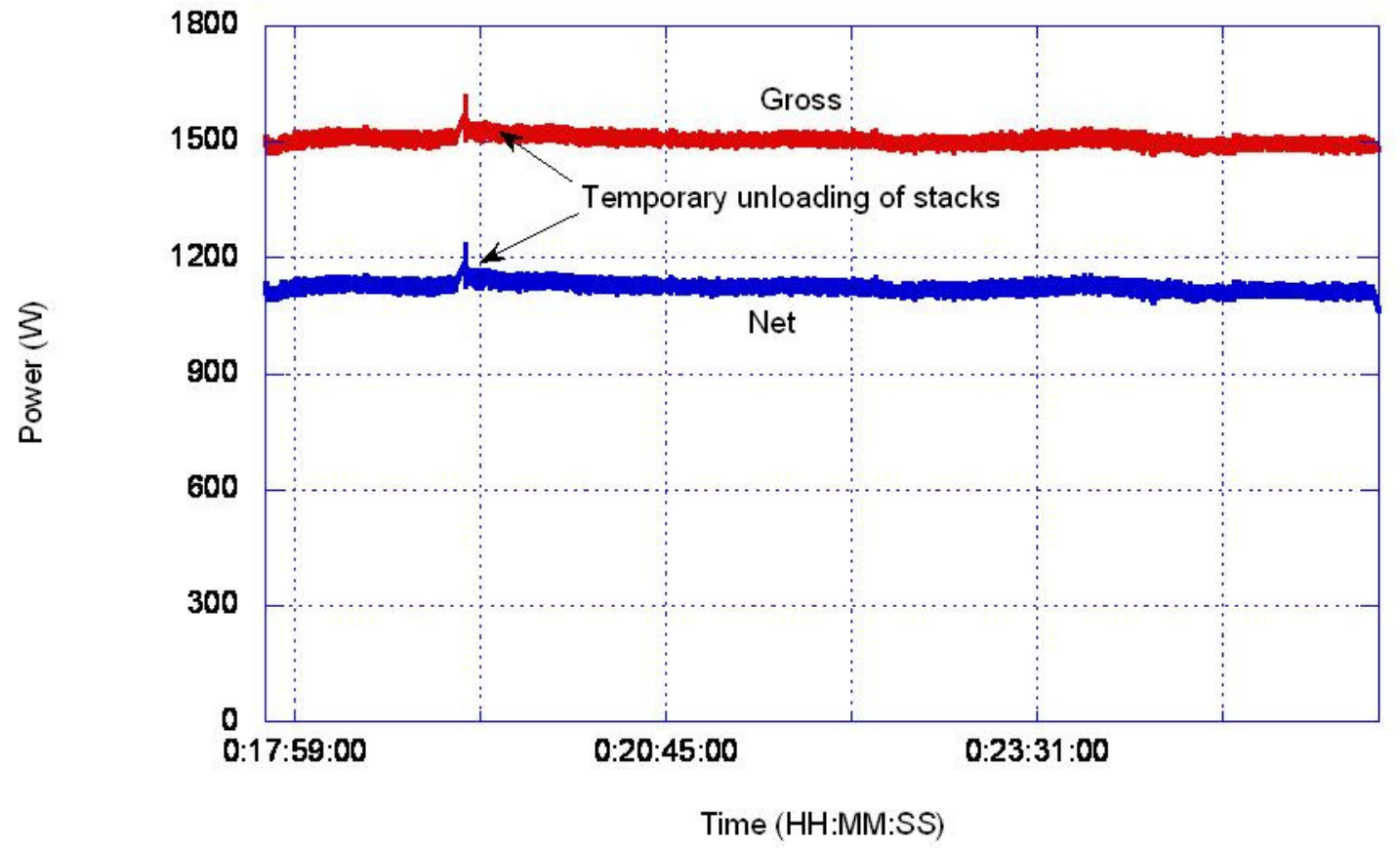

Figure 8-3. Average DC power produced by SOFC sub-system on ULSD during final testing at CPG.

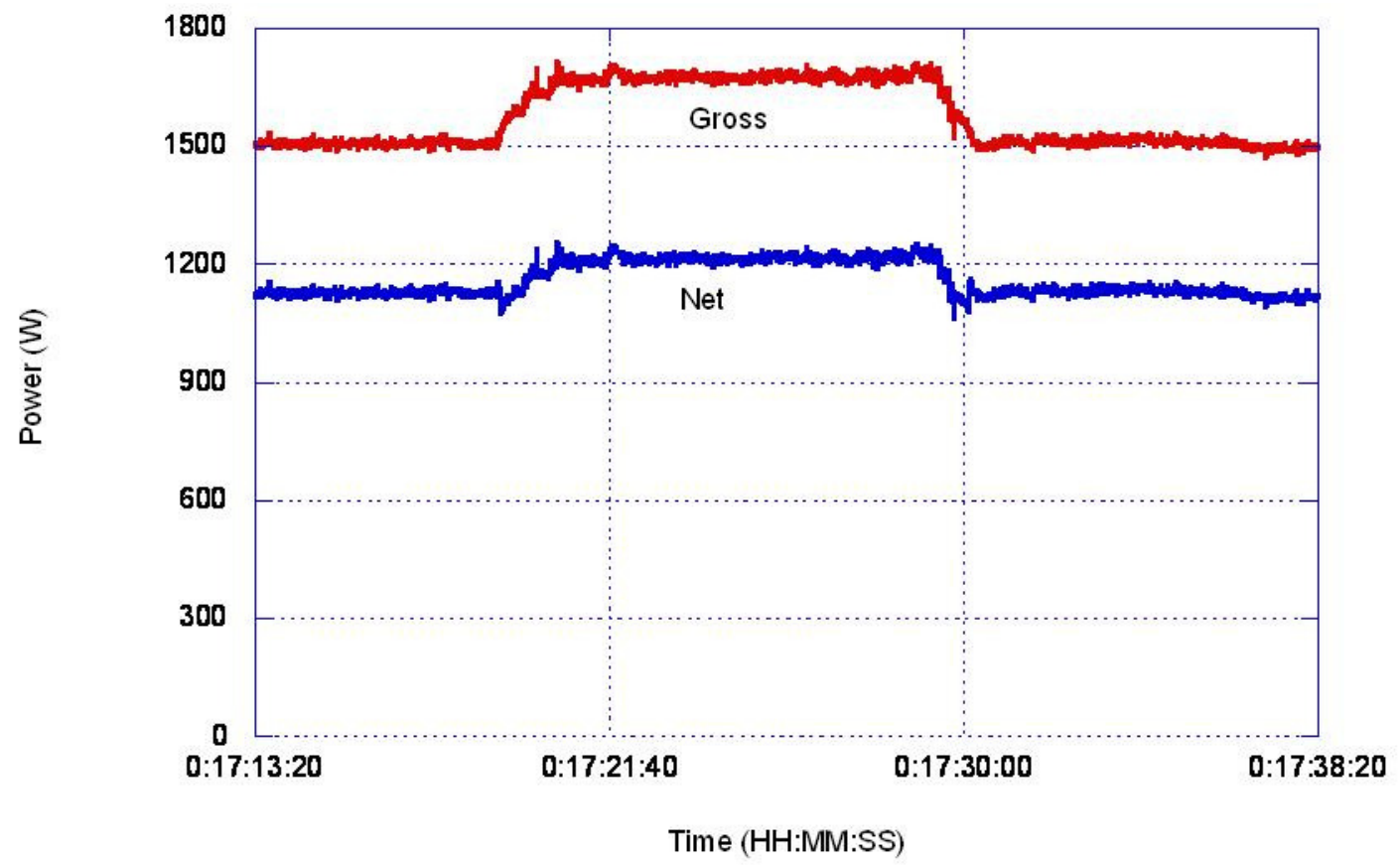


Figure 8-4. Peak DC power produced by SOFC sub-system on ULSD during final testing at CPG.

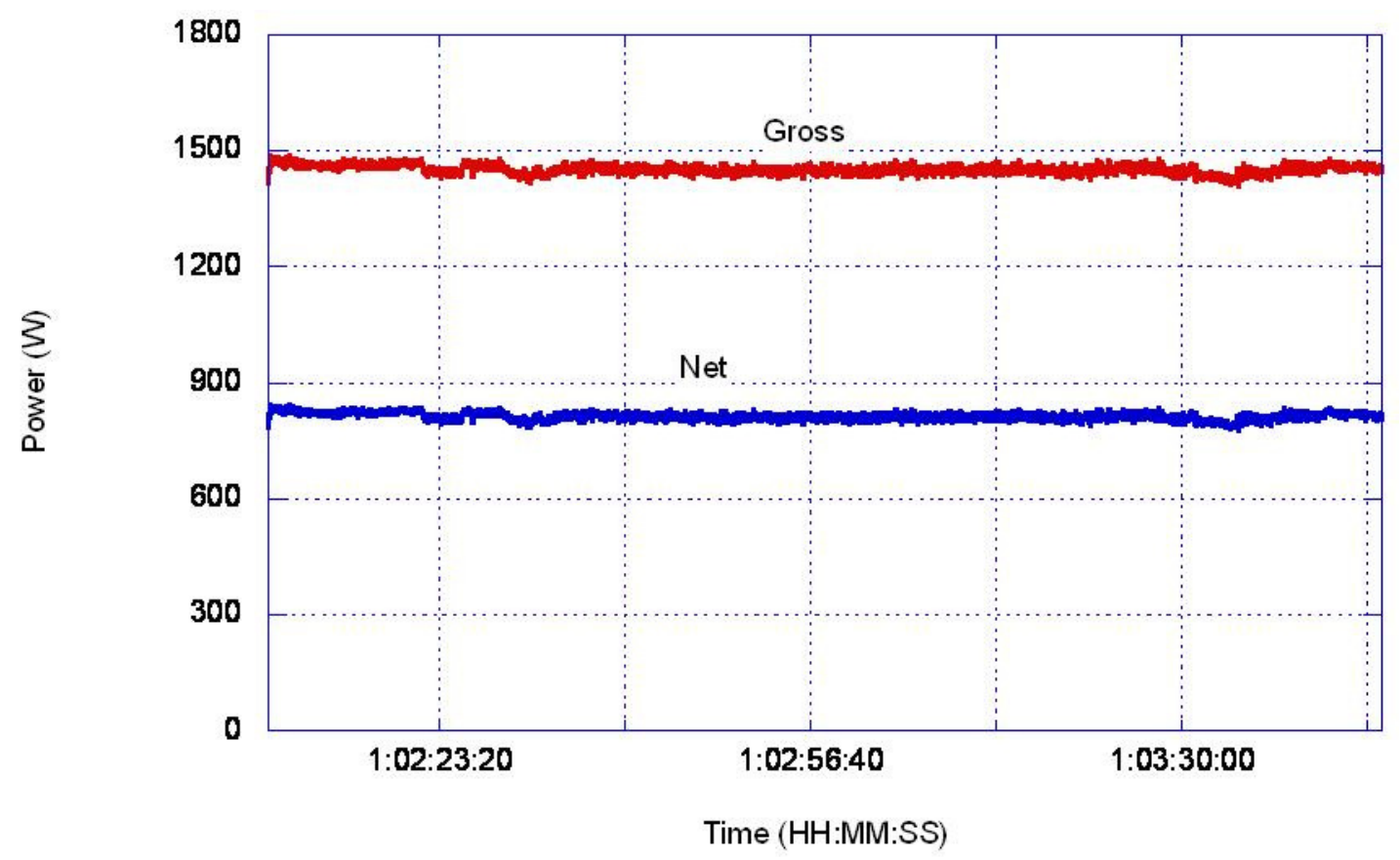

Figure 8-5. Average AC power produced by SOFC sub-system on ULSD during final testing at CPG.

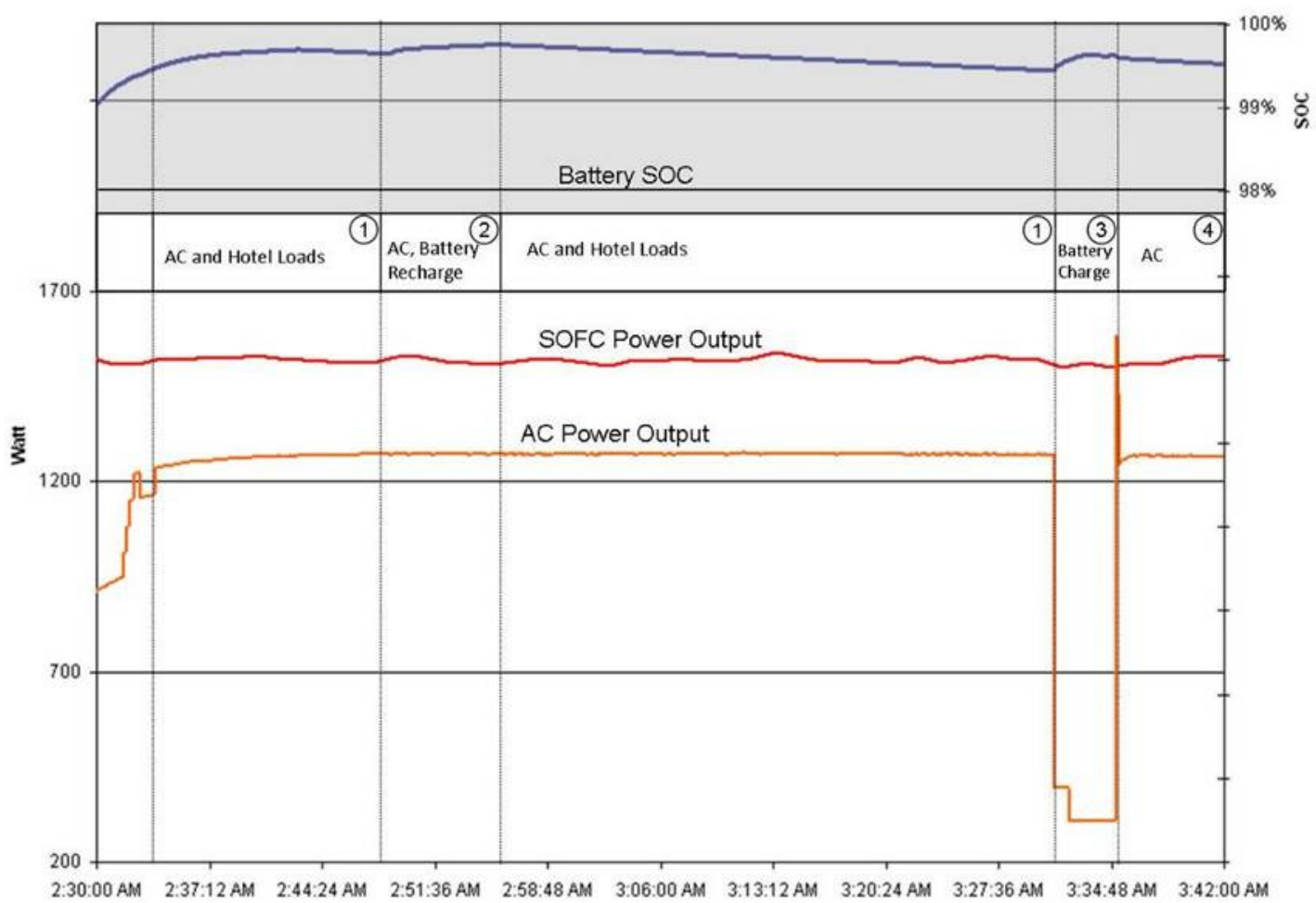


Figure 8-6 AC power output period.

Re-iterating from section 6 , that final test of the SOFC fuel cell system demonstrated all five operational modes (see Section 6.2) of the CPG HQD inverter system. Shown in Figure 8-6 is a time-based view of this portion of the test.

The time periods designated 1 in Figure 8-6 are time periods where the fuel cell system was powering the complete cab air conditioning system, 300 Watts of simulated hotel loads, and approximately 200 Watts of external DC loads. Hotel loads consist of in-cab lighting, televisions, or other conveyance loads. During the time period designated 2, the hotel loads were removed and the 300 Watts of extra fuel cell capacity was used to recharge the automotive battery bank. Once battery state of charge (SOC) indicated a charged battery bank, battery charging current was automatically minimized and the hotel loads were turned back on, fully loading the fuel cell system and halting battery charging. During time period 3 the air conditioning turned was turned off and the full output of the fuel cell was used to recharge the automotive battery bank. Once charging was complete, the air conditioning was turned back on. Hybrid mode was automatically entered between time period 3 and time period 4 when the motor starting current of the air conditioning system was larger then the fuel cell output power. Once the air conditioning compressor was started, the inverter system transitioned back into powering the air conditioning and hotel loads completely from the fuel cell stacks. 


\section{Outlook}

At the conclusion of the SOFC APU program the technology may be seen to be approaching the necessary requirements for creating successful commercial implementation(s) in CPG mobile power markets in the five to ten year range.

Key technical obstacles for commercial implementation were addressed in this project:

Diesel fuel reforming without water (including sulfur handling). The PTX module demonstrated short term operation on commercial ULSD without supplementary water or water recycling under controlled $\mathrm{O} / \mathrm{C}$ ratio conditions.

Cost. The implementation of low cost automotive control components was demonstrated through novel adaptations to achieve required accuracy and resolution. SLA components demonstrated potential for cost-effective integration of multiple functions in tooled components. A commercial, low cost, high efficiency cathode blower was matched to system requirements.

Performance. The APU power unit demonstrated the potential to produce required mission levels of power generation from a package envelope comparable to current production APU products.

Durability and efficiency are two areas that require additional development to reach commercial requirements. Observed levels of stack degradation during this program are recognized to be inadequate to support commercial product and are the object of ongoing development at PTX. Observed system efficiency, while comparable to small diesel gensets operating at light load conditions, needs improvement to maximize economic benefits.

After some experience in control full SOFC fuel cell systems it is apparent that proper mechanical system design allows utilization of low cost sub-system components and reduces parts count. 


\section{Summary}

It has been shown that primary goals of the SOFC APU demonstration have been attained. Performance of note is the continuous operation on pump grade ULSD fuel. AC power output that exceeds the mobile requirements for basic air conditioning and hotel loads. Table 10.1 reiterates the results achieved:

Table 10.1 - Performance Results

\begin{tabular}{|l|l|l|}
\hline RESULTS AGAINST PROJECT OBJECTIVES \\
\hline OBJECTIVE & TARGET & DEMONSTRATED \\
\hline Operation on Liquid Fuel & ULSD & ULSD \\
\hline Average Power (Net DC) & & 1100 Watts \\
\hline Average Power (Net AC) & & 820 Watts \\
\hline Combined Heat and Power (CHP) & & $>4 \mathrm{kWatts}$ \\
\hline Peak Power (Net DC) & & $1250 \mathrm{Watts}$ \\
\hline Specific Power (Net DC) & $17 \mathrm{~W} / \mathrm{kg}$ & $9 \mathrm{~W} / \mathrm{kg}$ \\
\hline Power Density & $8 \mathrm{~W} / \mathrm{L}$ & $3 \mathrm{~W} / \mathrm{L}$ \\
\hline Start-up Time (Cold) & 1 hour & 1 hour \\
\hline Efficiency @ Rated Power & $25 \%$ LHV & $11 \%$ LHV \\
\hline In Vehicle Demonstration & $\begin{array}{l}\text { Operation on a Class } 8 \\
\text { Truck }\end{array}$ & $\begin{array}{l}\text { Operation on } \\
\text { Hardware in Lab }\end{array}$ \\
\hline
\end{tabular}

\section{Acknowledgements}

The author(s) would like to thank the team members at CPG and Protonex LLC who have contributed greatly both through their technical accomplishments and in the development of this presentation:

\section{Table 11.1 - Acknowledgements}

\begin{tabular}{|l|l|}
\hline Charles Vesely (CPG) & Dr. Chuck Booten (PTX) \\
\hline Ben Fuchs (CPG) & Dr. Caine Finnerty (PTX) \\
\hline Dr. Xin Li (CPG) & Dr. Joe Poshusta (PTX) \\
\hline Dr. Madhukar Mahishi (CPG) & Victor Castillo (PTX) \\
\hline Dr. Jie Luo (CPG) & Colin Casey (International Truck \& Engine) \\
\hline Dennis Otremba (CPG) & Glenn Madison (CPG) \\
\hline
\end{tabular}

